\title{
AVALIAÇÃO DE DESEMPENHO DE 4 MODELOS DE PNEUMÁTICOS AGRÍCOLAS EM SOLO DE TEXTURA MÉDIA
}

\author{
MARCOS MILAN \\ Engonheiro Agrônomo
}

Orientador: LUIZ GERALDO MIALHE

Dissertação apresentada à Escola Superior de Agricultura "Luiz de Queiroz", da Universidade de São Paulo, para obtenção do título de Mestro em Irrigação e Drenagem.

PIRACICABA

Estado de São Paulo - Brasil

Setembro - 1986 


\section{A meus pais \\ Manoel Miian Aguilar \\ e \\ Ana Goegan Milan \\ minha homenagem $\dot{e}$ gratidão.}


- Ao Prof. Luiz Gerald Miahe, pela orientação e estímulo;

- A PIRELLI do BRASIL S.A., pelo pioneirismo e apoio para a realização desta pesquisa e em especial aos Engenheiros: Fulcieri Fausti e Roberto Iunes Junior.

- Ans Professores, respectivamente, Roberto Simionato de Morais, Anto nio Francisco Iemma e Cassio R. de Melo Godoi, pela orientação ... e sugestões na análise estatística;

- Aos Professores, respectivamente, Luiz A. Balastreire e Tomaz C.C. Ripoli, pelas sugestões;

- Aos colegas do Grupo Especial de Projetos IGPE/DER/ESALQ-USPI, sem os quais este trabalho não poderia ser realizado;

- A srta Solange Munhoz, secretäria do Departamento de Engenharia Rural (ESALQ/USP), pelos serviços de datilografia. 


\section{SUMARIO}

Lista de Tabelas $\ldots \ldots \ldots \ldots \ldots \ldots \ldots \ldots \ldots \ldots \ldots$

Lista de Figuras $\ldots \ldots \ldots \ldots \ldots \ldots \ldots \ldots \ldots \ldots \ldots$

v.i.

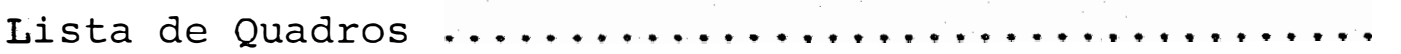

i.x.

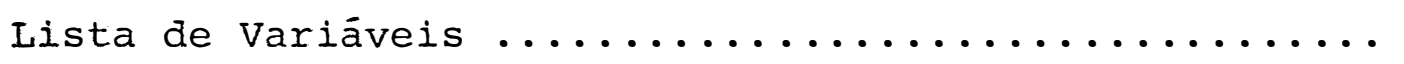

x.i.i.

RESUMO

x.i.i.i.

\section{SUMMARY}

x.i.v.

1. - INTRODUÇÃO

$\mathrm{x} \cdot \mathrm{v} \cdot \mathrm{i}$.

2. - REVISÃO DE LITERATURA $\ldots \ldots \ldots \ldots \ldots \ldots \ldots$

3. - MATERIAL E MÉTODO $\ldots \ldots \ldots \ldots \ldots \ldots \ldots \ldots \ldots$

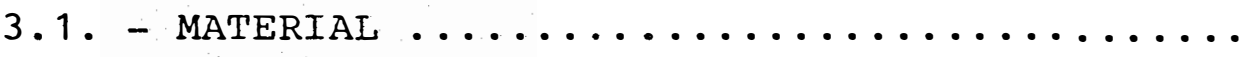

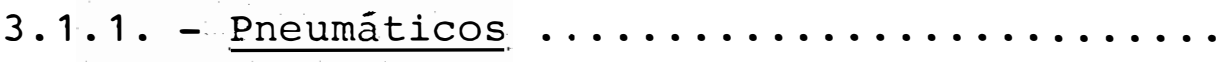

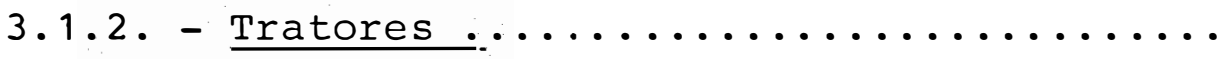

3.1.3. - Equipamentos de mensuração $\ldots \ldots \ldots \ldots$

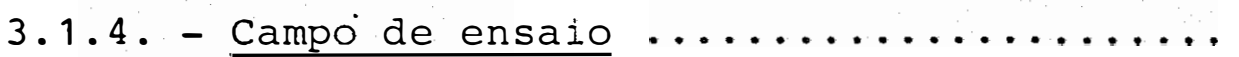

3.2.1. - Nétodo de avaliação do desempenho dós pneumáticos_.............

3.2.2. - Método de ensaio de campo .

3.2.2.1. - Programação dos ensaios 14

3.2.2.2. - Comboio de ensaio 15

3.2.2.3. - Mensuração da tração na barra (Ft) . . . . . . . . . . . . .

3.2.2.4. - Mensuração da velociciade de deslocamento (Vt) .............

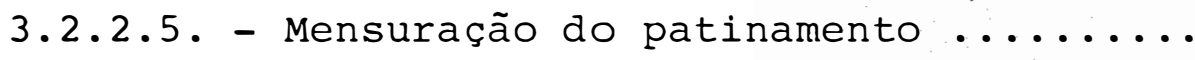

3.2.2.6. - Mensuração do consumo de combustivel (C.C) .............. 20

3.2.2.7. - Caracterização das condiçōes de campo ................. 20

3.2.3. - Vétodo estatístico de interpretação. . . . . . . . . . . . . . . 
4. - RESULTADO E DISCUSSÃO .................

4.1. - CARACTERIZAÇÃO DAS CONDIÇÕES DE

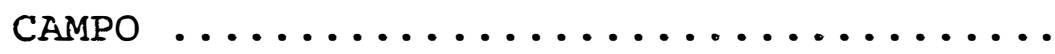

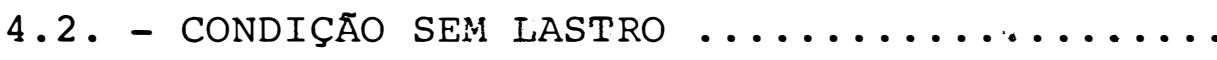

4.2.1. - Dados dos ensaios de campo ..........

4.2.2. - Parâmetros de desempenho dos pneumáticos .................. 28

4.2.3. - Equações de regressão............. 33

4.2.4. - Avaliação do desempenho .......... 37

4.2.4.1. - Desempenho máximo dos

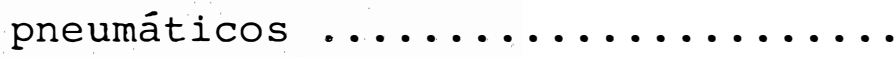

4.2.4.2. - Desempenho na faixa nor-

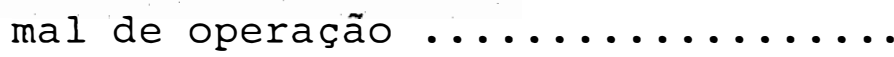

4.3. - CONDIÇÃO COM LASTRO ................

4.3.1. - Dados dos ensaios de campo .........

4.3.2. - Parâmetros de desempenho dos

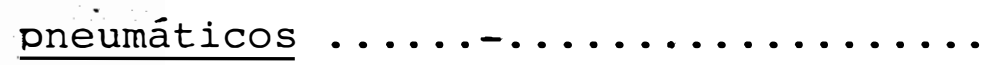

4.3 .3$. - Equações de regressão_............

4.3.4. - Avaliação do desempenho

4.3.4.1. - Desempenho máximo dos

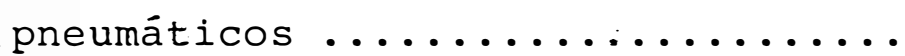

4.3.4.2. - Desempenho na faixa nor-

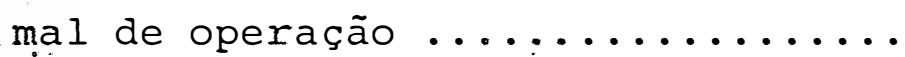

4.4. - COMPARAÇÃO DE DESEMPENHO ENTRE OS MODELOS OPERANDO NAS CONDI-

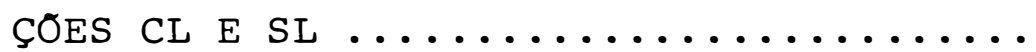

4.4.1. - Comparação entre níveis de patinamento que fornecer 0 máximo desempenho ..............

4.4.1.1. - Comparação em relação ao indice $1 \ldots \ldots \ldots \ldots \ldots \ldots \ldots . . \ldots \ldots$

4.4.1.2. - Comparação em relação ao indice $2 \ldots \ldots \ldots \ldots \ldots . . \ldots . . . \ldots$ 


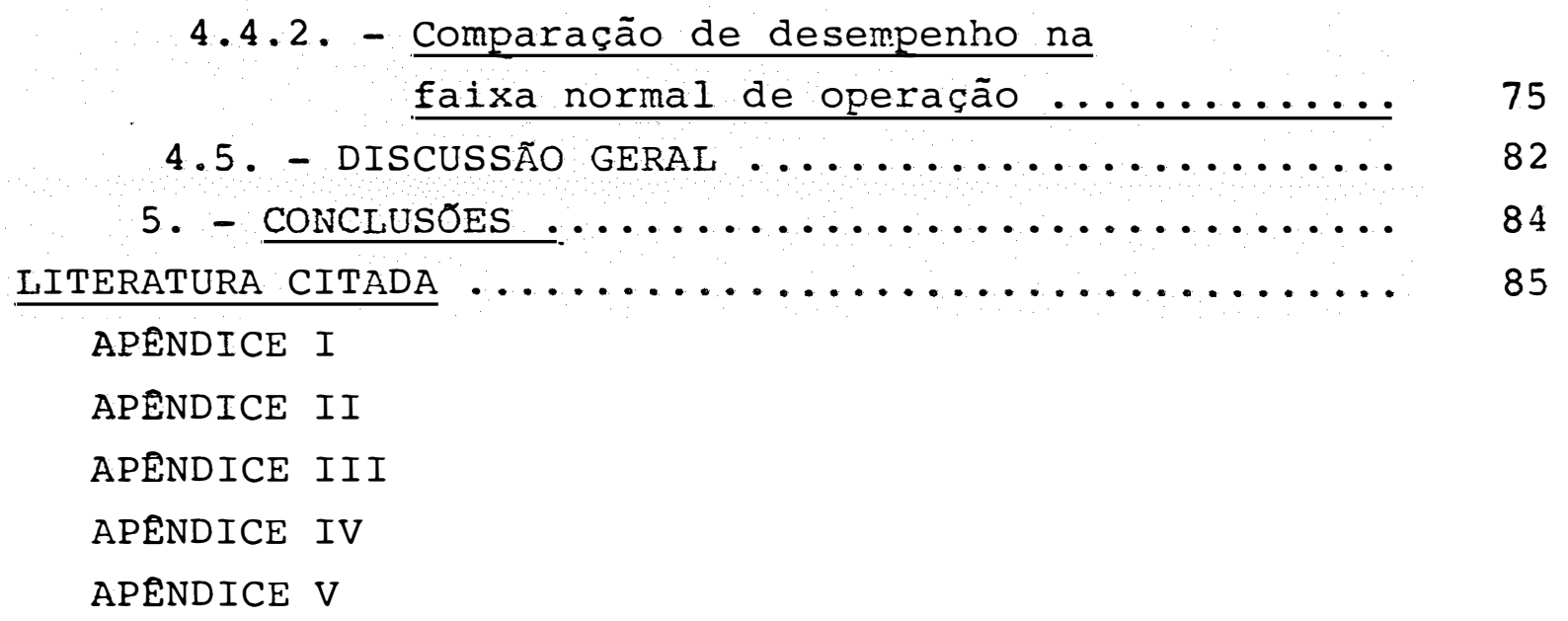


Tabela I. Dados obtidos para o pneu A na condição

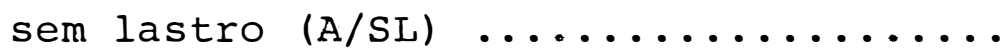

Tabela II. Dados obtidos para $O$ pneu $B$ na condição sem lastro (B/SL) $\ldots \ldots \ldots \ldots \ldots \ldots$

Tabela III. Dados obtidos para o pneu C na condição sem lastro (C/SL) $\ldots \ldots \ldots \ldots \ldots \ldots \ldots$

Tabela IV. Dados obtidos para o pneu D na condição sem lastro (D/SL) $\ldots \ldots \ldots \ldots \ldots \ldots \ldots$

Tabela $V$. Desempenho do pneumático $A$, na condição

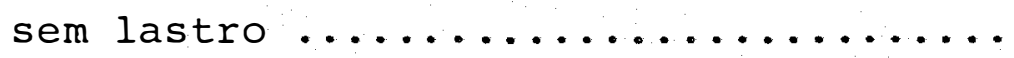

Tabela VI. Desempenho do pneumático B, na condição

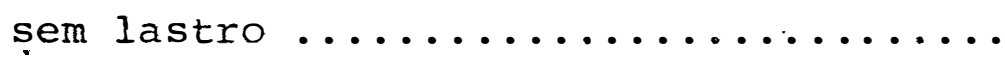

Tabela VII. Desempenho do pneumático $C$, na condição

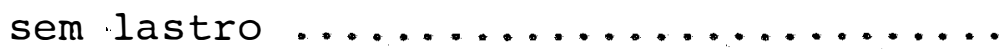

Tabela VIII.Desempenho do pneumático D, na condição

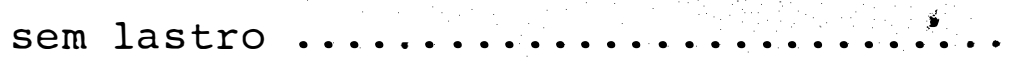

Tabela IX. Valores de F e dos coeficientes de determinação $\left(r^{2}\right)$, para a condição $S L$... 
v.i.i.

Página

Tabela X. Valores de Ft, $\mathrm{Pb}$ e Rdt máximos e C.èsp. mínimo, obtidos pelos pneumáticos para

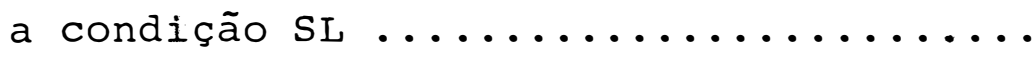

Tabela XI. Consumo específico dos pneumáticos para nivel de $\mathrm{Pi}$ que obteve C.esp. mínimo na condição $C / S L(P i \%=23,55) \ldots \ldots \ldots \ldots$

Tabela XII. Valores de Ft, Pb, Rdt e C.esp., para ín dices de $\mathrm{Pi}$ situados dentro da faixa nor mal de operação (condição SL) .........

Tabela XIII. Dados obtidos para o pneu A na condição com lastro $(A / C L) \quad \ldots \ldots \ldots \ldots \ldots \ldots \ldots$

Tabela XIV. Dados obtidos para o pneu B na condição com lastro $(\mathrm{B} / \mathrm{CL}) \ldots \ldots \ldots \ldots \ldots \ldots \ldots$

Tabela XV. Dados obtidos para o pneu C na condição

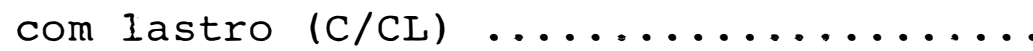

Tabela XVI. Dados obtidos para o pneu D na condição com lastro (D/CL) $\ldots \ldots \ldots \ldots \ldots \ldots \ldots$

Tabela XVII. Desempenho do pneumático A, na condição

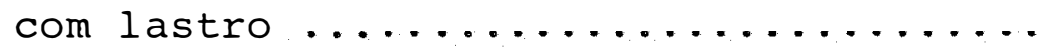

Tabela XVIII.Desempenho do pneumático B, na condição

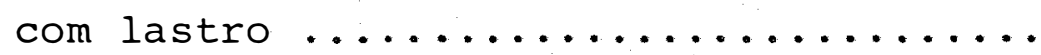

Tabela XIX. Desempenho do pneumático C, na condição com lastro ...................... 
Tabela Xx. Desempenho do pneumático D, na condição

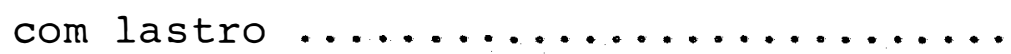

Tabela XXI. Valores de $F$ e dos coeficientes de determinação $\left(r^{2}\right)$, para a condição CL ...

Tabela XXII. Valores de Ft, Pb e Rdt máximos e C.esp. mínimo, obtidos pelos pneumāticos para a condição $C L$..............

Tabela XXIII. Valores de Ft, Pb, Rdt e C.esp., para indices de $\mathrm{Pi}$ situados dentro da faixa normal de operação (condição CL) .....

Tabela XXIV. Comparação de desempenho máximo dos pneumáticos nas condições SL e CL .....

Tabela XXV. Comparação de desempenho dos pneumáticos a $10 \%$ de $\mathrm{Pi}$ nas condições SI e

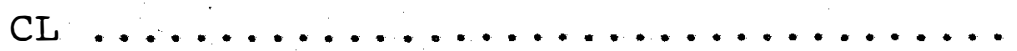

Tabela XXVI. Comparação de desempenho dos pneumáticos a $20 \%$ de $\mathrm{Pi}$ nas condições SL e

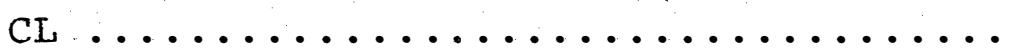

Tabela XXVII. Comparação de desempenho dos pneumáticos a 30\% de Pi nas condições SL e

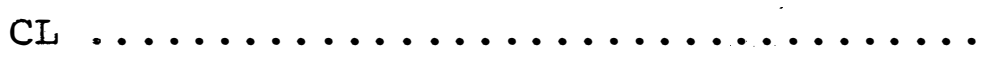


i.x.

LISTA DE FIGURAS

Pāgina

Figura 1. Desenho da banda de rodagem dos modelos

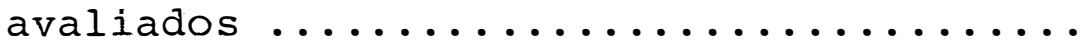

Figura 2. Código das condições de ensaio ..........

Figura 3 . Comboio de ensaio .................

Figura 4. Trecho de uma fita impressa ...........

Figura 5. Histograma da distribuição de frequência dos valores dos coeficientes de variação

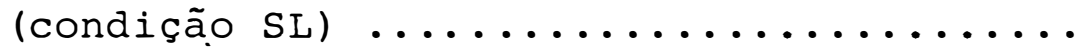

Figura 6. Região de inflexão a níveis altos de Pi

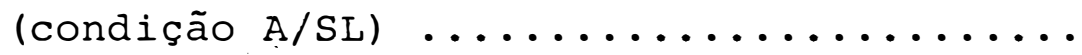

Figura 7. Gráfico da tração na barra (Ft) em função do patinamento (Pi) para a condição sem

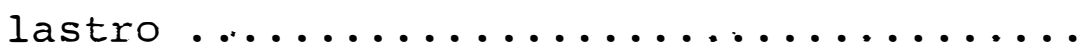

Figura 8. Gráfico da potência na barra (Pb) em função do patinamento (Pi) para a condição

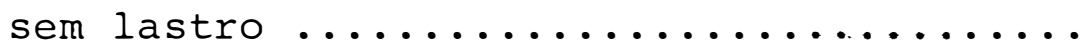

Figura 9. Gráfico da razão dinâmica de tração (Rdt) em função do patinamento (Pi) para a condi

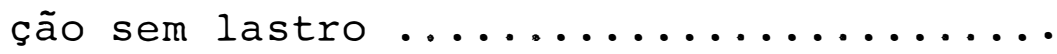


Figura 10. Gráfico do consumo específico (C.esp.) em função do patinamento (Pi) para a condi-

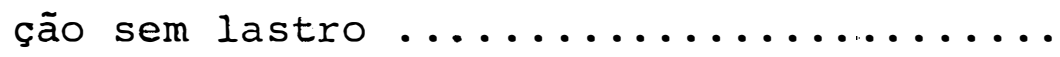

Figura 11. Desempenho dos pneumáticos para as variáveis Ft, $\mathrm{Pb}$, Rdt no ponto de máximo e C.esp. no ponto de mínimo - condição sem

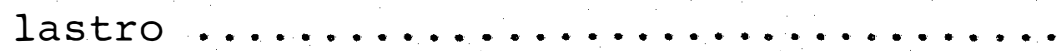

Figura 12. Desempenho dos pneumáticos para as variāveis Ft, $\mathrm{Pb}, \mathrm{Rdt}$ e C.esp. a $10 \%, 20 \%$ e

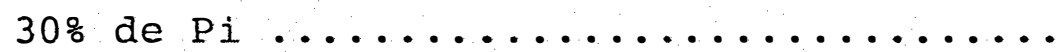

Figura 13. Histograma da distribuição de frequência dos valores dos coeficientes de variação (condição CL) ..................

Figura 14. Gráfico da tração na barra (Ft) em função do patinamento ( $\underline{P} i)$ para a condição com

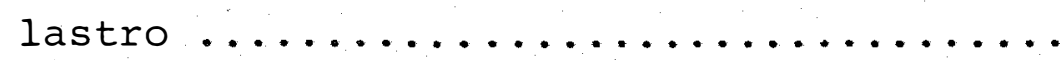

Figura 15. Gráfico da potência na barra ( $\mathrm{Pb}$ ) em função do patinamento (Pi) para a condição

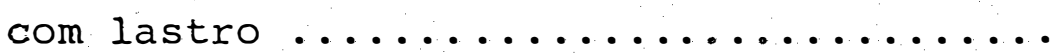

Figura 16. Gráfico da razão dinâmica de tração (Rdt) em função do patinamento (Pi) para a con-

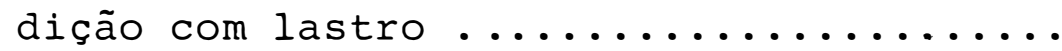

Figura 17. Gráfico do consumo especifico (C.esp.) em função do patinamento (Pi) para a condi-

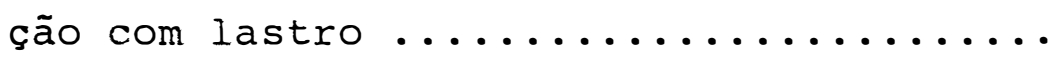


Figura 18. Desempenho dos pneumáticos para as variáveis Ft, $\mathrm{Pb}$, Rdt no ponto de máximo . e C.esp. no ponto de mínimo (condição com

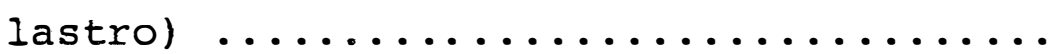

Figura 19. Desempenho dos pneumáticos para as variáveis Ft, $\mathrm{Pb}, \mathrm{Rdt}$ e C.esp. a $10 \%, 20 \%$ e $30 \%$ de $\mathrm{Pi}$ (condição com lastro) ........

Figura 20 . Comparação de desempenho máximo entre os modelos operando nas condições SL e CL ..

Figura 21. Comparação de desempenho, a $10 \%$ de $\mathrm{Pi}, \mathrm{pa}$ ra os modelos operando nas condições SL

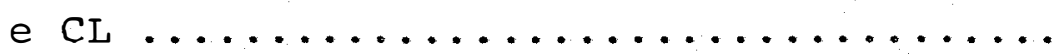

Figura 22. Comparação de desempenho, a $20 \%$ de $\mathrm{Pi}$, para os modelos operando nas condições SL e $C L \ldots \ldots \ldots \ldots \ldots \ldots \ldots \ldots \ldots \ldots \ldots \ldots \ldots \ldots \ldots \ldots \ldots \ldots$

Figura 23. Comparação de desempenho, a 30\% de Pi, para os modelos operando nas condições SL

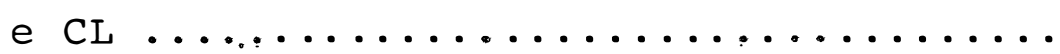


x.i.i.

\section{IISTA DE QUADROS}

Página

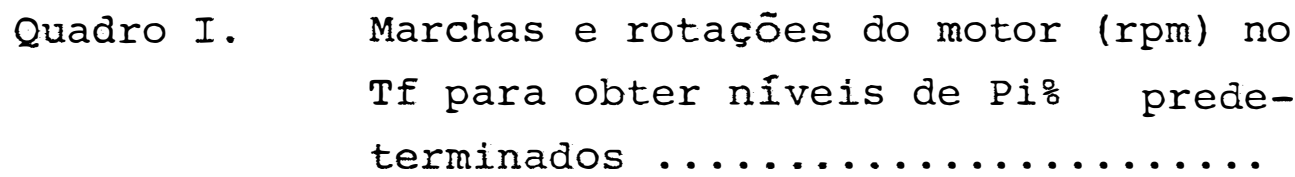


x.i.i.i.

LISTA DE VARIĀVEIS

Símbolo

Denominação

Unidade

- $\mathrm{Cc}$

C.esp

Consumo de combustivel

ml

Ft

Consumo especifico

$\mathrm{ml} / \mathrm{kW} \cdot \mathrm{h}$

Força de tração

$\mathrm{kN}$

$\mathrm{Pb}$

Potência na barra

$\mathrm{kW}$

$\mathrm{Pi}$

Patinamento

$\%$

Rdt

Razão dinâmica de tração

\%

$t$

Tempo

$\mathrm{S}$

Vt

velocidade

$\mathrm{m} / \mathrm{s}$

wd

Carga dinâmica sobre o roda

do traseiro

$\mathrm{kN}$

We

Carga estática sobre o roda

do traseiro

$\mathrm{kN}$ 
$\mathrm{x} \cdot \mathrm{i} \cdot \mathrm{v}$.

AVALIAÇÃO DE DESEMPENHO DE 4 MODELOS DE PNEUMÁtICOS AGRICOLAS EM SOLO DE TEXTURA MEDIA.

MARCOS MILAN

LUIZ GERALDO MIALHE

- orientador -

RESUMO

A presente pesquisa tem como objetivo avaliar o desempenho de 4 mođelos de pneumáticos agrícolas de medida $16.9 / 14 \times 30$. Os ensaios foram realizados em Latossolo VermeIho Amarelo de textura média, com cobertura vegetal. As avalia ções foram efetuadas com o trator operando nas condições com e sem lastros.

Os resultados obtidos a partir dos ensaios de campo foram:

- Tração na barra;

- Consumo de combustível;

- Tempo.de duração do ensaio;

- no de pulsos emitidos pelos sensores instalados na roda odométrica e no trator de tração.

A partir dos resultados de campo, os dados foram analisados obtendo-se as equações de regressão (polinômios de grau 2) para as variáveis tração na barra, potência na barra, consumo específico e razão dināmica de tração em função do patinamento. Das equações, efetuou-se a análise do desempenho 
dos pneumáticos no intèrvalo compreendido pela faixa normal de operação ( $0 \%$ a $30 \%$ de patinamento) e para o desempenho máximo dos pneus.

Os resultados evidenciaram o efeito da adição de lastros no aumento da tração e potência na barra, bem como uma melhor eficiência no aproveitamento do combustivel. Para a con dição sem lastro, o pneu denominado B obteve um melhor desempe nho na situação limite de exigência, enquanto que para a faixa normal de operação não ocorreram diferenças significativas entre os modelos A, B e C. Para a condição lastrada, os três modelos A, B e C, apresentaram desempenhos equivalentes nas duas situações (faixa normal de operação e condição limite de exigência), desempenho este sempre superior ao modelo $\mathrm{D}$. 
$\mathrm{x} \cdot \mathrm{v} \cdot \mathrm{i}$

PERFORMANCE EVALUATION OF 4 AGRICULTURAL TYRE MODELS

ON MEDIAN TEXTURE SOIL.

MARCOS MILAN

Adviser: Luiz Geraldo Mialhe

SUMMARY

In this work the performance of four models of $16.9 / 14 \times 30$ agricultural tyres was evaluated. The field tests were run on a median texture red-yellow clay, with grass cover. Data were obtained operating the tractor with and without ballast.

The results obtained in the field were the drawbar pull, fuel consumption, speed and slip. The field data were analysed to obtain the regression equations (second degree polynomials) for the variables drawbar pull, drawbar power, specific fuel consumption, and dynamic ratio vs slip.

With the equations the tyre performances were evaluated in the range of $0 \%$ to $30 \%$ slip, and of the slip for maximun performance. .

The results showed the effect of ballast addition in the increase of drawbar pull and power, as well as a better efficiency in fuel usage. For the condition. without ballast, tyre B showed the best performance for the limiting slip, while for the normal operating limit significant differences were not detected between tyres A, B and C. For the condition with ballast, tyres A, B and C showed equivalent performance in both situations (normal operating range and limiting slip), which in turn were always better then tyre $D$. 
1. - INTRODUÇÃO

No atual estágio da economia mundial, as ativi dades produtivas em qualquer setor, estão voltadas para a maximização dos recursos por elas empregados, através de mudanças em processos e/ou por um aumento na eficiência dos mesmos.

Segundo MIALHE (1930), o trabalho de produção agropecuária caracteriza-sé pela realizaçāo cíclica e cro nologicamente ordenada, de uma série de operações agrícolas. Estas, são realizadas por um conjunto diversificado de máquinas e ferramentas que exigem um fornecedor de energia mecânica - a máquina motora. O autor afirma que, ao analisar os avanços tecnológicos da mecanização agrícola nas ültimas décadas, e suas tendēncias atuais de desenvolvimento, verifica-se que o trator tem sido e provavelmente ainda continuará a ser a mais importante máquina motora na agricultura.

Tendo em vista estes aspectos, a seleção e uti lização criteriosa do trator, executada pelo usuário, bem como a melhoria do desempenho deste equipamento através de al terações no projeto, executada pelo fabricante, são fatores que contribuem decisivamente para a redução dos custos na ati vidade agropecuária.

Sob este enfoque, os pneumáticos apresentam-se como um dos mais importantes componentes do trator, na medida em que cabe a eles a responsabilidade de transmitir a potência gerada pela unidade motriz ao solo, para a realização das tarefas. De acordo com Heichel citado por TAYLOR et alii (1976), 60\% da energia gasta na agricultura dos EUA advém do 
petróleo e esta energia é consumida em sua maioria por tratores e colhedoras automotrizes. Portanto, um melhoramento que possa ser executado nos pneus, contribui diretamente para uma melhor eficiência de produção, reduzindo também o consumo de combustíveis fósseis.

A avaliação do desempenho de pneumáticos de tratores agricolas tem sido feita segundo duas diretrizes. A primeira delas, consiste na verificação da influência de uma característica de construção no desempenho do pneumático, por exemplo: a altura da garra, o espaçamento entre garras, a construção da carcaça (diagonal ou radial) etc. A outra, avalia. o desempenho de um pneumático isoladamente ou em comparação com outros. A primeira tem como vantagem fornecer dados precisos no tocante ao fator específico analisado; a sua principal desvantagem é o custo, por exigir moldes e processos especiais de fabricação dos modelos a serem avaliados. A segunda, reduz os custos da pesquisa e fornece subsidios quanto ao desempenho global do pneu em comparação com outros modelos, mas, não é possivel isolar as influências dos fatores de construção especifica.

A presente pesquisa, tem como objetivo a avaliação do desempenho de 4 modelos de pneumáticos comerciais agrícolas, de medida 16.9/14 x 30. Trata-se de uma avaliação dirigida de acordo com a segunda diretriz acima citada, ou seja, confronto entre diferentes espécimes. 


\section{2. - REVISÃO DE LITERATURA}

Um breve histórico sobre estudos desenvolvidos com rodados foi realizado por MIALHE (1980). Segundo o autor, os primeiros trabalhos foram executados após o término da I Grande Guerra; no periodo compreendido entre a I e II Grandes Guerras, desenvolveram-se vărias linhas de pesquisas em países como Estados Unidos, Inglaterra, França e União Soviética. Um impulso muito grande nos estudos sobre tração por rodados foi dado a partir da criação do "USDA Tillage Machinery Laboratory" no Estado do Alabama, EE.UU. Nesse laboratório, te ve inicio em 1946 um programa de ensaios com pneus de tratores sob condições controladas de solo, em colaboração com os mais importantes fabricantes de pneumáticos da época.

Esses ensaios, realizados por Reed e Shields (GIL e VANDEN BERG, 1967), foram executados com uma série de 37 pneus experimentais de dimensão 11-38, 4 lonas. Avaliou-se - efeito da altura, espaçamento e ângulo das garras, da largura e raio de curvatura da banda de rodagem no desempenho dos pneus. Os ensaios foram realizados em três tipos de solo: arenoso, marga e argiloso. Os resultados evidenciaram um melhor desempenho das garras de menor altura nas três condições de so. 10, em termos de eficiência de potência; para força de tração máxima, a influência do fator é pequena. Nos ensaios, incluiu-se um pneu liso (sem garras) que obteve melhor desempenho em solo arenoso; para solo de marga, a tração obtida foi muito me nor, comparando-se com as outras duas situações, indicando que alguma ação da garra é necessāria para penetrar ou escavar através da camada superficial. Em termos de espaçamento entre 
garras obteve-se, para as três condições, uma melhor eficiência de potência com maior espaçamento; este fato, é atribuido à menor movimentação do solo e consequentemente menor trabaIho deve ser realizado para obter tração, raciocínio este tam bém considerado válido para o efeito da altura da garra. Em relação a força de tração os dados obtidos não possibilitam a valiar a máxima tração desenvolvida. Em termos de āngulo da garra, os efeitos são menores que os observados para a altura e espaçamento e nenhuma tendência geral parece estar relacionada com este fator. Mesmo assim, para eficiência de potência, os dados indicam uma variação máxima de $2 \%$ a $6 \%$ para o ângulo da garra enquanto que as diferenças máximas obtidas pe la alteração da altura e espaçamento atingem o intervalo de $5 \%$ a 10\%. Os dois outros fatores estudados - largura e raio de curvatura da banda de rodagem - quando comparados com os $\underline{e}$ feitos obtidos pela altura, espaçamento e āngulo da garra, apresentam alterações negligíveis no desempenho.

VASEY e NAYLOR (1958), utilizando de 7 tipos de pneus, sendo 5 agrícolas com diferentes desenhos de banda de rodagem, um modelo industrial e um liso, tentaram realizar en saios de campo em três condições de solo: solo firme com restos de vegetação (marga argiloso), solo arado e solo irrigado recentemente sistematizado e nivelado. Incluiu-se também, uma superfície pavimentada para reproduzir as condições de ensaio padrão (ensaio de pista). Todavia, na condição de solo irrigado, não foi possivel manter a carga de frenação constante, razão pela qual esta condição foi excluída dos ensaios.os autores tentaram avaliar o desempenho dos pneumáticos em termos de tração na barra, patinamento e potência. Dada a inexistência de uma metodologia especifica as comparações foram realizadas, para cada superfície a três níveis de patinamento e com base na tração na barra. A avaliação em ter mos de potência não foi efetuada porque, a baixa velocidade de deslocamento não possibilitou a obtenção de dados que permitissem confiabilidade no confronto. A comparação entre os 
pneus foi realizada nos seguintes niveis de patinamento:

\begin{tabular}{lccc}
\hline Superficie & \multicolumn{3}{c}{ Patinamento $\%$} \\
\cline { 2 - 4 } pavimentada & 10 & 15 & 20 \\
solo firme & 10 & 20 & 30 \\
solo arado & 15 & 25 & 35 \\
\hline
\end{tabular}

Os resultados obtidos por VASEY e NAYLOR

(1958), demonstraram que em superfície pavimentada, o pneu in dustrial e o liso apresentaram um desempenho melhor, tendência esta contrária quando operando em superfícies com restos de cultura e arada, onde a ação da garra torna-se necessária. O pneu D, que possuía garras consideradas como mais agressivas, apresentou um melhor desempenho em terreno arado. Os autores ressaltam a tendência de os modelos de pneus apresentarem para um dado valor de patinamento, alta tração em supèrfí cie pavimentada, tração mínima em terreno arado e intermediária em superficie vegetada.

TAYLOR (1973 a), reavaliou alguns modelos de pneus da série de 37 ensaiados por REED e SHIELDS (1950), por considerar que os dados publicados foram insuficientes e que, na época, os autores julgaram alguns ensaios como não conclusivos. TAYLOR (1973 a) utilizou-se de 4 modelos de pneu máticos, onde a única variável consistia no ângulo da garra; um pneu liso foi incluído como padrão. Os pneus apresentavam ângulos de garra de $40^{\circ}, 50^{\circ}, 70^{\circ}$ e $80^{\circ}$ e por inversão do sen tido de giro, ângulos de $140^{\circ}, 130^{\circ}, 110^{\circ}$ e $100^{\circ}$. A dimensão dos pneumáticos era 11 x 38, 4 lonas com desenho da banda de rodagem $\mathrm{R}-1$. Os pneus foram avaliados em condição de laborató rio, em 6 tipos de solo, e os dados obtidos - razão dinâmica de tração e eficiência tratória - analisados em função do patinamento. A não existência de valores padrões fixados para o 
patinamento, levou o autor a utilizar a média dos dados obtidos para 10\%, 15\%, 20\%, 25\% e 30\% de redução de deslocamento nas análises. Quanto à razão dinâmica de tração os resultados revelaram que não houve variação significativa de desempenho para o ângulo das garras quando comparados ao pneu liso; a mesma tendência, embora com maior variação, foi encontrada pa ra a eficiência tratória. TAYLOR (1973 a) considera, com base em sua vivência na área de pesquisas, que diferenças de desem penho de até $3 \%$ podem não ser significativas. O autor conclui, baseado nos testes e em pesquisas anteriores, que os efeitos do ângulo da garra na performance de tração são negligiveis.

TAYLOR (1973 b), utilizou-se da mesma série de 37 pneumáticos e realizou novos estudos com relação ao efeito do espaçamento das garras no desempenho de tração. Um grupo de 5 pneus foi utilizado onde a única variável alterada foi o espaçamento entre as garras. Os pneus apresentavam 20 , 23 , 26 , 29 e 32 garras por lado, dimensão 11 x 38, 4 lonas e dese nho de banda de rodagem modelo $\mathrm{R}-1$; os ensaios foram realizados em canal de solo com 6 tipos de solos. Os dados obtidos razão dinâmica de tração e eficiência tratória - foram analisados em função do patinamento. Conforme citação anterior do mesmo autor, a inexistência de valor padrão para a patinagem levou-o a utilizar-se da média dos valores obtidos no interva 10 de $20 \%$ a $40 \%$ de patinamento. Para os resultados obtidos, 0 autor afirma ser válido admitir que no solo Hurricane (argilo sol, com cobertura vegetal, o espaçamento ideal é aquele do pneu com 23 garras por lado. No solo Norfolk (marga arenoso) existe uma ligeira superioridade dos pneus com 26 e 29 garras. Para os outros solos analisados, não se constatou évidên cia de que o espaçamento das garras afete o desempenho dos pneumáticos.

TAYLOR (1975), preocupado com o desgaste acentuado dos pneumáticos agrícolas que trafegam freqüentemente em superficies pavimentadas, realizou avaliações de desempe- 
nho de pneus com desenhos de banda de rodagem não adaptados a terrenos agrícolas. Foram utilizados pneus de dimensão $16.9 \times 24$ com desenhos de banda de rodagem R-1, R-3 e R-4 e em quatro tipos de solos. Os resultados dos coeficientes de tração líquida e razão dinâmica de tração - foram analisados em função do patinamento. O pneu com desenho $\mathrm{R}-1$ apresentou desempenho superior aos outros dois, principalmente em solo com condiçc̃es de tração não ideais. O autor sugere que o modelo $\mathrm{R}-4$ é uma alternativa a ser considerada, quando o trator deve trafegar sobre superficies pavimentadas por longos periodos de tempo, e desde que as características dos solos nos terrenos agricolas permitam boas condições de tração. Para patinamentos infe riores a $20 \%$, os modelos R-3 e R-4 são tão efetivos quanto o mo delo R-1, em termos de razão dinâmica de tração.

Forrest et alii (TAYLOR et alii 1976), obtiveram um desempenho ae 8\% a 33\% maior, em termos de tração na barra, para pneus de construção radial sobre os de construção diagonal em quatro condições de testes, para valores de patinamento situados dentro da faixa normal de operação. TAYLOR et alii (1976), definem esta faixa como o intervalo de patinamento situado entre $0 \%$ a $30 \%$, intervalo este a ser utilizado nas opera ções agricolas.

TAYLOR et alii (1976), pesquisaram as diferenças no desempenho entre pneumáticos de construção radial e diagonal, com dimensão 18.4 x 34, 6 lonas e desenho de banda de rodagem $\mathrm{R}-1$. Os ensaios foram realizados em oito diferentes tipos de solo e os resultados - eficiência tratória e razão dinâa mica de tração - analisados em função do patịamento. Para solos de consistência considerada macia, constatou-se pequena di ferença entre o desempenho dos pneus; em solos de consistência firme, observou-se uma nitida vantagem para o pneu radial em termos de razão dinâmica de tração em relação ao pneu diagonal (0,38 para 0,32). Esta diferença, 0,38 vs 0,32, a maior obtida em todos os ensaios, representa um incremento de $18 \%$ da razão dinâmica de tração do pneu radial em relação ao diagonal. Os 
autores atribuem essa diferença de desempenho à área de contato dos pneus. Em solos maciós, a maior parte da deformação ocorre no solo, existindo uma pequena diferença na área de contato pneu-solo entre o radial e o diagonal. Em solo firme, a maior parte da deformação ocorre nos pneus, maximizando as diferenças de área de contato do pneu radial em relação ao diago nal.

CAVALCHINI (1978), avaliou o desempenho de 3 modelos de pneus, um de construção radial e dois de construção diagonal (designados $A$ e B) de tamanho 18.4 - 38, 8 lonas. Os pneus foram ensaiados em duas condições de superfície: terreno com restos de cultura de alfafa e terreno com restos de cul tura de beterraba. Os resultados - tração na barra e potência na barra - foram analisados em função do patinamento, e o consumo específico em função da tração na barra; o modelo de cur va adotado foi o polinômio de grau 2. Os resultados demonstra ram, segundo o autor, uma nítida vantagem do pneu de construção radial em relação aos diagonais. CAVALCHINI (1978) ressal ta que o pneu radial forneceu $5 \%$ a mais de tração máxima, no campo de alfafa, e 10\% sobre o campo de beterraba quando comparado aos pneus $A$ e $B$; nas duas condições, o patinamento para o pneu radial foi menor. Para a potência máxima os valores obtidos foram 7\% e 4,5\% maiores respectivamente. O consumo es pecífico obtido para o pneu radial foi menor, quando comparado aos pneus $A$ e $B$ nas duas condições de solo (campo de alfafa e campo de beterraba).

BURT et alii (1979) realizaram um estudo sobre o efeito da carga dinâmica e do patinamento no desempenho de pneumáticos. Neste trabalho, foram utilizados pneus de dimensões $12.4 \times 28$ de 4 lonas e 12.4 × 38 de 6 lonas com desenho de banda de rodagem $\mathrm{R}-1$; os ensaios foram realizados em três tipos de solos. Os resultados foram expressos em termos de tra ção líquida, potência motora, potência útil e eficiência trató ria em função da carga dinâmica e patinamento; foram realizados gráficos tridimensionais com as variáveis independentes plotadas no eixo $x$ e $y$ e as dependentes no eixo $z$. Os re- 
sultados mostram a importância de se considerar a performance do pneu como uma função da redução de deslocamento e carga dí nâmica; mostram também que o inverso do raio de rolamento, pa ra uma dada condição de solo e pneu, é uma função linear da carga dinâmica aplicada. Com redução de deslocamento constante, verifica-se aumento na eficiência tratória com o aumento na carga dinâmica, sobre solo compactado e um decréscimo na e ficiência tratória com aumento da carga dinâmica, em solo com superficie não compactada. A potência motora apresenta relação linear com a carga dinâmica e não linear a redução de des locamento. A potência útil não apresenta linearidade com rela ção a carga dinâmica e a redução de deslocamento.

BURT e BAILEY (1982) estudaram o efeito de pres são de inflação e da carga dinâmica sobre os pneus $20.8 \mathrm{R}-38$, 8 lonas, com desenho de banda de rodagem $\mathrm{R}-1$. Os testes foram conduzidos em dois tipos de solos e os procedimentos adotados foram: variação da carga dinâmica com patinamento e. pressão de inflação constantes; variação na pressão de inflação com carga dinâmica e patinamento constantes. Os resultados obtidos mostraram que a eficiência tratória, para tração líquida constante, pode ser maximizada pela seleção apropriada do nível de carga dinâmica e pressão de inflação; diferenças de 6\% a $10 \%$ foram obtidas durante os ensaios. Os valores de carga dinâmica para obter a eficiência tratória máxima, encontram-se a niveis típicos de ocorrência em operações de campo. BURT et alii (1983), ressaltam que as pesquisas realizadas mundialmente, mostram que $20 \%$ a $55 \%$ da energia liberada pelos elementos de tração é përdida e, uma parte desta perda, gera a compactação no solo: Os autores realizaram um trabalho com o objetivo de avaliar os efeitos da interação en tre a carga aplicada aos rodados e a pressão de inríação, sobre a eficiência tratória; a tração na barra foi mantida cons tante em $10 \mathrm{kN}$. A escolha destas variáveis independentes justifica-se por serem promissoras para utilização de equipamento de controle automático, em um sistema para otimização da e 
ficiência tratória. Os autores ensaiaram dois modelos de pneus, um de construção radial e o outro diagonal, com tamanho $18.40 \times 30$. O solo utilizado, de textura argilosa, foi preparado para fornecer duas condiçōes distintas, a saber:

\begin{tabular}{crcc}
\hline $\begin{array}{c}\text { condição } \\
\text { de } \\
\text { solo }\end{array}$ & $\begin{array}{c}\text { profundi. } \\
\text { mm. }\end{array}$ & $\begin{array}{c}\text { umidade } \\
\%\end{array}$ & $\begin{array}{c}\text { densidade } \\
\text { g/cm }\end{array}$ \\
\cline { 2 - 4 } 1 & $0-75$ & 18,3 & 1,32 \\
& $75-150$ & 17,5 & 1,30 \\
2 & $0-75$ & 7,5 & 1,08 \\
& $75-150$ & 12,0 & 1,35 \\
\hline
\end{tabular}

O pneu radial operando na condição de solo 1 , apresentou uma eficiência tratōria de 0,70 , com carga dinâmica de $22,8 \mathrm{kN}$ e pressão de inflação de $62 \mathrm{kPa}$. Este ensaio mostrou uma diferença apreciável entre os valores "mínimo $(0,55)$ e máximo $(0,70)$ da eficiência tratória. Nesta condição de solo, o pneu diagonal obteve a máxima eficiência com 124 $\mathrm{kPa}$ de pressão, sob carga dinâmica de $26 \mathrm{kN}$ : A mínima eficiên cia obtida foi 0,54 e a máxima 0,75. Para a condição de solo 2 , operando com pneu radial, a máxima efịciência tratória foi 0,76 e para 0 pneu diagonal 0,69. Os resultados evidenciam que, para uma dada tração na barra, a eficiência do pneu pode ser maximizada pela seleção apropriada do nível de carga dinâa mica e pressão de inflação; a máxima eficiência tratória não ocorre a um nivel minimo de patinamento. Um intervalo de 0,10 a 0,21 de diferença na eficiência tratória foi obtido. 
11.

3. - MATERIAL E MÉTODO

3.1. - MATERIAL

O material utilizado na presente pesquisa abran ge os pneumáticos submetidos a ensaios, os tratores - de tração e frenagem - os equipamentos utilizados na mensuração dos parâmetros de desempenho e na determinação "in situ" das caracteristicas da camada superficial do campo de ensaio.

3.1.1. - Pneumāticos

Os pneumáticos* utilizados, designados pelas le tras A, B, C e D apresentam as seguintes especificações:

- Designação de tamanho: 16.9/14 - 30

- Capacidade de Ionas: 6

- Construção: diagonal

- Desenho de banda de rodagem: $\mathrm{R}-1$

Os desenhos das bandas de rodagem dos pneus podem ser observados na. Figura 1.

* As caracteristicas de construção e terminologia empregadas são apresentadas no Apêndice I. 
12 .

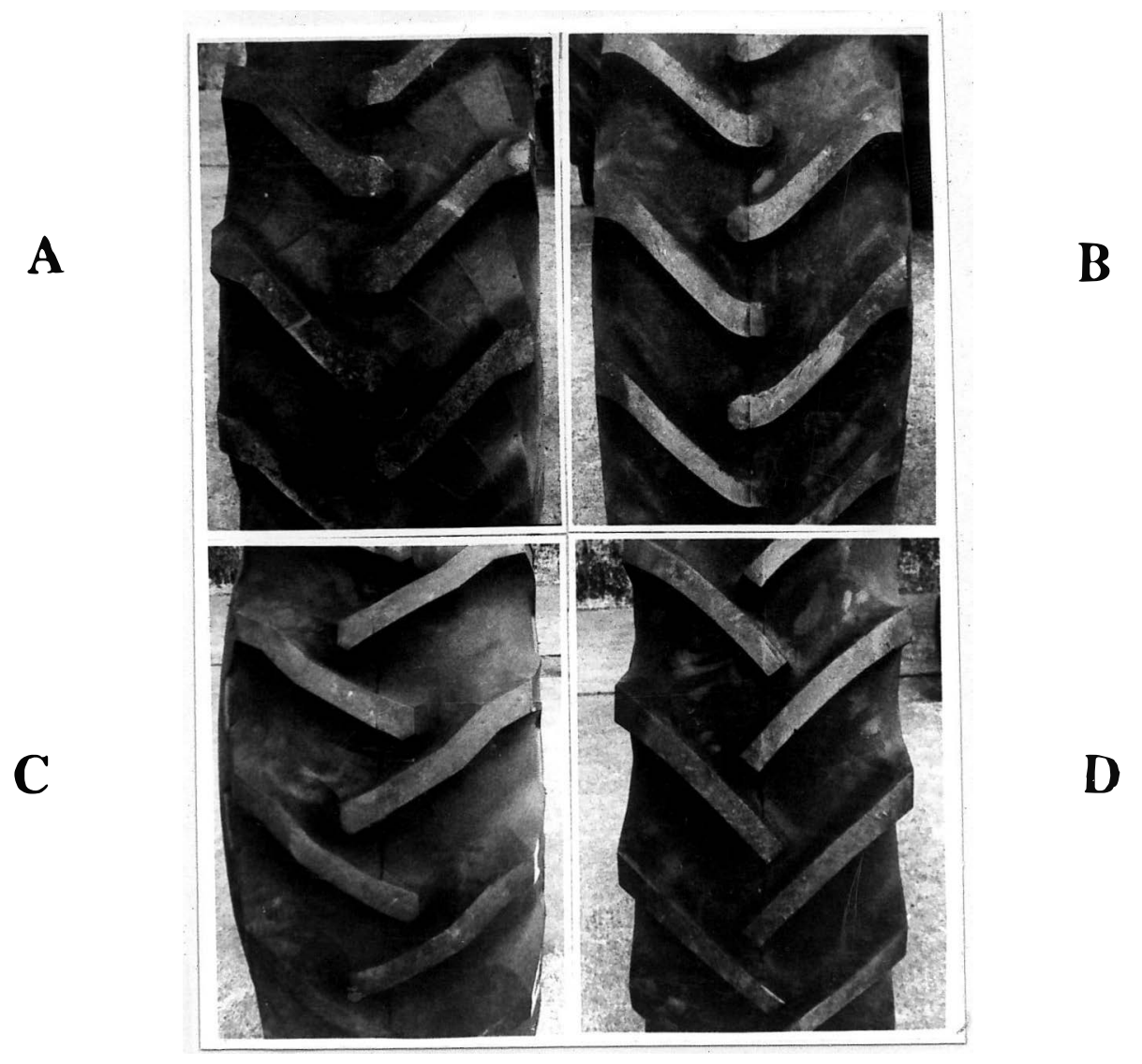

Figura 1 - Desenhos das bandas de rodagem dos modelos avaliados.

\subsection{2. - Tratores}

Para o presente ensaio foram utilizados dois tra tores: um da marca Ford, modelo 5600 doravante denominado trator de tração (Tt); o outro da marca Valmet, modelo 118-4 com tração auxiliar, doravante denominado trator de frenagem (Tf). As características técnicas de ambos os modelos constam do Apêndice II. O trator Tt foi utilizado sob duas condições de operação, com e sem lastros, designadas respectivamente pelas letras CL e SL. 


\subsection{3. - Equipamentos de mensuração}

Os equipamentos de mensuração utilizados na presente pesquisa foram:

-) Célula de carga com extensômetros elétricos, de marca Kratos, modelo CCI, no de série 4768, capacidade para 196 kiv, com impressora. O equipamento foi fornecido com garantia de aferição e sua precisão é de $\pm 0,2 \%$.

.) Conjunto odométrico, constituído de roda odométrica e dois dispositivos compostos de sensores magnéticos e engrenagens (100 dentes).

-) Cronodômetro de fabricação própria (Depto de Engą Rural ESALQ/USP), composto de três "displays", dois para indicação de número de pulsos emitidos pelos sensores do conjunto odométrico e um, para indicação do tempo.

-) Medidor de consumo de combustivel de fabricação própria, (Depto de Engạ Rural, ESALQ/USP) composto de bure tas e eletroválvulas.

A descrição, as calibrações efetuadas e os detalhes de instalação dos equipamentos constam do Apêndice III.

\subsection{4. - Campo de ensaio}

Para os ensaios, escolheu-se uma área de terreno plano, de propriedade da E.S.A. "Luiz de Queiroz". O solo é classificado como Iatossolo vermelho Amarelo de textura média, de acordo com o Sistema Brasileiro de Classificação de Solos, que está sendo desenvolvido pelo SNLCS/EMBRAPA (1986).

Os ensaios foram realizados em ârea de formato retangular com aproximadamente $60-70 \mathrm{~m}$. de largura por 300-350 m. de comprimento; a superfície estava coberta com vegetação rasteira (vegetação natural), predominantemente gramíneas. 
3.2. - MÉTODO

o método utilizado na presente pesquisa abrange:

- Método de avaliação do desempenho dos pneumáticos.

- Método de ensaio de campo.

- Método estatístico de interpretação.

3.2.1. - Método de avaliação do desempenho dos pneumáticos

As análises comparativas do desempenho dos pneu máticos, nas condições propostas por este trabalho e dentro dos recursos técnicos disponiveis, foram realizadas utilizando-se os seguintes parâmetros:

-) Trạção na barra (Ft)

-) Potência na barra de tração (Pb)

-) Razão dinâmica de tração (Rdto)

.) Patinamento ( $\mathrm{Pi}$ \%)

-) Consumo específico (C. esp).

- As definições dos parâmetros $\mathrm{Ft}, \mathrm{Pb}$, Rdt e $\mathrm{Pi}$ são aquelas preconizadas pela padronização ASAE S 296.2 e de $\underline{s}$ critas no Apêndice IV.

\subsection{2. - Método de ensaio de campo.}

A metodologia utilizada nos ensaios de campo abrange a programação dos ensaios e os procedimentos para a mensuração da tração da barra, velocidade de deslocamento, pa tinamento e consumo de combustivel. 


\subsubsection{1. - Programação dos ensaios}

Os ensaios foram delineados segundo um esquema fatorial, incluindo as seguintes variáveis:

tipos de pneus - A, B, C e D*.

Lastragem do Tt - SI e CL

A Figura 2 apresenta as combinações das variáveis, resultando em 8 condições de ensaios que serão doravante designadas através dos códigos

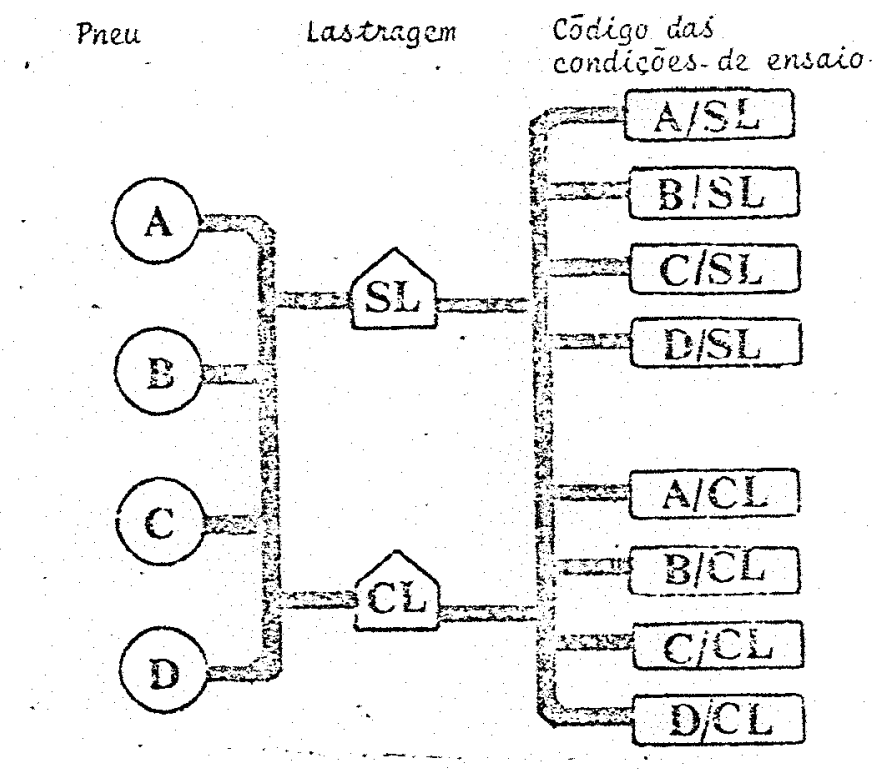

Figura 2 - Códigos das conäiçōes de ensaio.

(*) A pressão de inflação adotada para os pneumáticos e verificada antes do início de cada condição de ensaio, foi de $110 \mathrm{kPa}(16 \mathrm{psi})$. 


\subsubsection{2. - Comboio de ensaio}

Os tratores, equipamentos e dispositivos utilizados na realização dos ensaios foram dispostos em um conjunto doravante denominado como "comboio de ensaio". A disposição dos elementos do conjunto pode ser visualizada na Figura 3 .

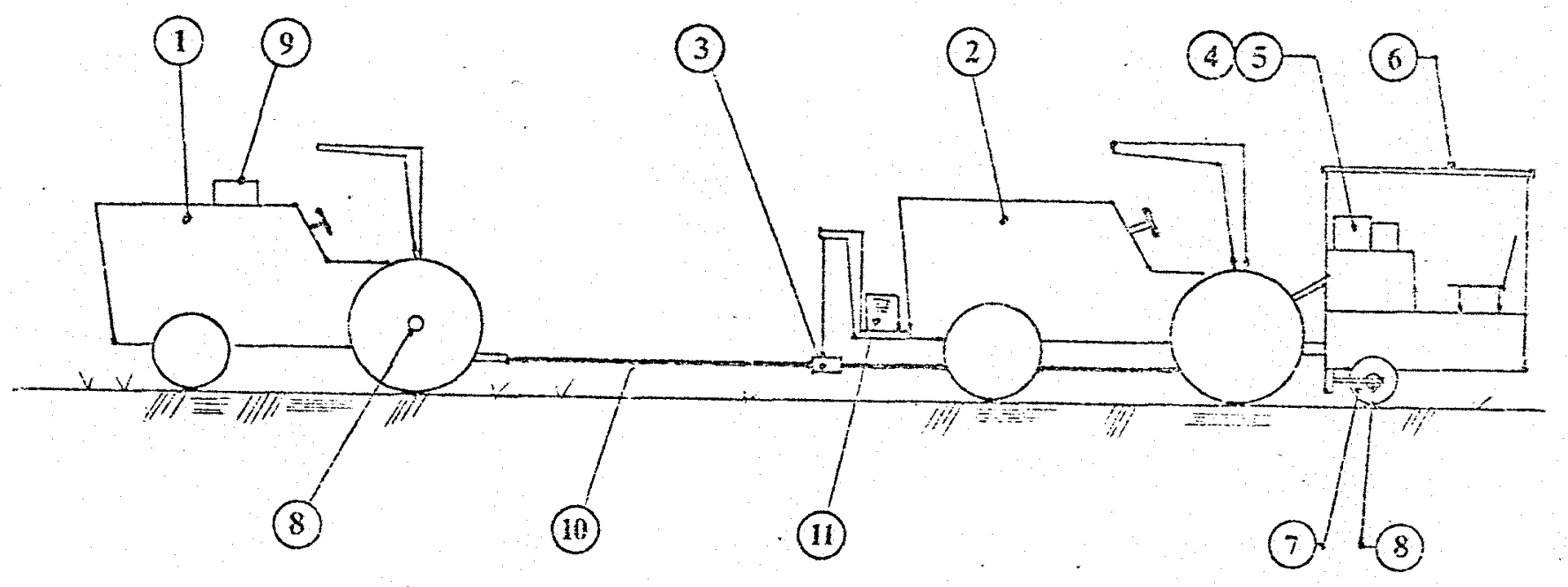

Figura 3 - Comboio de ensaio (1) Trator de tração - Tt; Trator de frenagem - Tf; (3) Célula de carga; (4) Indicador digital e impressora; (5) Cronodômetro; (6) Estrutura para alojar técnicos e equipamentos; (7) Roda odométrica; (8) Senso res; (9) Medidor de consumo; (10) Cabo de aço; (11) Gerador.

\subsubsection{3. - Mensuração da tração na barra (Ft)}

A mensuração da tração desenvolvida na barra do Tt, foi realizada através da célula de carga em conexão com o equipamento de impressão e indicador.

A célula de carga foi mantida suspensa à frente do Tf, através de um dispositivo e acopladà à barra de tração por um cabo de aço. Também, através de um cabo de aço, com a- 
proximadamente $6 \mathrm{~m}$. de comprimento estabeleceu-se a ligação en tre a célula de carga e a barra de tração do Tt.

Por ocasião dos ensaios, tomou-se a precaução de manter o cabo de aço paralelo ao nível do solo e o alinhamento entre os planos médios verticais do Tt e Tf.

A variação da carga imposta ao $\mathrm{Tt}$, durante o decorrer dos ensaios, realizou-se de maneira a obter niveis de patinamento predeterminados e esse procedimento acha-se descrí to em 3.2 .2 .5 .

o equipamento permite uma velocidade máxima de impressão de 2 dados por segundo; um dado impresso representa a média aritmética de três leituras. A Figura 4 apresenta um trecho da fita impressa, com dados obtidos no decorrer de um ensaio.

\begin{tabular}{|c|c|c|c|c|c|}
\hline 0 & j & 1 & 1 & 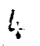 & . 2 \\
\hline 9 & i) & i) & 9 & 9 & .9 \\
\hline 0 & i) & 1 & 1 & 2 & .3 \\
\hline i) & 0 & 1 & 0 & 0 & .9 \\
\hline 0 & i) & 1 & 0 & 5 & .3 \\
\hline i) & 0 & 1 & $?$ & 4 & .9 \\
\hline 1) & 0 & 1 & 0 & 3 & . 3 \\
\hline 0 & 0 & 1 & 1 & 9 & .1 \\
\hline 0 & j) & 0 & 9 & 1 & .1 \\
\hline ) & 0 & 0 & 9 & $!$ & .3 \\
\hline 0 & 0 & 0 & 9) & 5 & .7 \\
\hline
\end{tabular}

Figura 4 - Trécho de uma fita impressa - (Valores em kgf).

A cada nivel de carga de frenagem imposta ao $\mathrm{Tt}$, obteve-se um mínimo de 22 e um máximo de 145 dados impressos.

3.2.2.4. - Mensuração da velocidade de deslocamento (Vt)

A velocidade média de deslocamento (Vt) por ocasião de cada condição de ensaio é calculada através da equação: 


$$
\operatorname{Vt}(\mathrm{m} / \mathrm{s})=\frac{\mathrm{NO} / \mathrm{Pm}}{t}
$$

onde:

$$
\begin{aligned}
\text { Noi }= & \text { número de pulsos da roda odométrica, no } \\
& \text { ensaio } i . \\
\text { Pm }= & \text { número de pulsos por metro linear percor- } \\
& \text { rido pela roda odométrica (fpêndice III) } \\
t= & \text { tempo de duração do ensaio } i, \text { em segun- } \\
& \text { dos. }
\end{aligned}
$$

3.2.2.5. - Mensuração do patinamento.

A determinação do patinamento ( $\mathrm{P} i$ ), ao qual está submetido o Tt em um determinado ensaio, consiste em obter a relação entre o número de pulsos emitidos pelo sensor instalado no Tt e na rodá odométrica. o patinamento é expresso pela equação:

$$
\mathrm{Pio}=\left(1-\frac{\mathrm{NO}}{\mathrm{N} t} \cdot \mathrm{R}\right) \cdot 100
$$

onde:

$$
\begin{aligned}
\text { No }= & \text { número de pulsos registrados durante o en- } \\
& \text { saio } i \text { e emitidos pelo sensor instalado na } \\
& \text { roda odométrica. } \\
\mathrm{Nt}= & \text { número de pulsos registrados durante o en- } \\
& \text { saio } i \text { e emitidos pelo sensor instalado no } \\
& \text { eixo de tração do } \mathrm{Tt} .
\end{aligned}
$$

$$
R=\frac{n \& \text { de pulsos sensor } \mathrm{Tt}}{\text { n@ de pulsos roda odométrica }}
$$

o valor de $R$ foi determinado antes do início de cada ensaio para levar em conta as alterações de perímetro efí 
caz ${ }^{\star}$ entre os pneumáticos do Tt e pela adição e retirada de lastros.

Os niveis de patinamento e consequentemente a Ft à qual submeteu-se o Tt foram obtidos pela seleção da relação de transmissão e do débito da bomba injetora do Tf. Para tanto, calculou-se previamente as marchas e rotações do mo tor do Tf que impõem níveis de $\mathrm{Pi}$ predeterminados. Estes cálculos - Pi, rotação do motor e relação de transmissão - são realizados baseados na diferença de velocidade entre 0 Tt, que operou nos ensaios em 3 ạ marcha a $1800 \mathrm{rpm}$ do motor com bloqueio de diferencial acionado, e o Tf operando a rotação e marchas previamente determinadas. O Quadro I exemplifica as relações de transmissão** e rotações do motor do Tf que impõem ao Tt os níveis de Pi desejados.

Quadro I - Marchas e rotações do motor (r@̣) no tf para obter niveis de $\mathrm{Pi}$ \% predeterminados

\begin{tabular}{|c|c|c|c|c|c|c|c|}
\hline $\mathrm{Pi}$ & \multicolumn{2}{|c|}{ Marcha/rpm } & & \multirow{2}{*}{$\begin{array}{l}\text { Pi\% } \\
40\end{array}$} & \multicolumn{2}{|c|}{ Marcha/ rom } & \\
\hline 5 & L4/1880 & $\mathrm{M} 1 / 2050$ & & & $\mathrm{M} 1 / 1300$ & $\mathrm{~L} 2 / 1890$ & L $3 / 1580$ \\
\hline 10 & L $4 / 1780$ & M1/1950 & & 45 & L $2 / 1730$ & $\mathrm{~L} 3 / 1450$ & $\mathrm{M} 1 / 1: 90$ \\
\hline 15 & M1/1840 & M1/1730 & L4/168ิ0 & 50 & $\mathrm{~L} 1 / 2100$ & L2/1570 & $\mathrm{L} 3 / 1320$ \\
\hline 20 & $\mathrm{~L} 3 / 2100$ & $M 1 / 1620$ & L4/1590 & 55 & L $1 / 1900$ & $\mathrm{~L} 2 / 1420$ & $\mathrm{~L} 3 / 1.190$ \\
\hline 25 & L3/1980 & M1/1730 & & 60 & $\mathrm{~L} 1 / 1690$ & $\mathrm{~L} 2 / 1260$ & $23 / 1050$ \\
\hline 30 & L3/1840 & M1/1510 & & 65 & L.1/1400 & $\cdot I, 2 / 1100$ & \\
\hline 35 & L2/2040 & L3/1710 & $M 1 / 1400$ & 70 & L $1 / 1270$ & & \\
\hline
\end{tabular}

(*) Perímetro eficaz - perímetro da roda medido na condição de ensaio. (**) Os códigos utilizados para as marchas do Tf são apresentados no Apêndice II com a respectiva relação de transmissão. 
De acordo com o nivel de $\mathrm{Pi}$ a ser obtido, seleciona-se a condição de Marcha/rọm adequada à situação desejada; para um nivel de Pio esperado, duas ou mais condições podem ser utilizadas.

3.2.2.6. - Mensuração do consumo de combustiveĺ (CC).

Ao final de cada ensaio, realizava-se a leitura do valor apresentado na bureta central do medidor de combustivel; o consumo, no ensaio, é fornecido pela aplicação do valor lido à equação de calibração. (R̂pêndice III).

3.2.2.7. - Caracterização das condições de campo.

Para caracterizar as condições de campo durante os ensaios litilizou-seos seguintes parâmetros:

a) Umidade

Para cada condição de ensaio, foram tomadas amostras com duas repetições na profundidade de 0-10 cm.

As amostras, acondicionadas em recipientes herméticos e previamente tarados, foram levadas ao laboratório e submetidas a secagem por $48 \mathrm{~h}$., em estufa, a 100-105 ${ }^{\circ} \mathrm{C}$. teor de umidade foi obtido utilizando-se da equação:

Umidade $\left.(\mathrm{U} \%)=\mid \begin{array}{c}\text { Peso total úmido-Peso total seco } \\ \text { Peso total seco-tara }\end{array}\right) \cdot 100$

b) Granulometria

A partir das amostras de umidade constitui-se uma amostra composta para caracterizar a textura do solo; a a- 
nálise granulométrica foi realizada de acordo com 0 procedimento descrito por MEDINA (1975).

3.2.3. - Método estatistico de interpretação

Os dados dos ensaios foram ajustadoś através de regressão polinomial da forma:

$$
y_{i}=a_{0}+a_{i} x_{i}+a_{2} x_{i}^{2} \ldots \ldots+a_{k} x_{i}^{k}+l_{i}
$$

onde:

$x_{i}$ - nivel de patinamento

$Y_{i}$ - variāvel sob análise

o grau de ajuste dos dados observados ao modelo polinomial, foi avaliado através do coeficiente de determinação $\left(r^{2}\right)$ e do teste $F$ de acordo com o seguinte esquema de aná lise de variância:

\begin{tabular}{lc}
\hline Causas de Variação & G.L \\
\hline Reg. Linear & 1 \\
Reg. Quadrática & 1 \\
Reg. Cúbica & 1 \\
Reg. 4o Grau & 1 \\
Desvios de Regressão & $\mathrm{n}-5$ \\
\hline & $\mathrm{n}-1$ \\
\hline
\end{tabular}

$$
\mathrm{n} \text { = nümero de observações. }
$$


4. - RESUltAdO E DISCUSSÃo

4.1. - CARACTERIZAÇÃO DAS CONDIÇÕES DE CAMPO

A análise granulométrica do solo apresentou os seguintes resultados médios:
Areia
$22,3 \%$
Silte
$57,7 \%$
Argila
20,0 웅

- De acordo com esses dados o solo, na área de ensaio, é classificado como Limo Areno Barrento.

Os valores que caracterizam a condição de umida de do solo, no momento da realização dos ensaios são apresentados nas Tabelas de dados dos ensaios de campo.

\section{2. - CONDIÇÃO SEM LASTRO}

\subsection{1. - Dados dos ensaios de campo}

Os dados obtidos no campo, são apresentados nas Tabelas I a IV. O valor de Pm obtido para a presente condição é de 46,792 pulsos por metro, correspondendo a média de 4 determinações; o valor de $\mathrm{R}$ é fornecido com as Tabelas para cada condição de ensaio.

Os dados de tração na barra (Ft) correspondem à média dos valores obtidos no campo e são apresentados seguidos dos respectivos valores de desvio padrão e coeficiente de 
TABELA I - Dados obtidos para o pneu A na condição sem lastro $(A / S L)$.

\begin{tabular}{|c|c|c|c|c|c|c|c|}
\hline \multirow{3}{*}{$\begin{array}{c}\text { Ensaio } \\
\text { no }\end{array}$} & \multicolumn{3}{|c|}{ Ft } & \multirow{2}{*}{$\begin{array}{c}\text { Consumo } \\
\text { CC }\end{array}$} & \multicolumn{2}{|c|}{ Sensores } & \multirow{2}{*}{$\begin{array}{r}\text { Tempo } \\
(t)\end{array}$} \\
\hline & $\bar{M}$ & s. & $\mathrm{c} \cdot \mathrm{v}$. & & no de & pulsos & \\
\hline & $(\mathrm{kN})$ & & $\%$ & $(\mathrm{ml})$ & No & $\mathrm{Nt}$ & $s$ \\
\hline 01 & 7,685 & 0,949 & 12,36 & 51,6 & 1522 & 840 & 24,4 \\
\hline 02 & 14,187 & 1,131 & 7,97 & 174,6 & 1602 & 2042 & 59,3 \\
\hline 03 & 13,287 & 1,099 & 8,27 & 139,6 & 1514 & 1700 & 50,0 \\
\hline 04 & 10,459 & 0,993 & 9,49 & 72,1 & 1646 & 1040 & 31,1 \\
\hline 05 & 10,780 & 0,948 & 8,79 & 81,1 & 1771 & 1156 & 34,7 \\
\hline 06 & 9,654 & 1,030 & 10,67 & 82,1 & 1984 & 1189 & 35,5 \\
\hline 07 & 11,803 & 1,206 & 10,21 & 105,1 & 1837 & 1413 & 42,3 \\
\hline 08 & 10,930 & 1,054 & 9,64 & 88,6 & 1708 & 1218 & 36,4 \\
\hline 09 & 9,726 & 0,824 & 8,47 & 67,6 & 1749 & 1015 & 30,6 \\
\hline 10 & 13,153 & 1,077 & 8,19 & 108,1 & 1709 & 1302 & 41,6 \\
\hline 11 & 13,089 & 1,258 & 9,61 & 117,6 & 1744 & 1493 & 44,7 \\
\hline 12 & 8,794 & 0,809 & 9,20 & 64,6 & 1827 & 1035 & 30,7 \\
\hline 13 & 4,063 & 0,496 & 12,20 & 47,1 & 1710 & 870 & 25,8 \\
\hline 14 & 10,406 & 0,985 & 9,47 & 82,1 & 2030 & 1209 & 36,0 \\
\hline 15 & 13,577 & 1,166 & 8,59 & 133,6 & 1777 & 1654 & 50,3 \\
\hline
\end{tabular}

$\bar{M}=$ média; s. = desvio padrão; $c \cdot v \cdot$ = coeficiente de variação; valor de $\mathrm{R}=0,4835$ (média de duas determinações); umidade do solo $(\mathrm{U} \%)=13,1$ 
TABELA II - Dados obtidos para o pneu B na condição sem lastro $(B / S L)$.

\begin{tabular}{|c|c|c|c|c|c|c|c|}
\hline \multirow{3}{*}{$\begin{array}{c}\text { Ensaio } \\
\text { no }\end{array}$} & \multicolumn{3}{|c|}{ Ft } & \multirow{2}{*}{$\begin{array}{c}\text { Consumo } \\
\mathrm{CC}\end{array}$} & \multicolumn{2}{|c|}{ Sensores } & \multirow{2}{*}{$\begin{array}{r}\text { Tempo } \\
(t)\end{array}$} \\
\hline & M & s. & $c \cdot v$. & & no de & pulsos & \\
\hline & $(\mathrm{kN})$ & &.$\%$ & (ml) & No & $\mathrm{Nt}$ & $\mathrm{s}$ \\
\hline 01 & 12,809 & 0,816 & 6,37 & 88,6 & 1547 & 1089 & 32,3 \\
\hline 02 & 11,234 & 0,691 & 6,15 & 73,6 & 1576 & 984 & 29,3 \\
\hline 03 & 7,551 & 0,667 & 8,84 & 46,1 & 1328 & 715 & 21,2 \\
\hline 04 & 14,782 & 1,614 & 10,92 & 175,6 & 1584 & 1973 & 58,2 \\
\hline 05 & 14,482 & 1,073 & 7,41 & 149,2 & 1580 & 1720 & 51,4 \\
\hline 06 & 13,772 & 1,257 & 9,12 & 121,6 & 1706 & 1475 & 43,9 \\
\hline 07 & 12,637 & 0,771 & 6,10 & 90,6 & 1669 & 1181 & 35,2 \\
\hline 08 & 14,186 & 1,211 & 8,54 & 131,1 & 1555 & 1569 & 47,1 \\
\hline 09 & 11,857 & $1,0.28$ & 8,67 & 80,6 & 1663 & 1085 & 32,2 \\
\hline 10 & 13,065 & 1,097 & 8,40 & 75,6 & 1187 & 962 & 29,0 \\
\hline 11 & 12,878 & 0,740 & 5,74 & 84,6 & 1435 & 1085 & 32,7 \\
\hline 12 & 9,522 & 0,872 & 9,15 & 59,6 & 1554 & 906 & 27,1 \\
\hline 13 & 8,440 & 0,829 & 9,82 & 49,6 & 1384 & 773 & 23,2 \\
\hline 14 & 4,521 & 0,411 & 9,09 & 39,6 & 1527 & 785 & 23,2 \\
\hline 15 & 1,550 & 0,221 & 14,25 & 37,1 & 1532 & 776 & 22,7 \\
\hline 16 & 13,112 & 1,003 & 7,65 & 93,1 & 1296 & 1175 & 35,4 \\
\hline 17 & 10,049 & 0,794 & 7,90 & 63,6 & 1553 & 941 & 28,0 \\
\hline
\end{tabular}

$\mathbb{M}=$ média; $s .=$ desvio padrão; $\mathrm{c} \cdot \mathrm{v}$. = coeficiente de variação; valor de $R=0,4850$ (média de duas determinações); umidade do solo $(U \%)=14,2$ 
TABELA III - Dados obtidos para o pneu C na condição sem lastro $(\mathrm{C} / \mathrm{SL})$.

\begin{tabular}{|c|c|c|c|c|c|c|c|}
\hline \multirow{3}{*}{$\begin{array}{c}\text { Ensaio } \\
\text { no }\end{array}$} & \multicolumn{3}{|c|}{ Ft } & \multirow{2}{*}{$\begin{array}{c}\text { Consumo } \\
\text { CC } \\
\end{array}$} & \multicolumn{2}{|c|}{ Sensores } & \multirow{2}{*}{$\begin{array}{c}\text { Tempo } \\
(t)\end{array}$} \\
\hline & $\bar{M}$ & s. & $c . v$. & & ne & ulsos & \\
\hline & $(\mathrm{kN})$ & & $\%$ & $\mathrm{ml}$ & No & $\mathrm{Nt}$ & $\mathrm{s}$ \\
\hline 01 & 11,130 & 0,902 & 8,10 & 61,1 & 1256 & 837 & 25,0 \\
\hline 02 & 9,342 & 0,940 & 10,06 & 75,6 & 1905 & 1143 & 34,0 \\
\hline 03 & 7,036 & 0,838 & 11,91 & 41,6 & 1195 & 673 & 20,1 \\
\hline 04 & 5,503 & 0,802 & 14,58 & 31,1 & 1008 & 538 & 16,1 \\
\hline 05 & 10,837 & 1,014 & 9,36 & 121,1 & 1267 & 1483 & 44,2 \\
\hline 06 & 12,555 & 1,100 & 8,76 & 134,1 & 1623 & 1645 & 49,6 \\
\hline 07 & 12,148 & 2,195 & 18,07 & 78,6 & 1050 & 1019 & 30,5 \\
\hline 08 & 13,179 & 1,522 & 11,55 & 100,1 & 1447 & 1235 & 37,0 \\
\hline 09 & 9,700 & 1,763 & 18,18 & 43,1 & 992 & 636 & 18,8 \\
\hline 10 & 11,094 & 0,902 & 8,13 & 86,6 & 1583 & 1104 & 33,3 \\
\hline 11 & 11,430 & 1,254 & 10,97 & 94,1 & 1575 & 1202 & 36,1 \\
\hline 12 & 11,502 & 1,697 & 14,75 & 100,1 & 1514 & 1267 & 36,9 \\
\hline 13 & 12,561 & 0,734 & 5,84 & 72,6 & 995 & 905 & 27,2 \\
\hline 14 & 9,846 & 1,110 & 11,27 & 55,1 & 1240 & 773 & 23,0 \\
\hline
\end{tabular}

$M=$ média; $\mathrm{s} .=$ desvio padrão; $\mathrm{c} \cdot \mathrm{v}$. = coeficiente de variação; valor de $\mathrm{R}=0,5041$ (média de duas determinações); umidade do solo $(U \circ)=12,4$. 
TABELA IV - Dados obtidos para o pneu D na condição sem las$\operatorname{tro}(D / S L)$

\begin{tabular}{|c|c|c|c|c|c|c|c|}
\hline \multirow{2}{*}{$\begin{array}{c}\text { Ensaio } \\
\text { n8 }\end{array}$} & \multicolumn{3}{|c|}{ Ft } & \multirow{2}{*}{$\begin{array}{c}\text { Consumo } \\
\mathrm{CC}\end{array}$} & \multicolumn{2}{|c|}{ Sensores } & \multirow{2}{*}{$\begin{array}{c}\text { Tempo } \\
(t)\end{array}$} \\
\hline & $\overline{7}$ & s. & $\overline{c . v}$. & & no de & pulsos & \\
\hline & $(\mathrm{kN})$ & & $\frac{\circ}{6}$ & (ml) & No & $\mathrm{Nt}$ & $\mathrm{s}$ \\
\hline 01 & 13,996 & 1,067 & 7,62 & 138,6 & 1488 & 1587 & 47,8 \\
\hline 02 & 9,061 & 1,446 & 11,56 & 60,1 & 1508 & 896 & 26,7 \\
\hline 03 & 8,680 & 1,075 & 12,38 & 65,6 & 1695 & 1005 & 29,9 \\
\hline 04 & 6,498 & 0,703 & 10,82 & 44,1 & 1495 & 791 & 23,7 \\
\hline 05 & 11,420 & 0,820 & 7,18 & 92,6 & 1834 & 1287 & 38,6 \\
\hline 06 & 8,904 & 0,929 & 10,43 & 71,6 & 1896 & 1112 & 33,3 \\
\hline 07 & 12,710 & 1,066 & 8,39 & 103,1 & 1305 & 1322 & 39,1 \\
\hline 08 & 10,006 & $1,01.1$ & 10,10 & 77,1 & 1844 & 1146 & 34,2 \\
\hline 09 & 12,137 & 0,887 & 7,31 & 112,1 & 1966 & 1497 & 44,8 \\
\hline 10 & 8,356 & 0,812 & 9,71 & 64,6 & 1905 & 1068 & 31,7 \\
\hline 11 & 4,300 & 0,829 & 19,28 & 49,1 & 2039 & 1038 & 30,3 \\
\hline 12 & 12,212 & 0,769 & 6,29 & 119,6 & 1962 & 1579 & 47,4 \\
\hline 13 & 12,460 & 1,096 & 8,80 & 120,1 & 1869 & 1599 & 47,8 \\
\hline 14 & 10,443 & 1,085 & 10,39 & 81,6 & 1858 & 1209 & 35,9 \\
\hline 15 & 4,656 & 0,747 & 16,03 & 43,6 & 1761 & 895 & 26,4 \\
\hline 16 & 2,587 & 0,574 & 22,18 & 42,6 & 2007 & 1017 & 29,3 \\
\hline 17 & 14,464 & 1,245 & 8,61 & 114,1 & 1423 & 1391 & 41,7 \\
\hline 18 & 11,918 & 1,041 & 8,75 & 120,6 & 853 & 1480 & 44,3 \\
\hline 19 & 11,708 & 1,149 & 9,81 & 177,6 & 934 & 2201 & 64,8 \\
\hline
\end{tabular}

$\bar{M}=$ média; s. = desvio padrão; c.v. = coeficiente de variação; valor de $R=0,4747$ (média de duas determinações); umidade do solo (U\%) $=11,1$. 
variação. Os dados de consumo de combustivel (CC), representam o consumo do trator ao longo de cada ensaio, no tempo $t$. Utilizando-se dos dados dos coeficientes de variação ( $c$ \%o) obtidos para cada condição de ensaio, construiu-se os histogramas de freqtência apresentados na Figura 5. Os intervalos de classe foram estabelecidos com base na classificação proposta por PIMENTEL GOMES (1963), a saber:

\begin{tabular}{cc}
$\begin{array}{c}\text { Intervalo do } \\
c v \%\end{array}$ & $\begin{array}{r}\text { Qualificação do } \\
\text { coeficiente }\end{array}$ \\
\hline$[0-10]$ & baixo \\
$(10-20]$ & médio \\
$(20-30]$ & alto \\
$>30$ & muito alto
\end{tabular}
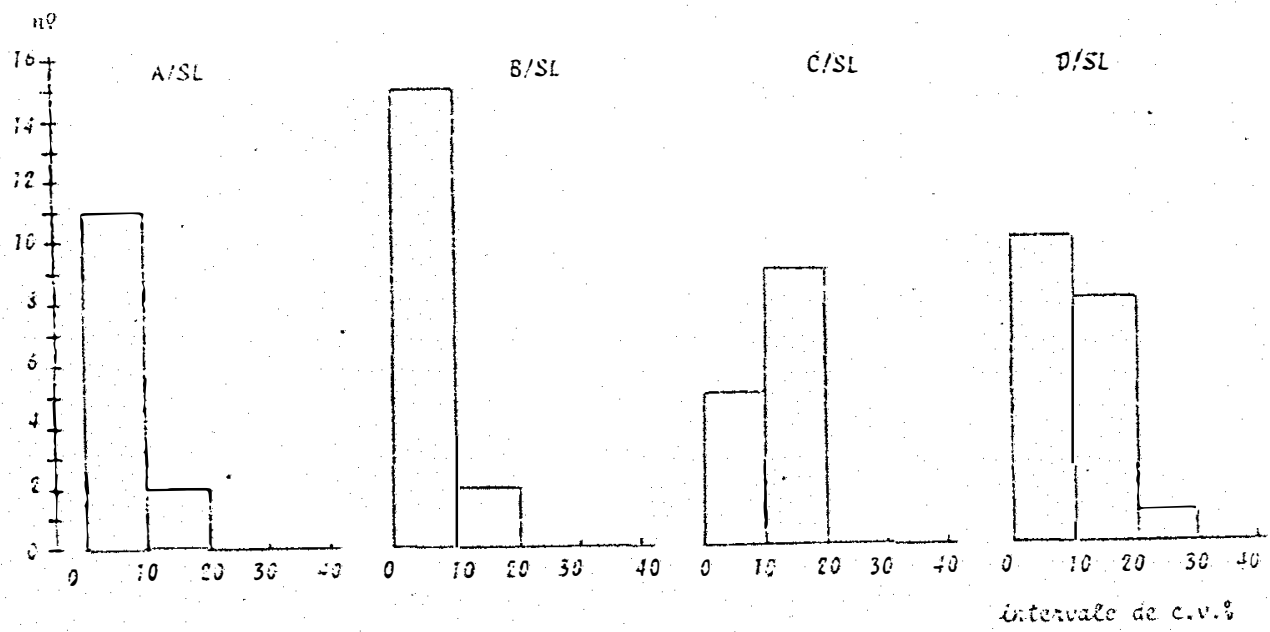

Figura 5 - Histograma da distribuição de frequêencia dos vạ lores dos coeficientes de variação lcondição SI). 
Conforme se observa, no intervalo de classe de 0-10\% encontram-se 11 valores de cv\% (cerca de 73\%) para os ensaios na condição $\mathrm{A} / \mathrm{SL}, 15$ valores (88\%) na B/SL, 5 valores (36\%) na C/SL e 10 valores (53\%) na D/SL.

Tendo em vista que a maior parte dos cvo podem ser qualificados de baixos e médios, ficam evidenciados as adequadas características da metodologia, equipamentos e condi ções de uniformidade do solo.:

4.2.2. - Parâmetros de desempenho dos pneumáticos.

Com os dados apresentados no item 4.2.1. (Tabe las I a IV) e com base nas definições e equações apresentadas no Apêndice IV, obteve-se os valores dos parâmetros de desern penho dos pneumáticos constantes nas Tabelas V a VIII. Visando facilitar a interpretação, os valores obtidos foram listados na ordem crescente dos dados de patinamento. 
TABELA V - Desempenho do pneumático A, na condição sem lastro

\begin{tabular}{|c|c|c|c|c|c|}
\hline \multirow{3}{*}{$\begin{array}{c}\text { Ensaio } \\
\text { no }\end{array}$} & \multicolumn{5}{|c|}{ Variāvel } \\
\hline & $\mathrm{Pi}$ & Ft & $\mathrm{Pb}$ & $\mathrm{Rdt}$ & C.esp. \\
\hline & $\%$ & $k N$ & $\mathrm{~kW}$ & $\frac{\circ}{0}$ & $\mathrm{ml} / \mathrm{kW} \cdot \mathrm{h}$ \\
\hline 13 & 4,98 & 4,063 & 5,753 & 23,16 & 1142,4 \\
\hline 01 & 12,41 & 7,685 & 10,244 & 42,12 & 743,2 \\
\hline 12 & 14,66 & 8,794 & 11,177 & 47,63 & 677,7 \\
\hline 09 & 16,70 & 9,726 & 11,875 & 52,17 & 669,7 \\
\hline 14 & 18,83 & 10,406 & 12,539 & 55,43 & 654,8 \\
\hline 06 & 19,33 & 9,654 & 11,527 & 51,83 & 722,3 \\
\hline 04 & 23,49 & 10,459 & 11,829 & 55,68 & 705,6 \\
\hline 05 & 25,94 & 10,780 & 11,750 & 57,20 & 716,1 \\
\hline 08 & 32,21 & 10,930 & 10,963 & 57,91 & 799,3 \\
\hline 10 & 36,54 & 13,153 & 11,548 & 68,13 & 810,1 \\
\hline 07 & 37,15 & 11,803 & 10,953 & 61,98 & 816,7 \\
\hline 11 & 43,53 & 13,089 & 10,916 & 67,84 & 867,6 \\
\hline 15 & 48,06 & 13,577 & 10,251 & 70,03 & 932,8 \\
\hline 03 & 56,95 & 13,287 & 8,597 & 68,73 & 1169,1 \\
\hline 02 & 62,07 & 14,187 & 8,186 & 72,73 & 1294,9 \\
\hline
\end{tabular}


30 .

TABELA VI - Desempenho do pneumático B, na condição sem lastro

\begin{tabular}{|c|c|c|c|c|c|}
\hline \multirow{2}{*}{$\begin{array}{c}\text { Ensaio } \\
\text { no }\end{array}$} & \multicolumn{5}{|c|}{ Variável } \\
\hline & $\mathrm{Pi}$ & Ft & $\mathrm{Pb}$ & $R d t$ & C.esp. \\
\hline & $\%$ & $\mathrm{kN}$ & $\mathrm{KW}$ & 응 & $\mathrm{ml} / \mathrm{kW} \cdot \mathrm{h}$ \\
\hline 15 & 4,28 & 1,550 & 7,574 & 9,09 & 776,8 \\
\hline 14 & 5,69 & 4,521 & 6,358 & 25,64 & 966,5 \\
\hline 03 & 9,95 & 7,551 & 10,107 & 41,44 & 774,5 \\
\hline 13 & 13,19 & 8,440 & 10,757 & 45,89 & 715,5 \\
\hline 12 & 16,84 & 9,522 & 11,667 & 51,19 & 678,6 \\
\hline 17 & 19,98 & $1.0,049$ & 11,909 & 53,73 & 686,6 \\
\hline 02 & 22,35 & 11,234 & 12,910 & 59,33 & 700,4 \\
\hline 09 & 25,69 & 11,857 & 13,083 & $62 ., 23$ & 688,8 \\
\hline 01 & 31,12 & 12,809 & 13,108 & 66,58 & 753,4 \\
\hline 07 & 31,48 & 12,637 & 12,802 & 65,80 & 723,8 \\
\hline 11 & 35,87 & 12,878 & 12,074 & 66,89 & 771,4 \\
\hline 10 & 40,18 & 13,065 & 11,426 & 67,73 & 821,4 \\
\hline 06 & 43,92 & 13,772 & 11,435 & 70,90 & 872,1 \\
\hline 16 & 46,52 & 13,112 & 10,256 & 67,95 & 923,2 \\
\hline 08 & 51,95 & 14,186 & 10,007 & 72,73 & 1001,3 \\
\hline 05 & 55,46 & 14,482 & 9,512 & 74,03 & 1097,9 \\
\hline 04 & 61,07 & 14,782 & 8,596 & 75,34 & 1263,7 \\
\hline
\end{tabular}


TABELA VII - Desempenho do pneumático C, na condição sem lastro

\begin{tabular}{|c|c|c|c|c|c|}
\hline \multirow{3}{*}{$\begin{array}{c}\text { Ensaio } \\
\text { no }\end{array}$} & \multicolumn{5}{|c|}{ Variável } \\
\hline & $\mathrm{Pi}$ & Ft & $\mathrm{Pb}$ & Rdt & C.esp. \\
\hline & $\frac{\circ}{0}$ & $\mathrm{kN}$ & $\mathrm{kW}$ & $\%$ & $\mathrm{ml} / \mathrm{kW} \cdot \mathrm{h}$ \\
\hline 04 & 5,56 & 5,503 & 7,361 & 30,87 & 944,7 \\
\hline 03 & 10,50 & 7,036 & 8,937 & 38,83 & 33,7 \\
\hline 02 & 15,99 & 9,342 & 11,183 & 50,32 & 715,8 \\
\hline 14 & 19,14 & 9,846 & 11,342 & 52,75 & 760,4 \\
\hline 09 & 21,38 & 9,700 & 10,936 & 52,05 & 754,7 \\
\hline 01 & 24,36 & 11,130 & 11,947 & 58,85 & 736,4 \\
\hline 10 & 27,73 & 11,094 & 11,271 & 58,62 & 830,7 \\
\hline 11 & 33,95 & 11,430 & 11,609 & 60,25 & 808,4 \\
\hline 12 & 39,77 & 11,502 & 10,083 & 60,58 & 968,6 \\
\hline 08 & 40,94 & 13,179 & 11,015 & 68,18 & 883,3 \\
\hline 13 & 44,58 & 12,561 & 9,818 & 65,46 & 978,7 \\
\hline 07 & 48,06 & 12,148 & 8,935 & 63,57 & 1038,3 \\
\hline 06 & 50,27 & 12,555 & 8,777 & 65,43 & 1108,9 \\
\hline 05 & 56,94 & 10,837 & 6,639 & 57,47 & 1485,7 \\
\hline
\end{tabular}


TABELA VIII - Desempenho do pneumático D, na condição sem lastro.

\begin{tabular}{|c|c|c|c|c|c|}
\hline \multirow{3}{*}{$\begin{array}{c}\text { Ensaio } \\
\text { no }\end{array}$} & \multicolumn{5}{|c|}{ Variāvel } \\
\hline & $\mathrm{Pi}$ & Ft & $\mathrm{Pb}$ & $R d t$ & C.esp. \\
\hline & 응 & $\mathrm{kN}$ & $\mathrm{kW}$ & $\%$ & $\mathrm{ml} / \mathrm{kW} \cdot \mathrm{h}$ \\
\hline 16 & 6,30 & 2,587 & 3,786 & 14,99 & 1382,4 \\
\hline 15 & 6,58 & 4,656 & 6,636 & 26,36 & 895,9 \\
\hline 11 & 6,73 & 4,300 & 6,183 & 24,44 & 943,6 \\
\hline 04 & 10,26 & 6,498 & 8,757 & 36,07 & 765,0 \\
\hline 10 & 15,31 & 8,356 & 10,728 & 45,47 & 683,8 \\
\hline 06 & 19,04 & 8,904 & 10,832 & 48,17 & 714,7 \\
\hline 03 & 19,92 & 8,680 & 10,513 & 47,07 & 751,2 \\
\hline 02 & 20,09 & $9 ; 061$ & 10,934 & 48,94 & 741,1 \\
\hline 08 & 23,60 & 10,006 & 11,527 & 53,52 & 704,1 \\
\hline 14 & 27,03 & 10,443 & 11,548 & 55,60 & 708,6 \\
\hline 05 & 32,34 & 11,420 & 11,592 & 60,20 & 745,0 \\
\hline 09 & 37,64 & $12, .937$ & 11,380 & 63,52 & 791,6 \\
\hline 12 & 41,00 & 12,212 & 10,800 & 63,86 & 841,1 \\
\hline 13 & 44,50 & 12,460 & 10,409 & 64,99 & 869,0 \\
\hline 17 & 51,77 & 14,464 & 10,472 & 73,95 & 940,6 \\
\hline 07 & 53,13 & 12,710 & 9,064 & 66,13 & 1047,4 \\
\hline 01 & 55,48 & 13,996 & 9,309 & 71,89 & 1121,3 \\
\hline 18 & 72,63 & 11,918 & 4,903 & 62,51 & 1998,7 \\
\hline 19 & 79,85 & 11,708 & 3,606 & 61,54 & 2736,2 \\
\hline
\end{tabular}




\subsection{3. - Equações de regressao}

Com a finalidade de verificar o melhor grau de ajuste do modelo polinomial adotado, os dados das Tabelas $\mathrm{V}$ a VIII foram ajustados até polinômios de grau 4 . No Apênaice $V$ são apresentados os resultados da análise de variância, os coeficientes de determinação $\left(r^{2}\right)$ e as equações de regressão obtidas para os pneumáticos.

A Tabela IX, mostra os valores de $F$ e os coefi cientes de determinação $\left(r^{2}\right)$ utilizados para a escolha do grau do polinômio a ser adotado. 


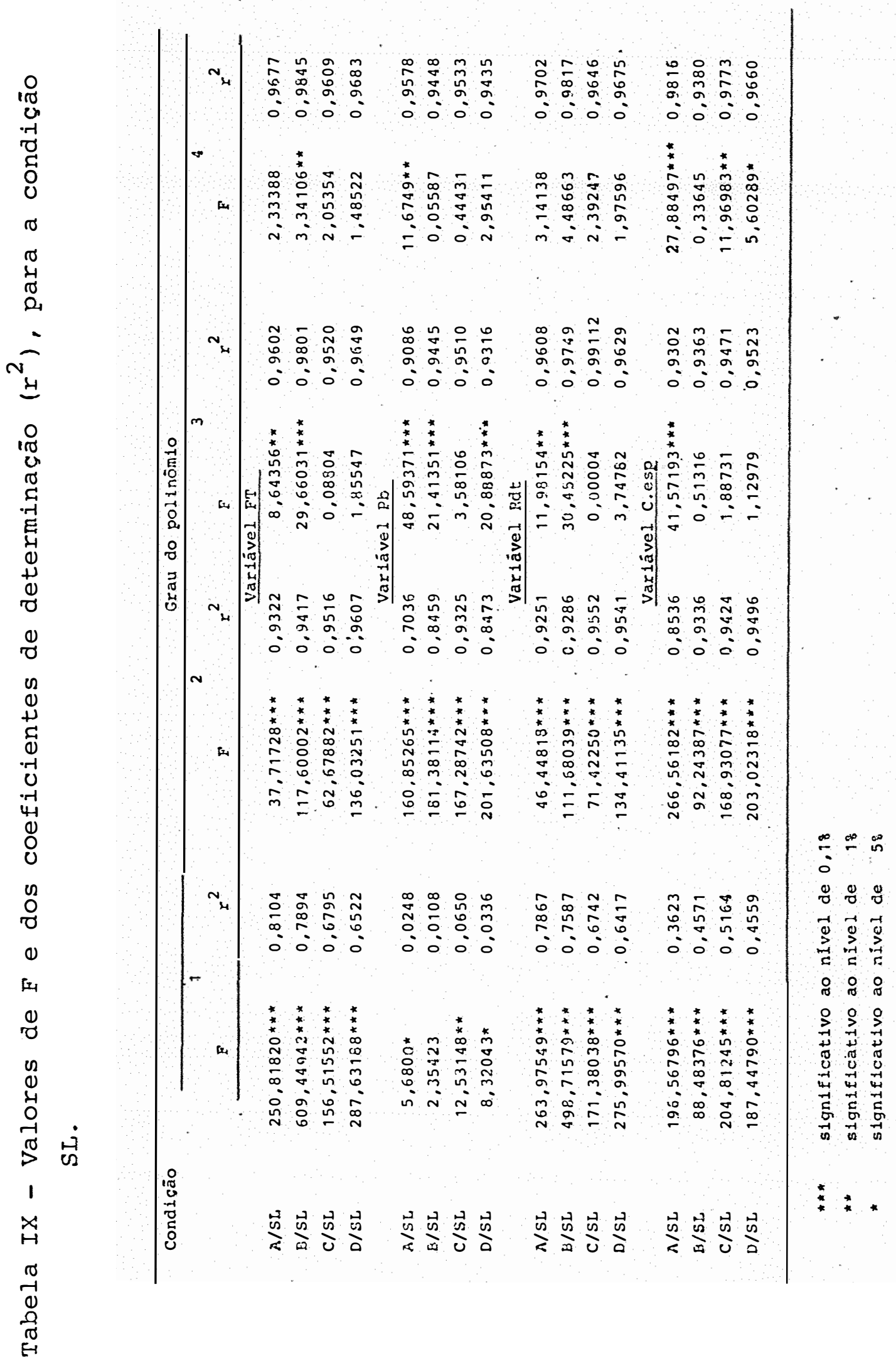


Com base nos valores apresentados, o modelo de regressão adotado é o polinômio de 20 grau pelas seguintes razões:

-) Para a variável Ft, os coeficientes de determinação $\left(r^{2}\right)$ obtidos para o polinômio de grau 2 estão acima de 0,90 e os valores de F, significativos a nivel de 0,1\%; o polinônio de grau 1 apresentou $\mathrm{r}^{2}$ inferiores a 0,70 em duas condições, enquanto que para os polinômios de grau 3 e 4 , embora apresentassem $r^{2}$ acima de 0,95 , os valores de $F$ foram não significativos a nivel de $5 \%$ nas condições $C / S L, D / S L$.

.) Para a variável $\mathrm{Pb}$, os polinômios de gráu 2, apresentaram três $r^{2}$ a níveis acima de 0,80 e um com valor de 0,7036; os valores de $F$ apresentaram-se significativos a nível de $0,1 \%$. Os polinômios de grau 1 apresentaram $r^{2}$ inferiores a 0,06 e os de grau 3 e 4, embora situassem a niveis superiores a 0,90 , os valores de $F$ foram não significativos a nível de 5\% nas condições B/SL (4\% grau), C/SL (3० e 4 \% graus) e D/SL (4\% grau).

.) Para a variável Rdt, os $\mathrm{r}^{2}$ obtidos para o polinômio de 2 ? grau estão acima de 0,90 e os valores de F, significativos a nível de $0,1 \%$. Os $\mathrm{r}^{2}$ para polinômios do 1 \% grau encontram-se abaixo de 0,80 enquanto que para os de 30 e 4\% graus acima de 0,95 embora para estes os valores de $F$ fo ram não significativos a nível de $5 \%$ para as condições A/SL

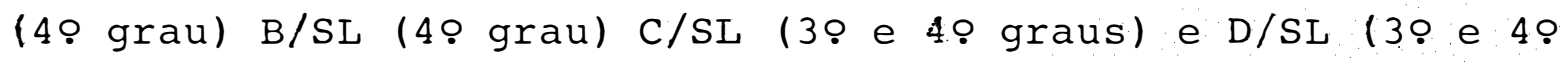
graus).

.) Para a variável c.esp.os $\mathrm{r}^{2}$ obtidos para o polinômio de 20 grau estão acima de 0,85 e os valores de $F$ significativos a nível de $0,1 \%$. Para o polinômio do 10 grau os valores de $\mathrm{r}^{2}$ estão abaixo de 0,52 enquanto que para os po linômios de $3 \circ$ e 4 \% graus, os valores de $r^{2}$ encontram-se acima de 0,93, mas os valores de $F$ foram não significativos a ní vel de $5 \%$ para as condições B/SL (3\% e $4 \%$ graus) C/SL (39 e 4 \% graus) e D/SL (3\% grau). 
Conforme o exposto, os polinômios de grau 2 apresentaram em todas as condições valores altos de $\mathrm{r}^{2}$ e os valores de $F$ foram significativos ao nivel de $0,1 \%$; os polinômios de grau 1 apresentaram $\mathrm{r}^{2}$ muito baixos, demonstrando claramente o não ajuste dos dados ao modelo proposto. Para os polinômios de grau 3 e 4 , embora os $r^{2}$ sejam superiores aos dos polinômios do grau 2 , seus valores de $F$, em várias condições, não são significativos ao nível de $5 \%$; isso demonstra que o au mento em 1 grau no polinômio não se traduz em um aumento no ní vel de precisão do ajuste dos pontos, em relação ao modelo ado tado.

Para o polinômio de grau 3 ocorre, em determina das condições, a tendência de existir uma região de inflexão da curva a níveis altos de $\mathrm{Pi}$ e dentro do intervalo amostrado. Esta tendência foi verificada para a condição $A / S L$ ilustrada na Figura 6 .

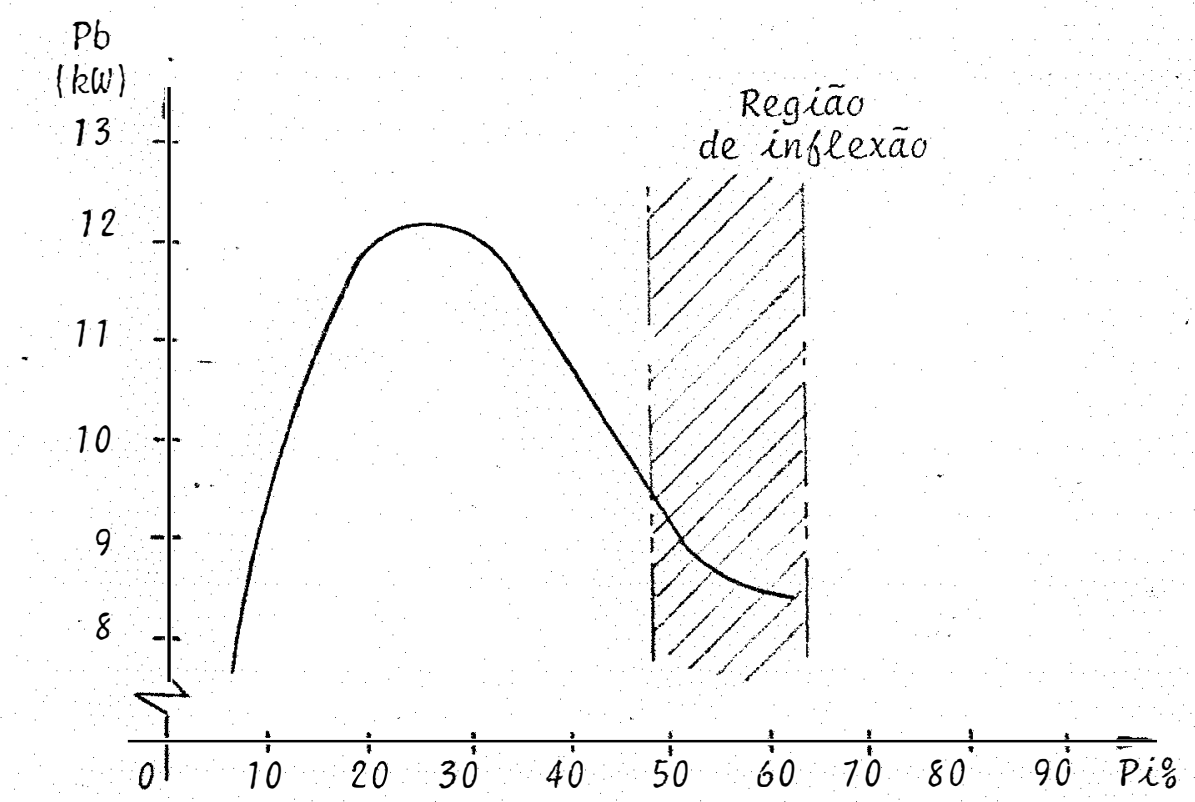

Figura 6 - Região de inflexão a níveis altos de $\mathrm{Pi}$ (condição $A / S L)$.

Essas considerações estão de acordo com o obser vado por CALVACHINI (1978), que adotou o polinômio de grau 2 para ajuste das curvas de desempenho de pneumáticos, em solos 
37.

agrícolas com restos de cultura.

4.2.4. - Avaliação do desempenho

A partir das equações polinomiais de grau 2, elaborou-se os gráficos apresentados nas Figuras $T$ a 10 . Obser va-se, através destas figuras, que não existe uma tendência definida de um pneu se destacar em relação aos outros, no intervalo de patinamento avaliado. O que ocorre são diferenças no desempenho, a determinados niveis de $\mathrm{Pi}$, como por exemplo para a variável Ft a níveis de $\mathrm{Pi}$ acima de $30 \%$, aproximadamen te (Figura 7).

A não existência de uma metodologia específica para avaliar comparativamente o desempenho dos pneumáticos, levou a adoção do critério de comparar os pneus a $10 \%, 20 \%$ e $30 \%$ de Pi; esses níveis,propostos por VASEY e NAYLOR (1958) para solo firme, encontram-se dentro da faixa normal de opera ção dos tratores agrícolas de acordo com TAYLOR et alii (1976). Por outro lado, o patinamento que forneça melhor desempenho constitui um aspecto a ser discutido, conforme propos to por CALVACHINI (1978). 
38.

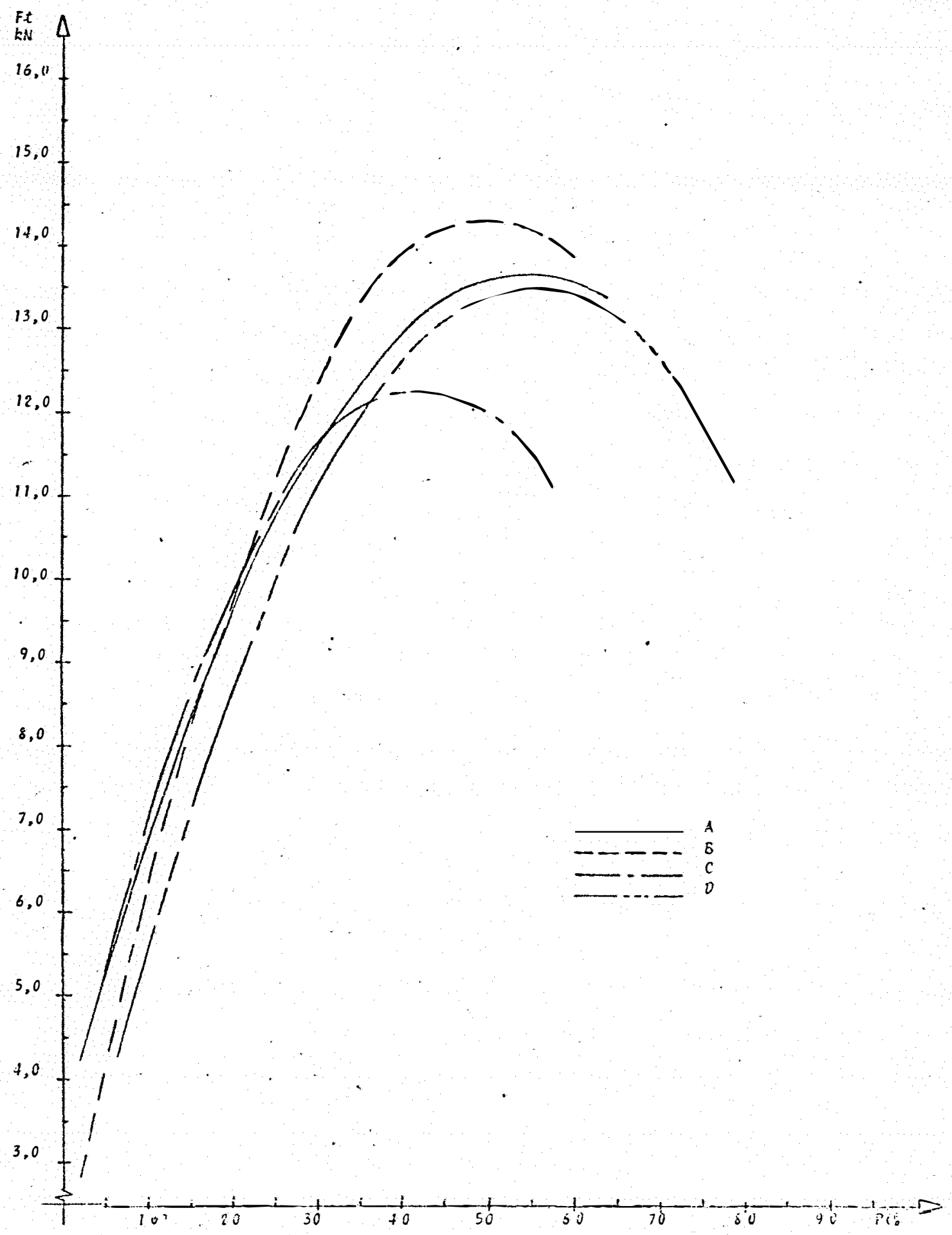

Figura 7 - Gráfico da tração na barra (Ft) em função do patinamento (Pi) para a condição sem Iastro. 


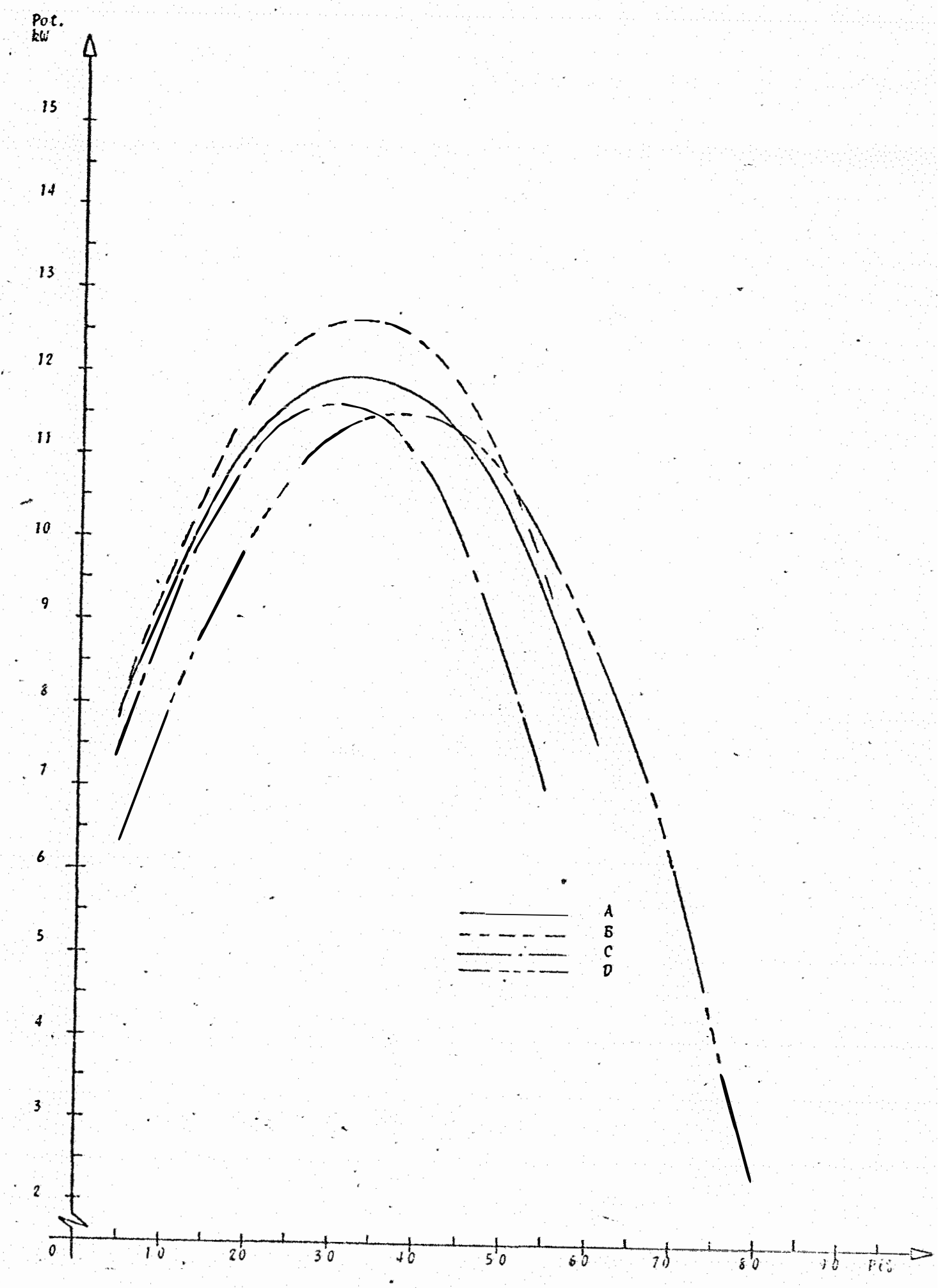

Figura 8 - Gráfico ảa potência na barra (Pb) em função do patinamento (Pi) para a condição sem las tro. 


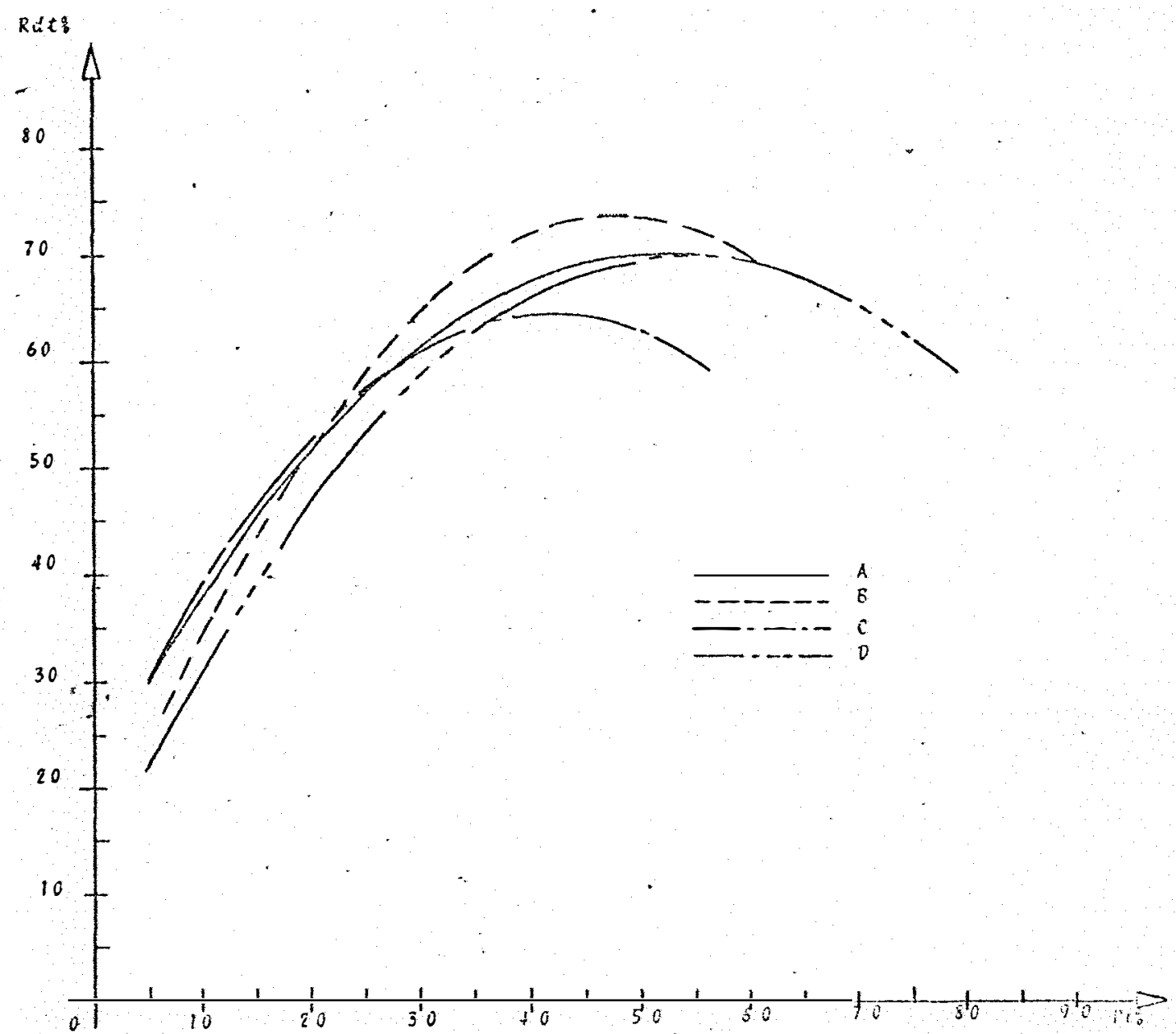

Figura 9 - Gráfico da razão dinâmica de tração (Rdt) em função do patinamento (Pi) para a condição sem lastro. 


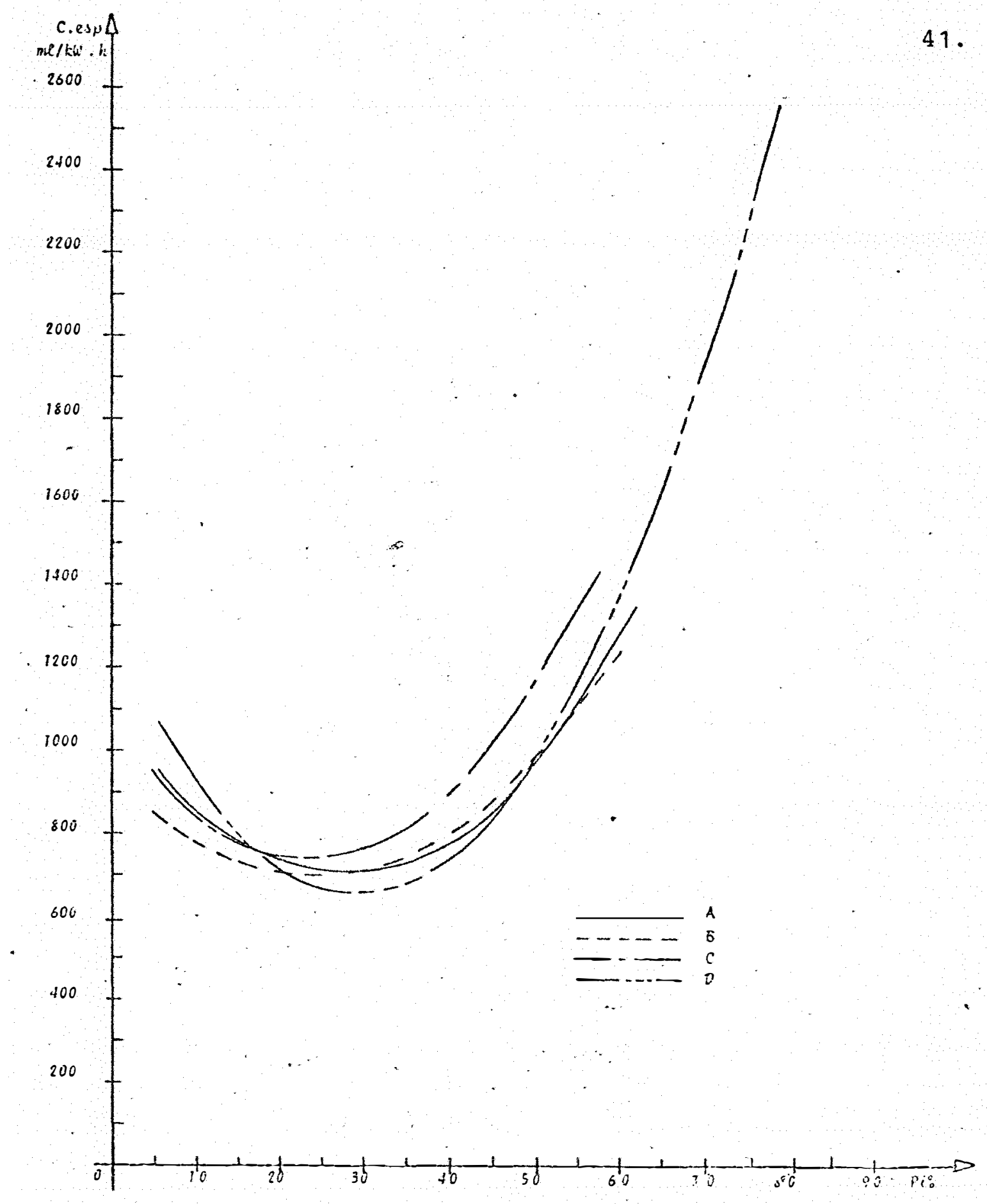

Figura 10 - Gráfico do consumo específico (c.esp.) em função do patinamento (Pi) para a condição sem lastro. 
4.2.4.1. - Desempenho máximo dos pneumáticos.

O desempenho máximo* dos pneumáticos e os niveis de patinamento em que foram obtidos, são apresentados na Tabela $X$. Atribuiu-se 0 indice 100 ao pneumático com melhor desernpenho e determinou-se as diferenças, para cada variável. Para cada pneu, estas diferenças podem ser melhor visualizadas no gráfico da Figura 11.

Tabela X - Valores de Ft, $\mathrm{Pb}$ e Rdt máximos e C.esp mí-. nimo, obtidos pelos pneumáticos para a condição SL.

\begin{tabular}{|c|c|c|c|c|c|c|c|c|}
\hline \multirow[t]{2}{*}{ Pneu } & \multicolumn{7}{|c|}{ Variável } & \multirow[b]{2}{*}{ Indice } \\
\hline & $\begin{array}{r}F t \\
-k N- \\
(P i \circ) \\
\end{array}$ & Indice & $\begin{array}{c}\mathrm{Pb} \\
-\mathrm{kW}- \\
(\mathrm{Pi} \%)\end{array}$ & Indice & $\begin{array}{l}\text { Rdt } \\
-\%- \\
\text { (Pi\%) }\end{array}$ & Indice & $\begin{array}{c}\text { C.esp. } \\
-\mathrm{ml} / \mathrm{kW} \cdot \mathrm{h} \\
\text { (Pi\%) }\end{array}$ & \\
\hline A & $\begin{array}{r}13,711 \\
(54,48)\end{array}$ & 95,3 & $\begin{array}{r}12,009 \\
(32,3.1)\end{array}$ & 94,6 & $\begin{array}{c}70,73 \\
(55,92)\end{array}$ & 95,6 & $\begin{array}{l}703,9 \\
(26,97)\end{array}$ & 107,0 \\
\hline B & $\begin{array}{r}14,382 \\
(49,71)\end{array}$ & 100 & $\begin{array}{r}12,699 \\
(32,50)\end{array}$ & 100 & $\begin{array}{c}73,98 \\
(48,41)\end{array}$ & 100 & $\begin{array}{l}699,7 \\
(23,80)\end{array}$ & 106,4 \\
\hline c & $\begin{array}{r}12,351 \\
(42,13)\end{array}$ & 85,9 & $\begin{array}{r}11,651 \\
(29,29)\end{array}$ & 91,7 & $\begin{array}{c}64,65 \\
(41,92)\end{array}$ & 87,4 & $\begin{array}{l}740,3 \\
(23,55)\end{array}$ & 112,6 \\
\hline D & $\begin{array}{r}13,555 \\
(55,30)\end{array}$ & 94,2 & $\begin{array}{r}11,548 \\
(37,24)\end{array}$ & 90,9 & $\begin{array}{c}70,48 \\
(55,10)\end{array}$ & 95,3 & $\begin{array}{l}657,6 \\
(28,97)\end{array}$ & 100 \\
\hline
\end{tabular}

(*) Como desempenho maximo dos pneumäticos, entende-se aquele onde ocorreu os maiores valores das variāveis $F t, P b$ e Rdt maximos e o menor valor de C.esp. na faixa de $P i$ avaliada. 


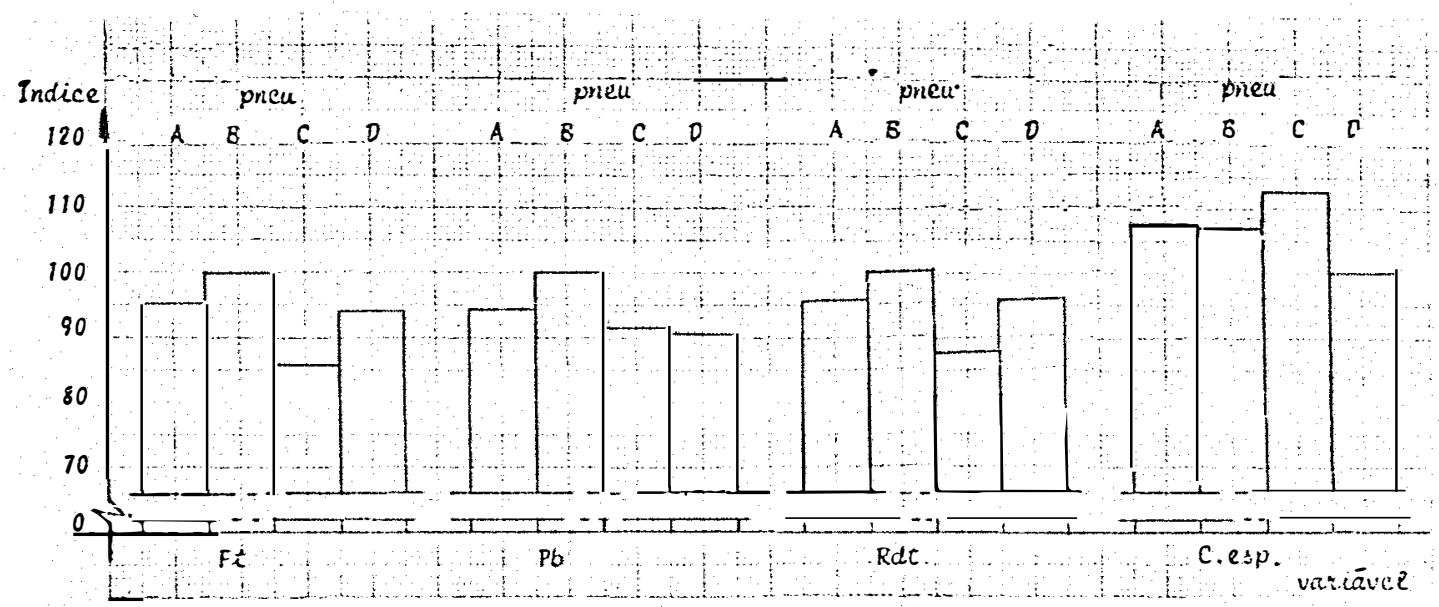

Figura 11 - Desempenho dos pneumáticos para as variáveis $\mathrm{Ft}, \mathrm{Pb}, \mathrm{Rdt}$ no ponto de máximo e C.esp. no ponto de mínimo condição sem lastro.

De acordo com os resultados obtidos e apresentados na Tabela X e Figura 11, o pneu que melhor desempenho apre-. sentou para as variáveis $\mathrm{Ft}, \mathrm{Pb}$ e Rdt foi $O \mathrm{~B}$, sendo que para C.esp, O pneu $D$ obteve $O$ melhor indice. Os niveis de patinamento situaram-se acima de $30 \%$ para as variáveis $\mathrm{Ft}, \mathrm{Pb}$ e Rdt, com exceção da condição $\mathrm{C} / \mathrm{SL}$ para a variável $\mathrm{Pb}$. Observa-se que os menores valores do C.esp. ocorreram dentro da faixa normal de operação $(0-30 \%$ de $\mathrm{Pi})$.

Para as variáveis Ft, Rdt e C.esp. o pneu C apresentou os piores indices com valores de 85,9 e 87,4 e 112,6 res pectivamente, cabendo ressaltar que para a variável c.esp. o indice 100 é atribuído ao pneu com menor consumo específico; no tocante a variável $\mathrm{Pb}, \mathrm{O}$ pneu $\mathrm{D}$ foi o que apresentou 0 pior desempenho com um indice de 90,9. Embora o pneu $C$ tenha apresenta do os piores indices para 3 variáveis (Ft, Rdt e C.esp.) estes valores foram observados a niveis inferiores de patinamento, em relação aos outros pneumáticos. 
Pelos valores obtidos, é válido afirmar que se o critério de escolha de um pneu fosse a exigência em tração, o pneu B deveria ser adotado para as condições de campo avaliadas. Embora o pneu C tenha obtido o seu melhor desempenho a niveis de $\mathrm{Pi}$ menores, a análise dos gráficos - Figuras 7 a 10 - revela que a esses níveis de patinamento, o desempenho do pneu B foi superior ao pneu C nas variáveis Ft, $\mathrm{Pb} e \mathrm{Rdt}$. Para a variável C.esp., as diferenças de desempenho são apresentadas na Tabela XI.

Tabela XI - Consumo específico dos pneumáticos para nivel de $\mathrm{Pi}$ que obteve c.esp. mínimo na condição $\mathrm{C} / \mathrm{SI}(\mathrm{Pi} \%=23,55)$

\begin{tabular}{lcccc}
\hline & \multicolumn{4}{c}{ Pneu } \\
\cline { 2 - 4 } & A & B & C & D \\
Cons. especifico & 710,0 & 699,8 & 740,3 & 679,8 \\
(ml/kW.h) & & & & \\
Indice & 104,4 & 102,9 & 108,9 & 100 \\
\hline
\end{tabular}

Conforme se observa, o pneu B apresentou uma diferença de apenas 2,9 em relação ao pneumático de melhor de sempenho (D - Indice 100) e um consumo especifico inferior ao C em 6 unidades. Com estes resultados, levando em conta o dis cutido no parágrafo anterior, é lícito afirmar-se que para si tuações limites de exigências e nas condiçōes de campo utilizadas nesta pesquisa, o pneu B deve ser o adotado.

4.2.4.2. - Desempenho na faixa normal de operação

Para os valores de $\mathrm{Pi}$ adotados dentro da faixa normal de operação - $10 \%, 20 \%$ e $30 \%$ - os resultados obtidos 
são apresentados na Tabela XII.

Tabela XII - Valores de Ft, Pb, Rdt e C.esp., para indices de Pi situados dentro da faixa normal de operação (condição SL).

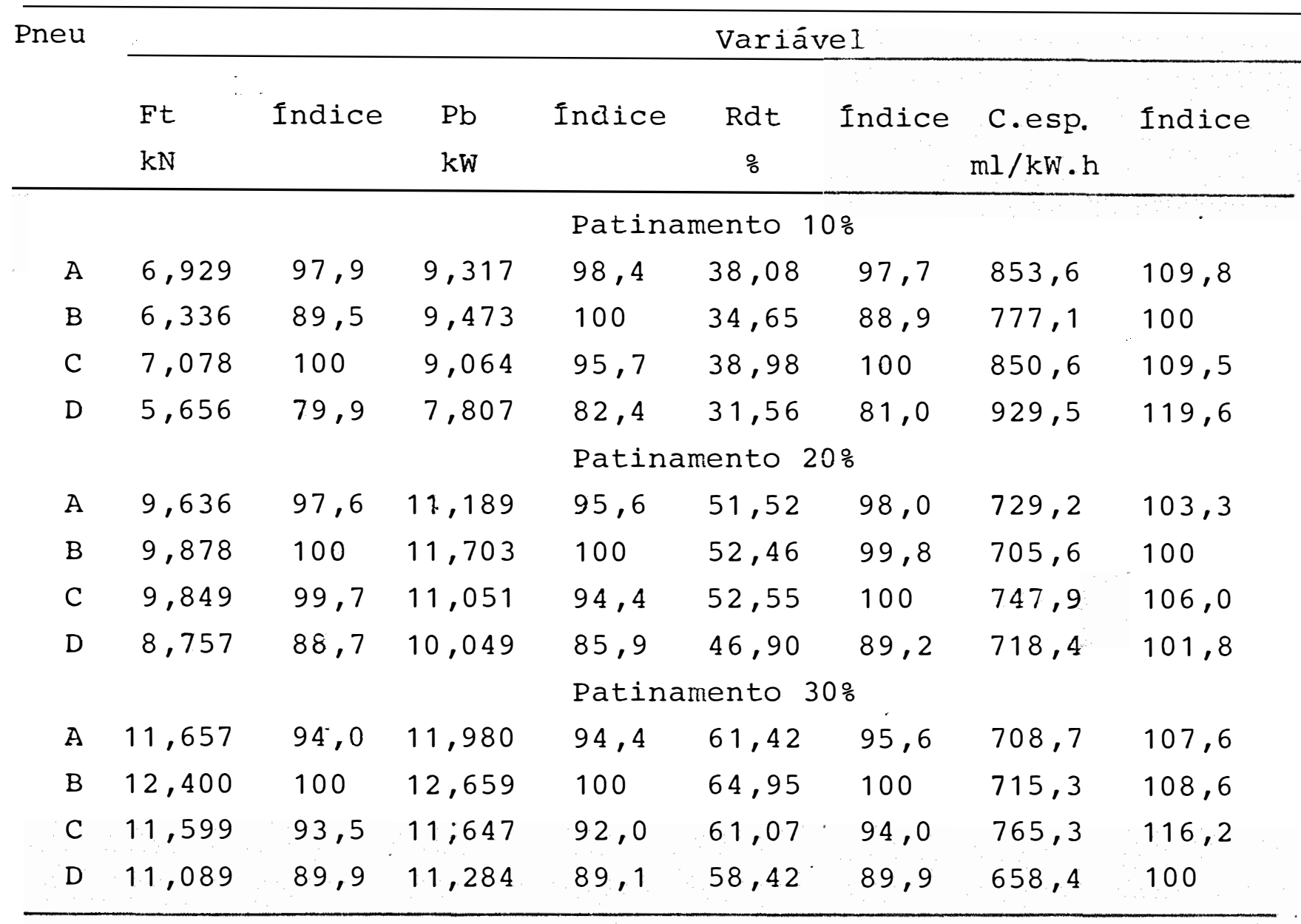


As diferenças de desempenho dos pneumäticos, para os três niveis de $\mathrm{Pi}$ analisados, são apresentadas no histograma da Figura 12.

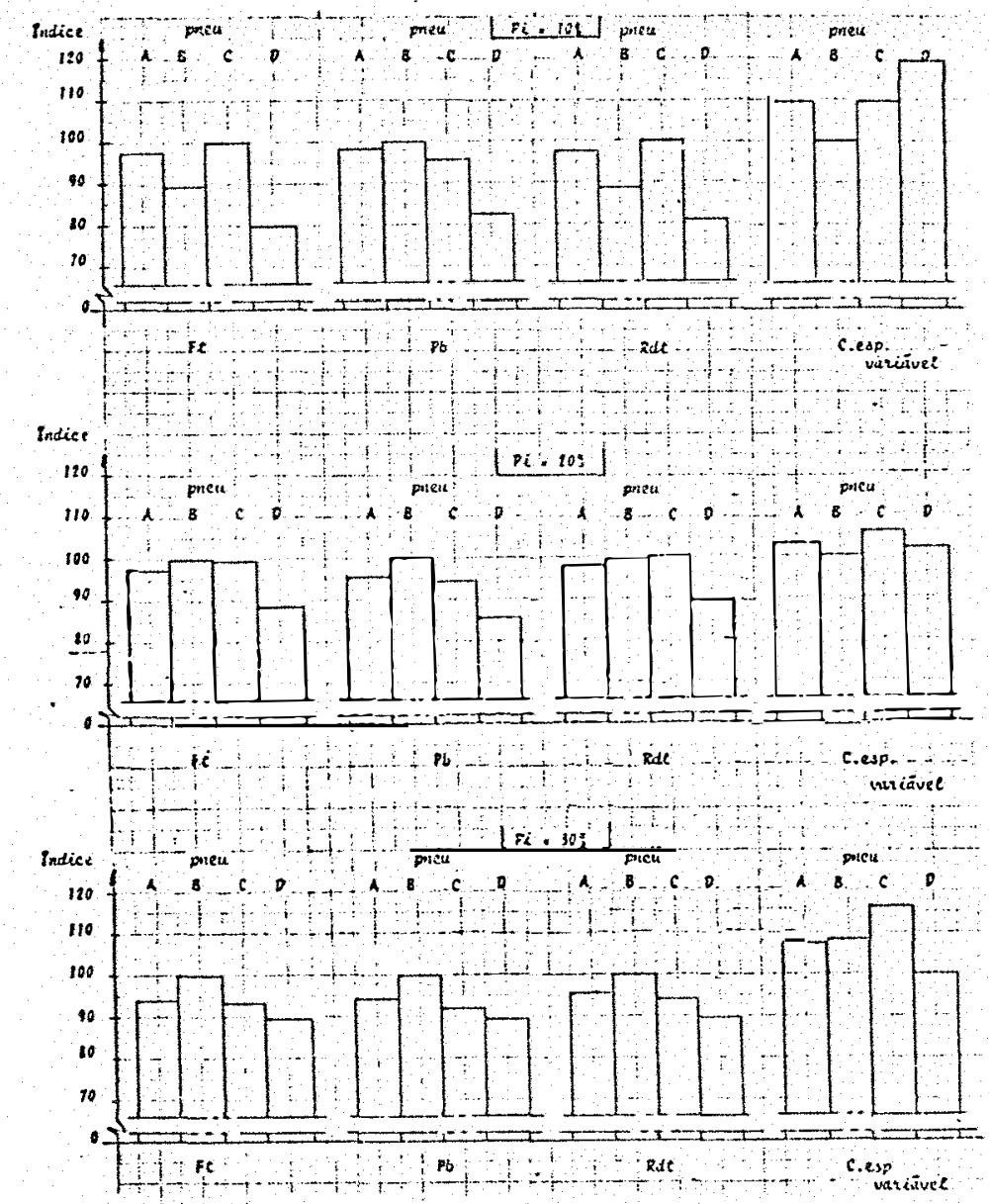

Figura 12 - Desemoenho

dos pneumáticos para as variáveis Ft, $\mathrm{Pb}, \mathrm{Rd}$ t e C.esp, a $10 \%$, $20 \%$ e $30 \%$ de Pi (condição sem lastro).

Pela análise da Tabela XII e Figura 12 observa-se que ao nivel de patinamento de $10 \%$, o pneu C apresentou $\mathrm{O}$ melhor desempenho para as variáveis Ft e Rdt enquanto para Pb e C.esp, O pneu B obteve os melhores indices. O pneu D apresen tou o pior desempenho para as quatro variáveis, com indices de $79,9,82,481,0$ e 119,6 respectivamente.

Para o nivel de $20 \%$ de $\mathrm{Pi} \circ$ pneu $\mathrm{B}$ apresentou $\mathrm{O}$ melhor desempenho para as variáveis $\mathrm{Ft}, \mathrm{Pb}$ e C.esp., sendo infe rior ao pneu $C$ na variável Rdt em 0,2 . Os menores indices fo- 
ram obtidos pelo pneu $D$, para as variáveis $F t, P b$, Rdt sendo que o pneu C obteve o maior consumo especifico $(747,9 \mathrm{ml} / \mathrm{kH} \cdot \mathrm{h}-$ $106,0)$.

A nivel de $30 \%$ de $\mathrm{Pi}$, o pneu B obteve os melhores indices para Ft, $\mathrm{Pb}$ e Rdt enquanto que para C.esp., o pneu D foi o que melhor se apresentou.

Como uma diferença de 3\% no desempenho, de acordo com TAYLOR (1973 a), pode não ser significativa, verifica-se que a tendência para o pneu B em obter um melhor desempenho acentua-se ao nivel de $30 \%$ de $\mathrm{Pi}$; isso vem de encontro ao exposto anteriormente, no item 4.2.4.1. Para níveis de 10\% e 20\% de Pi não se observa a tendência de um ảeterminado modelo ser mais eficiente que os outros; por um outro lado, o pneu. D foi o que obteve os piores indices, exceção feita à variável C.esp a $20 \%$ e $30 \%$ de Pi. Por essa razão, pode-se afirmar que o pneumático $\mathrm{D}$ é o menos recomendado para operar a níveis situados dentro da faixa normal de operação, e nas condições propos tas.

\section{3. - CONDIÇÃO COM LASTRO}

\subsection{1. - Dados dos ensaios de campo}

Os dados obtidos no campo, são apresentados nas Tabelas XIII a XVI. O valor de Pm obtido para a presente condi ção é de 46,792 pulsos por metrö; o valor de $\mathrm{R}$ é fornecido com as Tabelas para cada condição de ensaio.

Os dados de tração na barra (Ft) correspondem à média dos valores obtidos no campo e são apresentados seguidos dos respectivos valores de desvio padrão e coeficiente de variação. Os dados de consumo de combustivel (CC), representam o consumo do Tt ao longo de cada ensaio no tempo $t$.

(*) Este valor é idêntico para as condições SL e CL. 
TABELA XIII - Dados obtidos para o pneu A na condição com lastro (A/CL).

\begin{tabular}{|c|c|c|c|c|c|c|c|}
\hline \multirow{3}{*}{$\begin{array}{c}\text { Ensaio } \\
\text { no }\end{array}$} & \multicolumn{3}{|c|}{ Ft } & \multirow{2}{*}{$\begin{array}{c}\text { Consumo } \\
\text { CC }\end{array}$} & \multicolumn{2}{|c|}{ Sensores } & \multirow{2}{*}{$\begin{array}{c}\text { Tempo } \\
(t)\end{array}$} \\
\hline & $M$ & s. & $\mathrm{C} \cdot \mathrm{v}$. & & no de & pulsos & \\
\hline & $(\mathrm{kN})$ & & $\%$ & (ml) & No & $\mathrm{Nt}$ & $\mathrm{s}$ \\
\hline 01 & 16,103 & 1,223 & 7,59 & 175,1 & 1542 & 1790 & 54,9 \\
\hline 02 & 17,216 & 1,204 & 6,99 & 162,6 & 1725 & 1726 & 52,0 \\
\hline 03 & 12,570 & 1,170 & 9,31 & 76,6 & 1612 & 987 & 29,7 \\
\hline 04 & 7,502 & 0,780 & 10,40 & 65,6 & 1969 & 1047 & 31,5 \\
\hline 05 & 16,311 & 1,330 & 8,16 & 176,1 & 1744 & 1818 & 55,2 \\
\hline 06 & 12,383 & 1,149 & 9,28 & 75,6 & 1579 & 979 & 29,4 \\
\hline 07 & 10,149 & 0,837 & 8,25 & 63,1 & 1646 & 917 & 27,3 \\
\hline 08 & 16,310 & 1,731 & 10,61 & 139,6 & 1822 & 1505 & 45,1 \\
\hline 09 & 6,582 & 0,618 & 9,38 & 44,1 & 1450 & 762 & 22,6 \\
\hline 10 & 15,446 & 1,437 & 9,30 & 121,1 & 1687 & 1362 & 40,2 \\
\hline 11 & 11,275 & 0,820 & 7,28 & 69,1 & 1685 & 963 & 29,0 \\
\hline 12 & $13,107^{\circ}$ & 1,145 & 8,73 & 73,6 & 1495 & 939 & 28,2 \\
\hline 13 & 14,243 & 0,999 & 7,02 & 94,6 & 1615 & 1122 & 33,4 \\
\hline 14 & 14,802 & 0,933 & 6,30 & 110,6 & 1713 & 1284 & 38,6 \\
\hline 15 & 4,829 & 0,465 & 9,64 & 37,1 & 1378 & 684 & 20,3 \\
\hline 16 & 16,465 & 1,522 & 9,24 & 123,6 & 1395 & 1315 & 39,5 \\
\hline
\end{tabular}

$\widehat{M}=$ média; $\mathbf{s .}=$ desvio padrão; $\mathbf{c} \cdot \mathbf{v}$. = coeficiente de variação; valor de $\mathrm{R}=0,4880$ (média de duas determinações); umidade do solo $(U \%)=12,7$ 
TABELA XIV - Dados obtidos para o pneu B na condição com lastro $(\mathrm{B} / \mathrm{CL})$.

\begin{tabular}{|c|c|c|c|c|c|c|c|}
\hline \multirow{3}{*}{$\begin{array}{c}\text { Ensaio } \\
\text { no }\end{array}$} & \multicolumn{3}{|c|}{ Ft } & \multirow{2}{*}{$\begin{array}{c}\text { Consumo } \\
\text { CC }\end{array}$} & \multicolumn{2}{|c|}{ Sensores } & \multirow{2}{*}{$\begin{array}{r}\text { Tempo } \\
(t) \\
\end{array}$} \\
\hline & $\overline{\mathrm{M}}$ & s. & $\mathrm{C} \cdot \mathrm{V}$. & & no de & pulsos & \\
\hline & $(\mathrm{kN})$ & & 8 & $(\mathrm{mI})$ & No & Nt & $s$ \\
\hline 01 & 16,051 & 2,572 & 16,02 & 174,6 & 1646 & 1783 & 52,5 \\
\hline 02 & 16,013 & 1,293 & 8,07 & 101,1 & 1421 & 1132 & 33,9 \\
\hline 03 & 15,102 & 1,789 & 11,85 & 90,7 & 1474 & 1006 & 30,0 \\
\hline 04 & 10,512 & 1,494 & 14,22 & 66,6 & 1667 & 939 & 27,7 \\
\hline 05 & 13,446 & $1,0,08$ & 7,80 & 94,1 & 1766 & 1123 & 33,6 \\
\hline 06 & 8,219 & 1,065 & 12,95 & 53,1 & 1496 & 811 & 23,8 \\
\hline 07 & 11,142 & 0,976 & 8,76 & 67,1 & 1587 & 911 & 27,3 \\
\hline 08 & 14,888 & 1,134 & 7,61 & 113,6 & 1722 & 1285 & 38,7 \\
\hline 09 & 14,405 & $i, 517$ & 10,53 & 128,6 & 1705 & 1433 & 42,7 \\
\hline 10 & 15,813 & 1,180 & 7,46 & 180,1 & 1617 & 1973 & 58,4 \\
\hline 11 & 13,169 & 0,973 & 7,39 & 63,1 & 1284 & 779 & 24,4 \\
\hline 12 & 5,820 & 0,787 & 13,52 & 56,6 & 1804 & $963^{\circ}$ & 27,8 \\
\hline 13 & 6,436 & 0,823 & 12,79 & 50,1 & 1586 & 865 & 24,6 \\
\hline
\end{tabular}

$M=$ média; s. = desvio padrão; $c \cdot v \cdot$ = coeficiente de variação; valor de $\mathrm{R}=0,4842$ (média de duas determinações); umidade do solo (U\%) $=15,8$ 
TABELA XV - Dados obtidos para o pneu C na condição com lastro (C/CL).

\begin{tabular}{|c|c|c|c|c|c|c|}
\hline Ensaio & \multicolumn{2}{|c|}{ Ft } & \multirow[b]{2}{*}{$c . v}$. & \multirow{2}{*}{$\begin{array}{c}\text { Consumo } \\
\text { CC }\end{array}$} & Sensores & Temp \\
\hline \multirow[t]{2}{*}{ no } & $\mathrm{M}$ & s. & & & no de pulisos & $1 t$ \\
\hline & $(\mathrm{kN}$ & & 응 & $(\mathrm{ml})$ & No & \\
\hline
\end{tabular}

$\begin{array}{rrrrrrrr}01 & 12,859 & 2,037 & 15,84 & 106,1 & 2015 & 1301 & 38,5 \\ 02 & 10,068 & 1,553 & 15,42 & 83,1 & 1927 & 1129 & 33,6 \\ 03 & 17,005 & 2,311 & 13,59 & 195,1 & 1900 & 2035 & 60,4 \\ 04 & 13,980 & 1,066 & 7,62 & 110,1 & 1869 & 1308 & 38,9 \\ 05 & 15,807 & 1,412 & 8,93 & 136,6 & 1792 & 1477 & 43,9 \\ 06 & 12,692 & 1,642 & 12,94 & 123,6 & 2400 & 1546 & 45,7 \\ 07 & 16,704 & 1,573 & 9,41 & 200,6 & 2087 & 2086 & 60,7 \\ 08 & 6,252 & 1,195 & 19,12 & 51,1 & 1634 & 881 & 26,0 \\ 09 & 15,221 & 1,473 & 9,68 & 120,1 & 1827 & 1367 & 40,4 \\ 10 & 11,849 & 1,491 & 12,58 & 90,1 & 1927 & 1183 & 35,2 \\ 11 & 15,752 & 1,614 & 10,25 & 124,1 & 1736 & 1395 & 41,2 \\ 12 & 16,271 & 1,230 & 7,56 & 149,6 & 1683 & 1650 & 48,7 \\ 13 & 16,258 & 1,362 & 8,38 & 120,6 & 1468 & 1371 & 39,6\end{array}$

$\mathbb{M}=$ média; s. = desvio padrão; $\mathrm{c} \cdot \mathrm{v} \cdot$ = coeficiente de variação; valor de $R=0,5059$ (média de duas determinações); umidade do solo (Uo) $=12,1$ 
TABELA XVI - Dados obtidos para o pneu D na condição com lastro (D/CL).

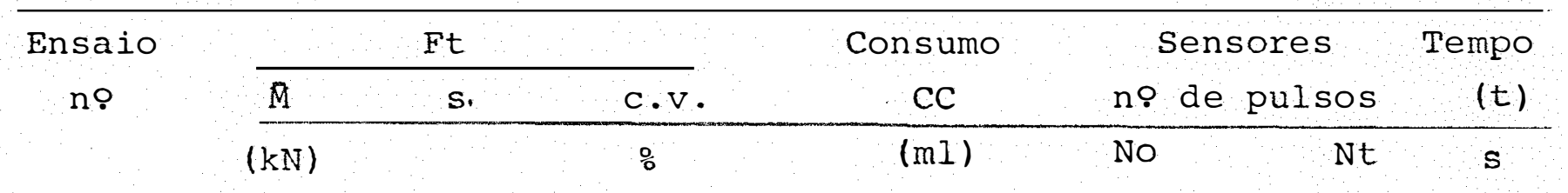

$\begin{array}{rrrrrrrr}01 & 17,272 & 1,417 & 8,21 & 159,6 & 1413 & 1647 & 49,7 \\ 02 & 15,108 & 1,499 & 9,92 & 117,6 & 1601 & 1291 & 39,1 \\ 03 & 15,896 & 1,523 & 9,58 & 151,1 & 1682 & 1626 & 49,0 \\ 04 & 14,197 & 1,792 & 12,62 & 111,6 & 1642 & 1281 & 38,6 \\ 05 & 14,168 & 1,602 & 11,31 & 111,6 & 1774 & 1326 & 39,6 \\ 06 & 11,575 & 1,210 & 10,45 & 83,1 & 1759 & 1107 & 33,3 \\ 07 & 11,192 & 1,466 & 13,10 & 88,6 & 2011 & 1220 & 36,7 \\ 08 & 8,447 & 1,355 & 16,04 & 66,1 & 1817 & 1022 & 30,1 \\ 09 & 4,513 & 0,693 & 15,36 & 53,6 & 1958 & 994 & 28,9 \\ 10 & 12,346 & 1,424 & 11,54 & 112,1 & 2070 & 1391 & 42,2 \\ 11 & 16,892 & 1,365 & 8,08 & 224,6 & 2056 & 2369 & 71,5 \\ 12 & 15,371 & 1,354 & 8,81 & 2524 & 2524 & 2210 & 66,6 \\ 13 & 7,363 & 1,307 & 17,75 & 76,6 & 2366 & 1292 & 38,3 \\ 14 & 11,412 & 1,668 & 14,62 & 85,6 & 2156 & 1308 & 39,4 \\ 15 & 5,906 & 1,240 & 20,99 & 82,6 & 2749 & 1475 & 43,4 \\ 16 & 5,258 & 4,823 & 15,65 & 52,6 & 2019 & 1061 & 30,6\end{array}$

$\mathbb{M}=$ média; s.= desvio padrão; c.v. = coeficiente de variação; valor de $\mathrm{R}=0,4804$ (média de duas determinações); umidade do solo $=15,4$ 
Utilizando-se dos dados dos coeficientes de variação (cvo) obtidos para cada condição de ensaio, construiu-se os histogramas de frequéncia apresentados na figura 13 . Os intervalos de classe foram estabelecidos de acordo com o proposto no item 4.2 .1 .
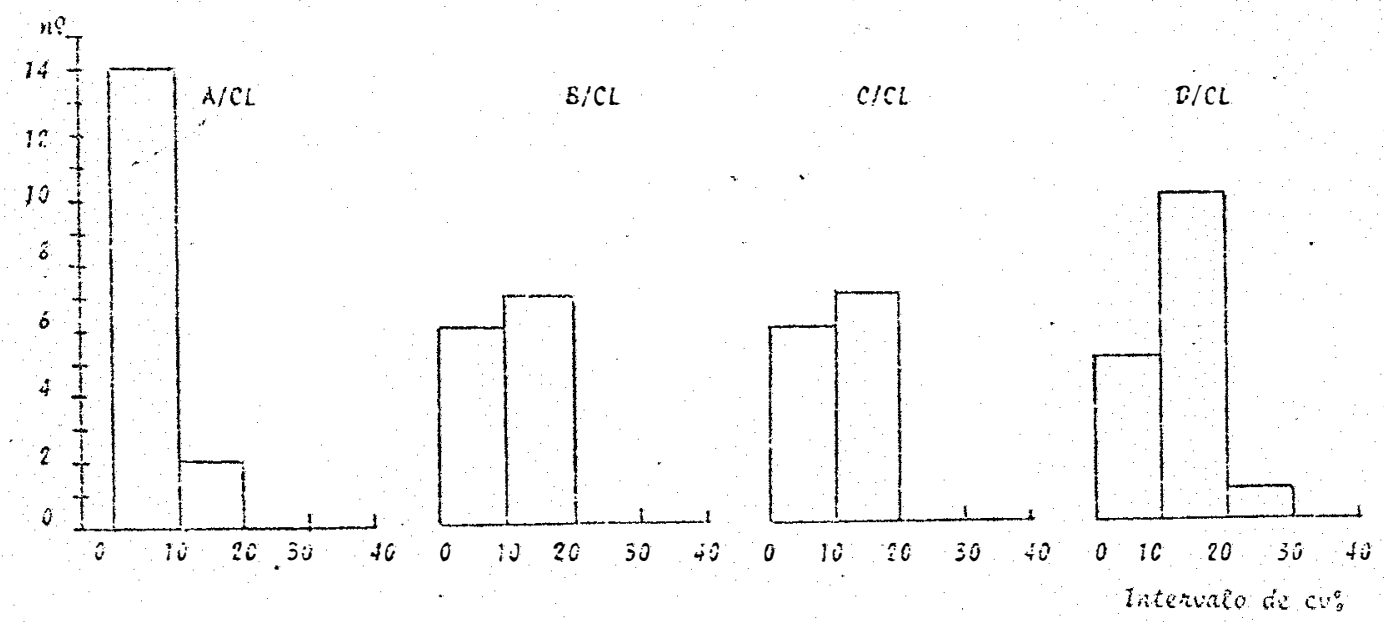

Figura 13 - Histograma da distribuição de frequência dos valores dos coeficientes de variação (condição CL) .

Conforme se observa, no intervalo de classe de $0-10 \%$ encontram-se 14 valores de cvo (73\%) para os ensaios na condição A/CL, 6 valóres (46\%) na condição B/CL, 6 valores (46\%) para a condição C/CL e 5 valores (31\%) na condição D/CL. No intervalo de 10-20\% enquadraram-se todos os valores restantes para as quatro condições, com exceção de um valor na condi Ção D/CL que se enquadrou no intervalo de 20-30\%.

Tendo em vista que a maior parte dos cvo podem ser qualificados de baixos e médios ficam evidenciadas, novamente, as boas caracteristicas da metodologia, equipamentos e condições de uniformidade do solo. 


\subsection{2. - Parâmetros de desempenho dos pneumáticos.}

Com os dados apresentados no item 4.3.1. (Tabelas XIII a XVI) e com base nas definições e equações apresentadas no Apêndice IV, obteve-se os valores dos parâmetros de desempenho dos pneumáticos constantes nas Tabelas XVII a XX. Visando facilitar a interpretação, os valores obtidos foram tabelados na ordem crescento do patinamento. 
54.

TABELA XVII - Desempenho do pneumático A, na condição com lastro.

\begin{tabular}{|c|c|c|c|c|c|}
\hline \multirow{3}{*}{$\begin{array}{c}\text { Ensaio } \\
\text { no }\end{array}$} & \multicolumn{5}{|c|}{ Variāvel } \\
\hline & $\mathrm{Pi}$ & Ft & $\mathrm{Pb}$ & $R d t$ & C.esp. \\
\hline & $\%$ & $\mathrm{kN}$ & $\mathrm{kW}$ & $\%$ & $\mathrm{ml} / \mathrm{kW} \cdot \mathrm{h}$ \\
\hline 15 & 1,82 & 4,829 & 7,003 & 22,99 & 939,4 \\
\hline 09 & 7,26 & 6,582 & 9,023 & 30,83 & 778,6 \\
\hline 04 & 8,35 & 7,502 & 10,019 & 34,85 & 748,3 \\
\hline 07 & 12,52 & 10,149 & 13,074 & 46,05 & 636,5 \\
\hline 11 & 14,73 & 11,275 & 13,997 & 50,66 & 612,9 \\
\hline 03 & 20,40 & 12,570 & 14,576 & 55,85 & 637,0 \\
\hline 06 & 21,40 & 12,383 & 14,209 & 55,11 & 651,5 \\
\hline 12 & 22,41 & 13,107 & 14,846 & 57,97 & 632,9 \\
\hline 13 & 29,85 & 14,243 & 14,714 & 62,39 & 692,9 \\
\hline 14 & 34,98 & 14,802 & 14,035 & 64,53 & 734,9 \\
\hline 10 & 39,64 & 15,446 & 13,849 & 66,97 & 783,1 \\
\hline 08 & 41,00 & 16,310 & 14,077 & 70,21 & 791,6 \\
\hline 16 & 48,30 & 16,465 & 12,413 & 70,78 & 906,8 \\
\hline 02 & 51,29 & 17,216 & 12,203 & 73,55 & 922,5 \\
\hline 05 & 53,25 & 16,311 & 11,010 & 70,21 & 1043,1 \\
\hline 01 & 58,02 & 16,103 & 9,663 & 69,44 & 1188,2 \\
\hline
\end{tabular}




\begin{abstract}
TABELE XVIII - Desempenho do pneumático B, na condição com lastro.
\end{abstract}

\begin{tabular}{|c|c|c|c|c|c|}
\hline \multirow{3}{*}{$\begin{array}{c}\text { Ensaio } \\
\text { no }\end{array}$} & \multicolumn{5}{|c|}{ Variável } \\
\hline & $\mathrm{Pi}$ & $\mathrm{Ft}$ & $\mathrm{Pb}$ & Rdt & C.esp. \\
\hline & 웅 & $\mathrm{kN}$ & $\mathrm{kW}$ & 응 & $\mathrm{ml} / \mathrm{kW} \cdot \mathrm{h}$ \\
\hline 12 & 9,05 & 5,820 & 8,069 & 27,45 & 908,3 \\
\hline 06 & 10,44 & 8,219 & 11,038 & 37,94 & 727,7 \\
\hline 13 & 10,98 & 6,436 & 8,866 & 30,19 & 827,0 \\
\hline 04 & 13,81 & 10,512 & 13,516 & 47,55 & 640,4 \\
\hline 07 & 15,42 & 11,142 & 13,838 & 50,12 & 639,4 \\
\hline 11 & 19,56 & 13,169 & 14,806 & 58,21 & 628,8 \\
\hline 05 & 23,65 & 13,446 & 15,1036 & 59,30 & 667,6 \\
\hline 03 & 28,86 & 15,102 & 15,854 & 65,67 & 685,7 \\
\hline 08 & 34,94 & 14,888 & 14,150 & 64,86 & 746,8 \\
\hline 02 & 39,05 & 16,013 & 14,341 & 69,10 & 748,6 \\
\hline 09 & 42,63 & 14,405 & 12,292 & 63,01 & 882,1 \\
\hline 01 & 55,18 & 16,051 & 10,753 & 69,24 & 1113,5 \\
\hline 10 & $60,2 \cdot 1$ & 15,813 & 9,355 & 68,35 & 1186,7 \\
\hline
\end{tabular}


TABELA XIX - Desempenho do pneumático $C$, na condição com lastro.

\begin{tabular}{|c|c|c|c|c|c|}
\hline \multirow{3}{*}{$\begin{array}{c}\text { Ensaio } \\
\text { no }\end{array}$} & \multicolumn{5}{|c|}{ Variável } \\
\hline & $\mathrm{Pi}$ & Ft & $\mathrm{Pb}$ & $R d t$ & C.esp. \\
\hline & $\%$ & $\mathrm{kN}$ & $\mathrm{kW}$ & $\%$ & $\mathrm{ml} / \mathrm{kW} \cdot \mathrm{h}$ \\
\hline 08 & 6,17 & 6,252 & 8,395 & 29,38 & 842,8 \\
\hline 02 & 13,65 & 10,068 & 12,336 & 45,72 & 721,8 \\
\hline 10 & 17,59 & 11,849 & 13,859 & 52,98 & 664,9 \\
\hline 06 & 21,46 & 12,692 & 14,240 & 56,33 & 683,8 \\
\hline 01 & 21,65 & 12,859 & 14,379 & 57,00 & 690,0 \\
\hline 04 & 27,71 & 13,980 & 14,355 & 61,37 & 709,8 \\
\hline 09 & 32,39 & 15,221 & 14,707 & 66,12 & 727,7 \\
\hline 11 & 37,04 & 15,752 & 14,180 & 68,12 & 764,7 \\
\hline 05 & 38,62 & 15,807 & 13,785 & 68,33 & 812,6 \\
\hline 13 & 45,83 & 16,258 & 12,876 & 70,01 & 851,5 \\
\hline 12 & 48,40 & 16,271 & 12,015 & 70,07 & 920,5 \\
\hline 07 & 49,39 & 16,704 & 12,271 & 71,67 & 969,5 \\
\hline 03 & 52,77 & 17,005 & 11,429 & 72,78 & 1017,4 \\
\hline
\end{tabular}


TABELA XX - Desempenho do pneumático D, na condição com lastro.

\begin{tabular}{|c|c|c|c|c|c|}
\hline \multirow{3}{*}{$\begin{array}{c}\text { Ensaio } \\
\text { no }\end{array}$} & \multicolumn{5}{|c|}{ Variável } \\
\hline & $\mathrm{Pi}$ & Ft & Pot & $R d t$ & C.esp. \\
\hline & 응 & $\mathrm{kN}$ & $\mathrm{kW}$ & 응 & $\mathrm{ml} / \mathrm{kW} \cdot \mathrm{h}$ \\
\hline 09 & 5,35 & 4,513 & 6,534 & 21,55 & 1020,4 \\
\hline 16 & 8,57 & 5,258 & 7,414 & 24,93 & 834,7 \\
\hline 15 & 10,45 & 5,906 & 7,993 & 27,84 & 857,3 \\
\hline 13 & 12,01 & 7,363 & 9,718 & 34,25 & 740,9 \\
\hline 08 & 14,57 & 8,447 & 10,894 & 38,91 & 725,7 \\
\hline 07 & 20,80 & 11,192 & 13,102 & 50,32 & 663,3 \\
\hline 14 & 20,80 & 11,412 & 13,342 & 51,22 & 586,2 \\
\hline 06 & 23,65 & 11,575 & 13,067 & 51,87 & 687,5 \\
\hline 10 & 28,50 & 12,346 & 12,939 & 54,96 & 739,1 \\
\hline 05 & 35,72 & 14,168 & 13,560 & 62,10 & 748,1 \\
\hline 04 & 38,41 & 14,197 & 12,904 & 62,21 & 806,6 \\
\hline 02 & 40,41 & 15,108 & 13,216 & 65,69 & 819,3 \\
\hline 12 & 45,12 & 15,371 & 12,737 & 66,69 & 825,8 \\
\hline 03 & 50,30 & 15,896 & 11,658 & 68,66 & 952,2 \\
\hline 11 & 58,30 & 16,892 & 10,378 & 72,36 & 1089,7 \\
\hline 01 & 58,78 & 17,272 & 10,491 & 73,76 & 1102,0 \\
\hline
\end{tabular}




\subsection{3. - Equações de regressao}

Core a finalidade de verificar o melhor grau de ajuste do modelo polinomial adotado, os dados das Tabelas XVII a XX foram ajustados até polinômios de grau 4. No Apêndi ce $V$ são apresentados os resultados da análise de variância, os coeficientes de determinação $\left(r^{2}\right)$ e as equações de regressão obtidas para os pneumáticos.

A Tabela XXI mostra os valores de $F$ e os coeficientes de determinação $\left(r^{2}\right)$ utilizados para a escolha do grau do polinômio a ser adotado.

Com base nos valores apresentados, o modelo ado tado é o polinômio de grau 2 pelas seguintes razões:

-) Para a variável Ft, os coeficientes de deter minação $\left(r^{2}\right)$ do polinômio de grau 2 , estão acima de 0,90 e ós valores de $F$ significativos a nivel de $0,1 \%$; o polinômio de grau 1 apresentou $r^{2}$ inferior a 0,70 (condição $B / C L$ ) enquan to que para polinômio de grau 3 e 4 , embora apresentem $r^{2}$ superiores a 0,95 , os valores de $F$ foram não significativos a nível de $5 \%$ nas condições $A / C L$ ( $3 \circ$ e $4 \%$ graus), $B / C L$ grau), C/CL (40 grau) e D/CL (4\% grau).

.) Para a variável $\mathrm{Pb}$, os polinômios de grau 2 apresentaram $r^{2}$ acima de $0,90 \mathrm{com}$ exceção da condição B/CL $\left(r^{2}=0,75\right)$ e os valores de $F$ significativos a nivel de $0,1 \%$. Para polinômios de grau 1 , os $r^{2}$ foram inferiores a 0,20 enquanto que para polinônios de grau 3 ocorreram duas situações onde 0 valor de F foi significativo a nível de $1 \%$; os polinômios de grau 4 apresentaram valores de $F$ não significativos ao nivel de $5 \%$, nas 4 condições.

.) Para a variável Rdt, os polinômios de grau 2 apresentaram $\mathrm{r}^{2}$ acima de 0,90 e 0 valor de $\mathrm{F}$ foi significativo ao nivel de $0,1 \%$; o polinômio de grau 1 apresentou $\mathrm{r}^{2}$ infe rior a 0,70 na condição B/CL. O polinômio de 39 grau apresentou valores de $\mathrm{r}^{2}$ acima de 0,95 mas, na condição $A / C L$ o valor 


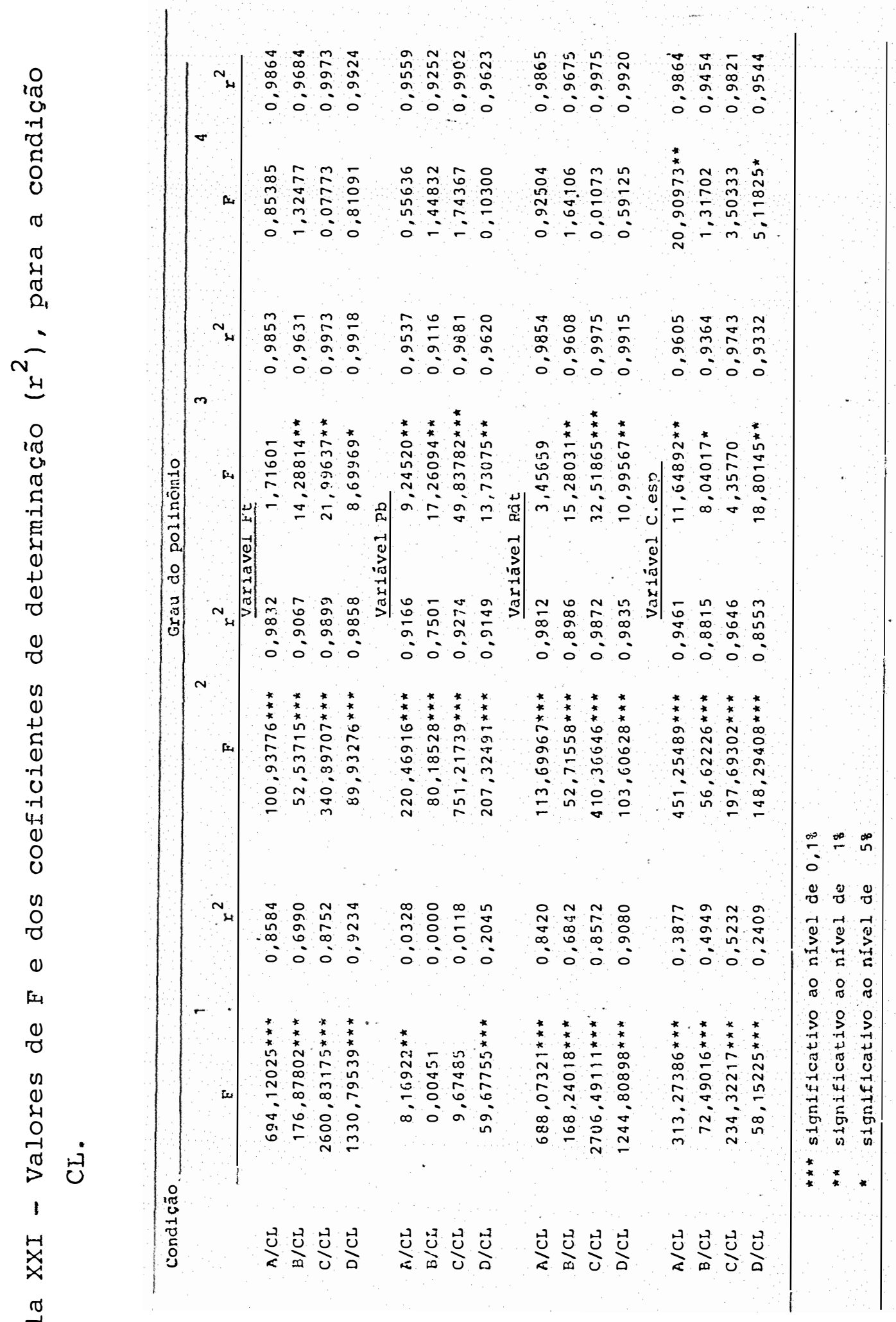


de $F$ não foi significativo do nivel de 5\%. O polinômio de grau 4 apresentou valores de $F$ não significativos a nível de 5\% em todas as condições.

-) Para a variável C.esp.. o polinômio de grau 2 apresentou $\mathrm{r}^{2}$ acima de 0,35 e os valores de $F$ foram significativos ao nível de $0,1 \%$; para o polinômio de grau 1 os valores de $r^{2}$ foram inferiores a 0,52 enquanto que o de grau 4 apresen tou valores de $F$ não significativos a nível de 5\%. lcondição $\mathrm{B} / \mathrm{CL}$ e $\mathrm{C} / \mathrm{CL}$ ). Os polinômios de grau 3, apresentaram $\mathrm{r}^{2}$ acima de 0,90 e na condição $C / C L$, o valor de $F$ não foi significativo a nível de 5\%.

Conforme o exposto, os polinômios de grau 2 apre sentaram em todas as condições valores altos de $r^{2}$ e os valores de $F$ foram significativos ao nível de 0,1\%; os polinômios de grau 1 apresentaram $r^{2}$ muito baixos, demonstrando o não ajuste dos dados ao modelo proposto. Os polinômios de 4 : grau embora apresentem valores altos de $r^{2}$, seus valores de $F$ não são significativos ao nível de 5\% para a maioria das condições avaliadas. Quanto aos polinômios de grau 3, os mesmos ap̣resentam valores não significativos a 5\% para as variáveis Ft, Rdt e C.esp. Para a variável Pb, embora o ajuste seja mais preciso em relação ao de grau 2, as considerações feitas no $\quad$ item 4.2.3. quanto a região de inflexão e a adoção do modelo polino mial de grau 2 por outros pesquisadores, são também válidas pa ra esta condição.

\subsection{4. - Avaliaçãa do desemoenho}

A partir das equações polinomiais de grau 2, ela borou-se os gráficos apresentados nas Figuras 14 a 17 . Observa -se, através destas Figuras, que não existe a tendência dos mo delos A, B e C apresentarem diferenças acentuadas de desempenho dentro do intervalo de Pi analisado; O pneu D foi o que apresentou o pior desempenho sendo que somente a altos indices 
61.

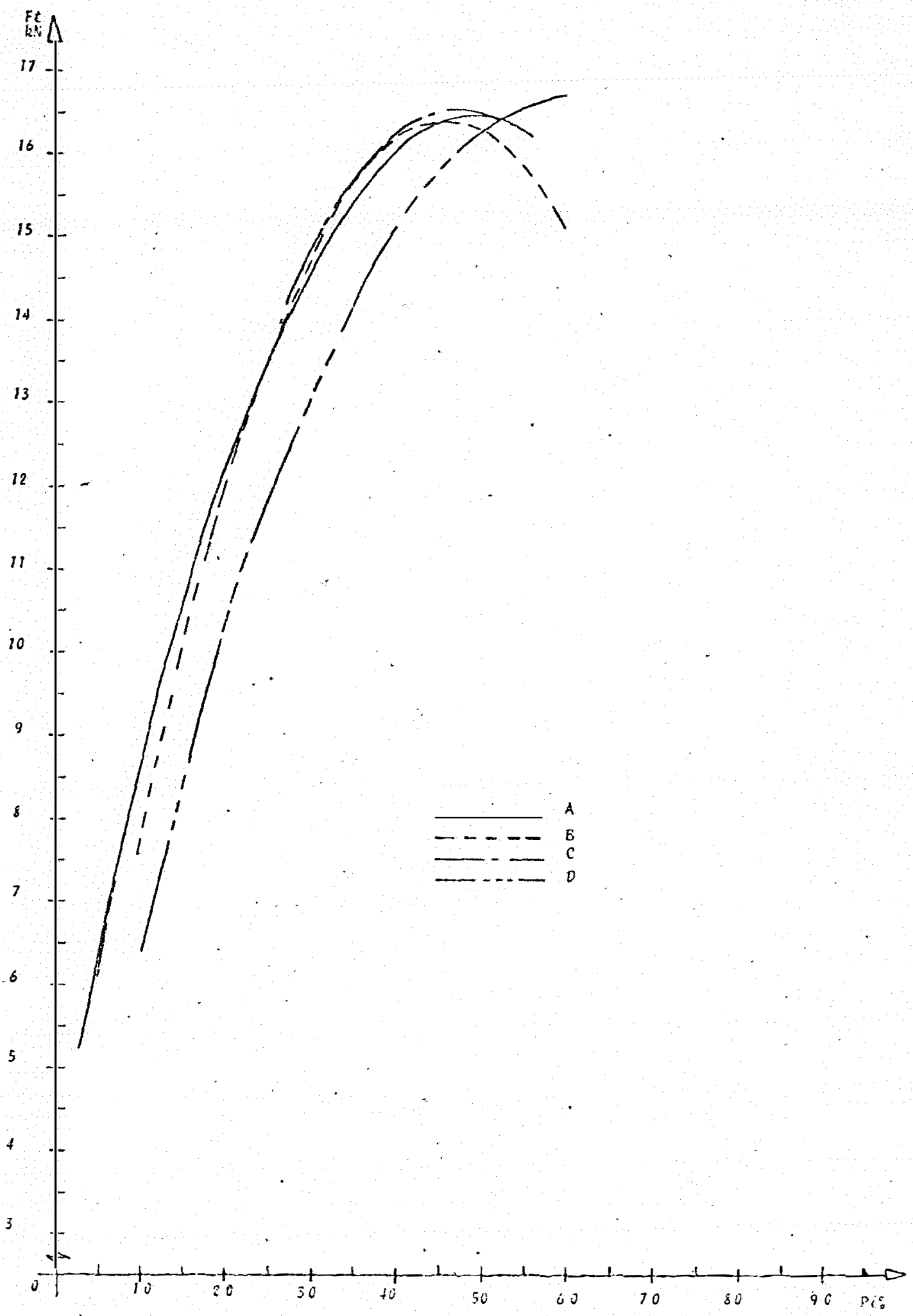

Figura 14 - Gráfico da tração na barra (Ft) em função do patinamento (Pi) para a condição com lastro. 
62 .

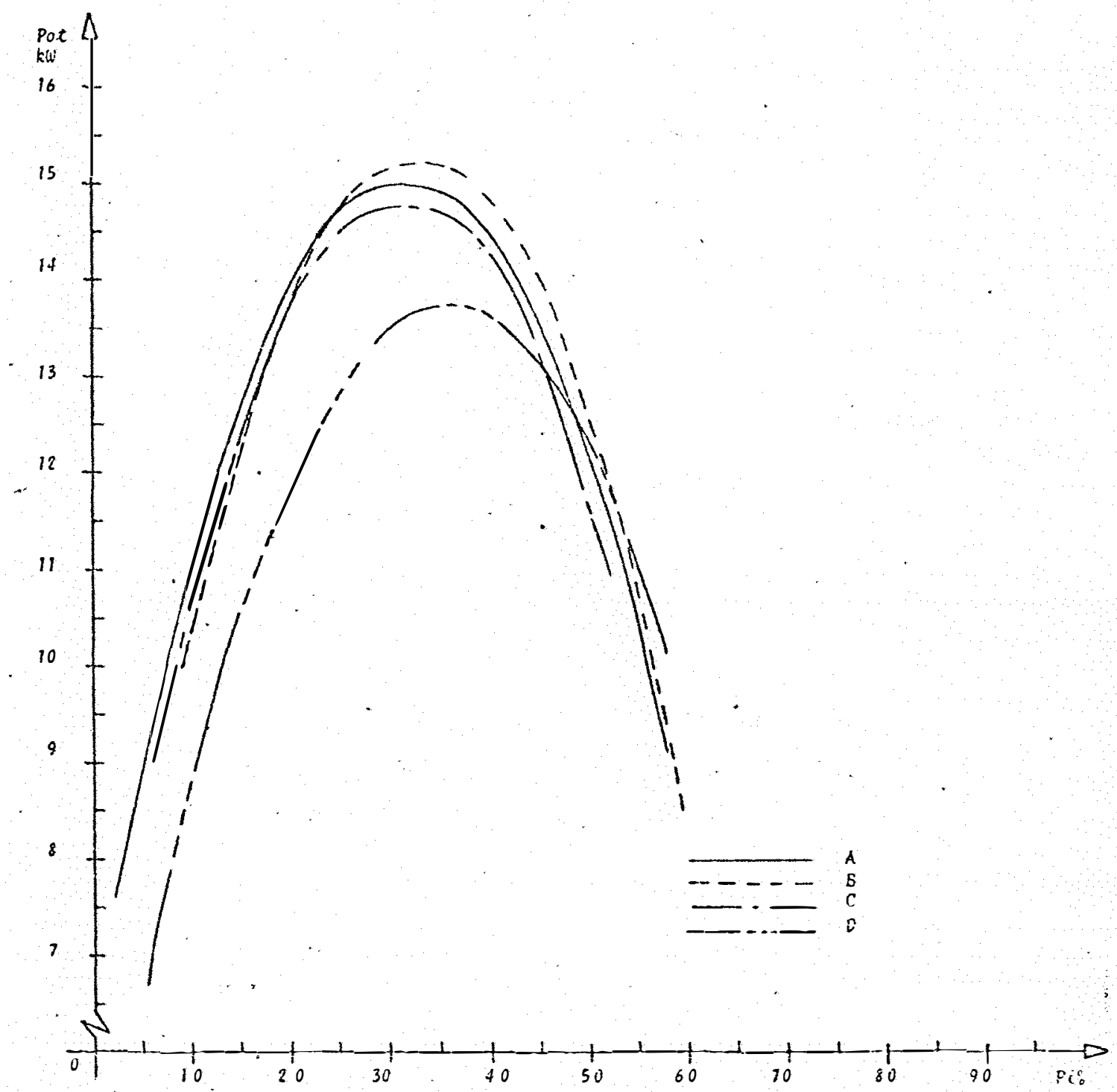

Figura 15 - Gráfico da potência na barra (Pb) em função do patinamento (Pi) para a condição com lastro. 
63.

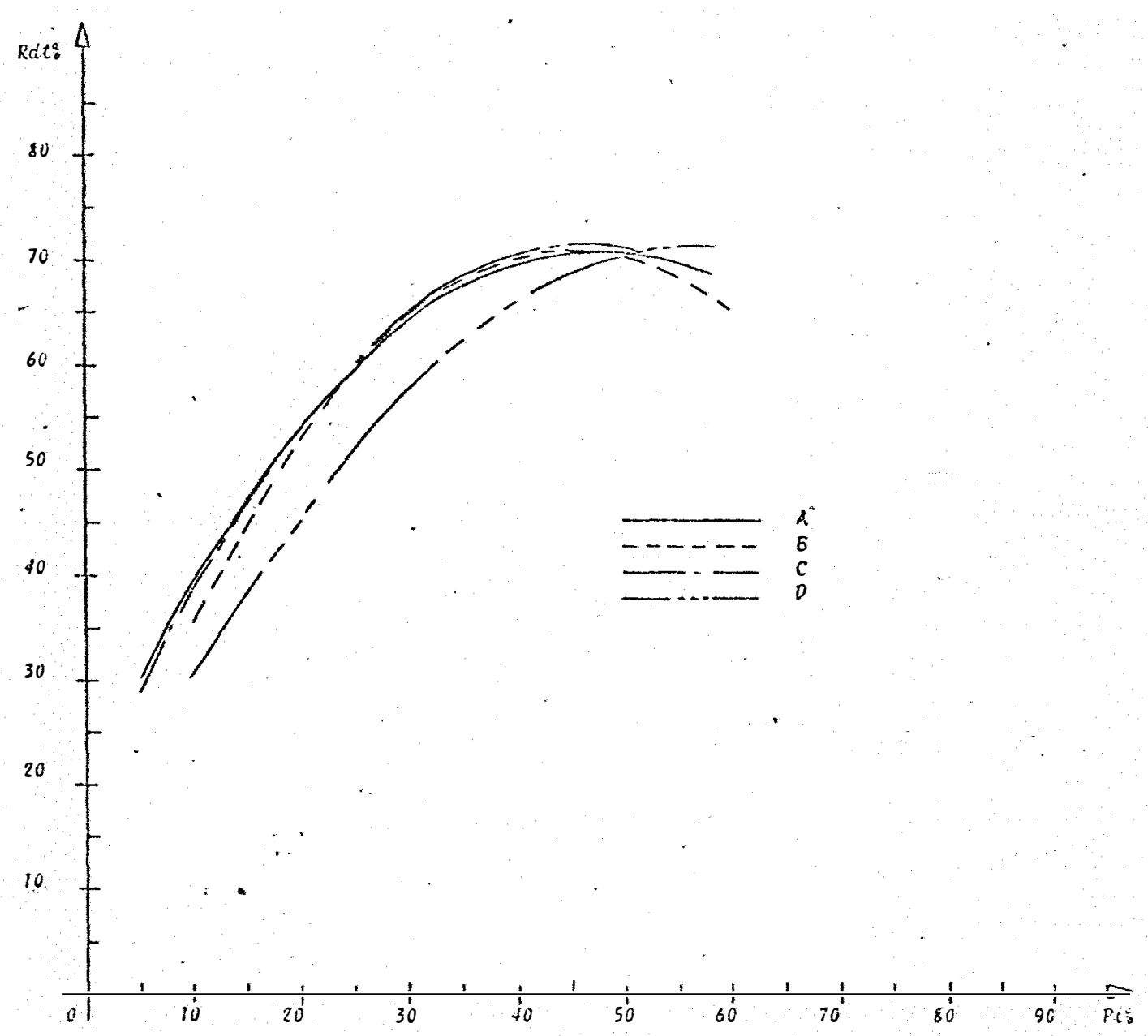

Figura 16 - Gráfico da razão dinâmica de tração (Rdt) em função do patinamento (Pi) para a condição com lastro. 
64.

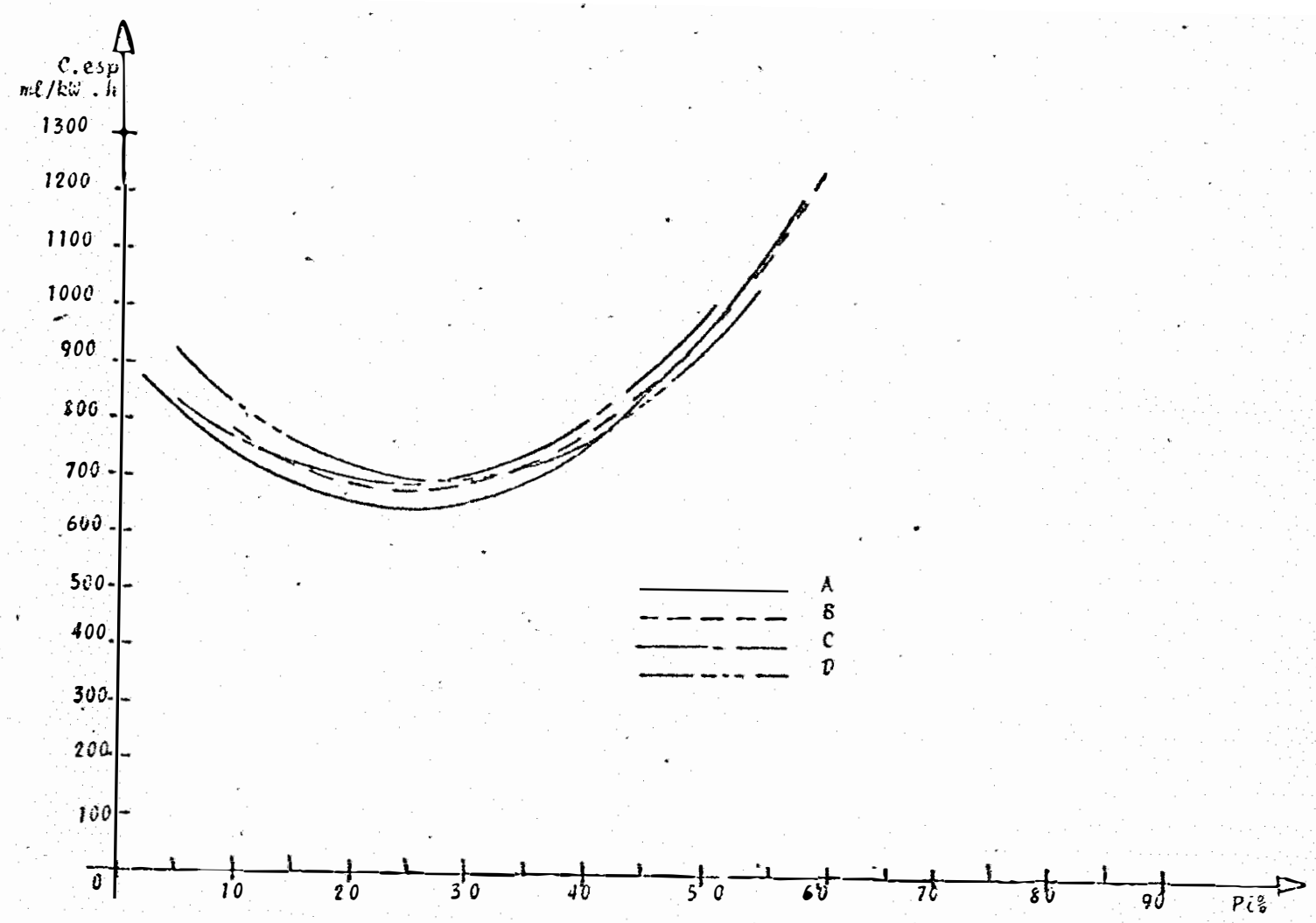

Figura 17 - Gráfico do consumo especifico (C.esp) em função do patinamento (Pi) para a condição com lastro. 
de $\mathrm{Pi}$, seu comportamento se iguala ou supera aos outros 3 modelos.

o critério a ser utilizado na avaliação dos pneu máticos será o mesmo que o proposto no item 4.2 .4 .

4.3.4.1. - Desempenho máximo dos pneumáticos.

O desempenho máximo dos pneumáticos e os níveis de patinamento em que foram obtidos, são apresentados na Tabela XXII. Atribui-se o índice 100 ao pneumático com melhor desempenho e determinou-se as diferenças, para.a. variável. $\quad$ Para cada pneu, estas diferenças podem ser melhor visualizadas no gráfico da Figura 18.

Tabela XXII - Valores de Ft, Pb e Rdt máximos e C.esp. minimo, obtidos pelos pneumáti cos para a condição CL.

\begin{tabular}{|c|c|c|c|c|c|c|c|c|}
\hline \multirow{2}{*}{ Pneu } & \multicolumn{8}{|c|}{ Variável } \\
\hline & Ft & Indice & $\mathrm{Pb}$ & Indice & $R d t$ & Indice & C.esp. & Indice \\
\hline & $k n$ & & $\mathrm{~kW}$ & & $\%$ & & $\mathrm{ml} / \mathrm{kW} \cdot \mathrm{h}$ & \\
\hline . & (Pi\%) & & (Pi) & & (Pi) & & (Pi) & \\
\hline \multirow[t]{2}{*}{ A } & 16,523 & 98,7 & 15,084 & 98,8 & 71,18 & 99,6 & 638,3 & 100 \\
\hline & $(49,30)$ & . & $(31,61)$ & & $(48,12)$ & & $(24,15$ & \\
\hline \multirow[t]{2}{*}{ B } & 16,441 & 93,2 & 15,266 & 100 & 71,12 & 99,5 & 671,2 & 105,2 \\
\hline & $(46,10)$ & & $(32,95)$ & & $(45,76)$ & & $(24,92$ & \\
\hline \multirow[t]{2}{*}{ C } & 16,590 & 99,1 & 14,818 & 97,1 & 71,28 & 99,7 & 689,6 & 108,0 \\
\hline & $(48,30)$ & & $(31,54)$ & & $(47,08)$ & & $(23,93$ & \\
\hline \multirow[t]{2}{*}{$\mathrm{D}$} & $16,741 *$ & $=100$ & 13,758 & 90,1 & 71,47 & 100 & 690,5 & 108,2 \\
\hline & $(50,23) *$ & & $(35,96)$ & & $(57,44)$ & & $(27,44$ & \\
\hline
\end{tabular}

* Valor obtido fora do intervalo de Pi\% avaliado. o maior valor de Pi\% ob tido na condição $\mathrm{D} / \mathrm{CL}$ foi 58,78 . 


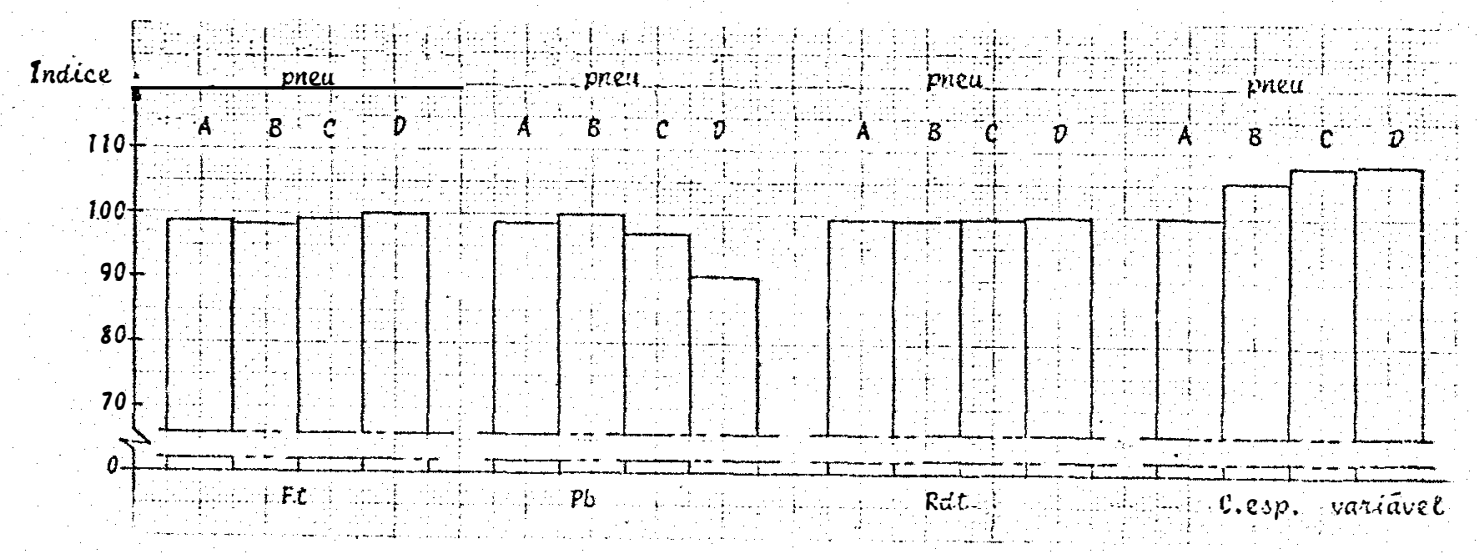

Figura 18 -Desempenho dos pneumáticos para as variáveis Ft, $\mathrm{Pb}$ e Rdt no ponto de máximo e C.esp. no ponto de mínimo (condição CL) .

De acordo com os resultados obtidos apresentados na Tabela XXII e Figura 18, 0 indice 100 para as variáveis Ft e Rdt foi obtido pelo pneu $D$, mas com diferenças mínimas em relação aos demais; todavia, segundo TAYLOR (1973-a) tais dife renças não podem ser consideradas significativas. Cabe ressaltar que o ponto de Ft máximo para o pneu D,é obtido acima do maior valor de $\mathrm{Pi}$ avaliado nos ensaios. O nível de patinamento que fornece os valores máximos de $F t$ e p.dt para os pneus A, B e C situam-se na faixa de 46 a $50 \%$; já para 0 pneu $D$, mesmo com um patinamento de 58,78\%, este não alcançou o valor máximo para Ft. Esta diferença entre o pneu $D$ em relação aos de mais pode significar, ao longo do tempo de uso, em maior desgaste quando operando nas condições de desempenho máximo.

Para a variável $\mathrm{Pb}$, os pneus $\mathrm{A}, \mathrm{B}$ e C apresenta ram um desempenho equivalente, com indices de 98,8; 100 e 97,1 respectivamente; $O$ pneu $D$ foi $O$ que pior desempenho apresentou com um indice de 90,1 .

Para a variável C.espı, o pneu A foi o que melhor desempenho apresentou e os niveis de Pi obtidos situaram-se dentro da faixa normal de operação.

Com estes resultados é lícito afirmar que não e 
xistem praticamente diferenças acentuadas de desempenho entre os modelos A, B e C; quanto ao modelo D, apresenta um desempe nho inferior aos outros em termos de potência na barra.

Para uma recomendação de utilização nas condiçoes de máximo desempenho e na situação proposta por esta pes quisa, os 3 modelos A, B e C são mais adequados do gue o modelo $D$.

4.3.4.2. - Desempenho na faixa normal de operação

Conforme critério descrito no item 4.2.4. já adotado para a condição SL (item 4.2.4.2), os resultados obtidos a 10,20 e $30 \%$ d̀e Pi para a condição CL, são apresentados na Tabela XXIII.

As diferenças de desempenho dos pneumáticos para os três niveis de $\mathrm{Pi}$ analisados, são apresentadas no histo grama da Figura 19. 
Tabela XXIII - Valores de Ft, $\mathrm{Pb}$, Rdt e C.esp para indices de patinamento situados dentro da faixa nor mal de operação (conảição CL).

\begin{tabular}{|c|c|c|c|c|c|c|c|c|}
\hline \multirow[t]{3}{*}{ Pneu } & \multicolumn{8}{|c|}{ Variável } \\
\hline & Ft & Indice & $\mathrm{Pb}$ & Indice & Rdt & Indice & C.esp. & Indice \\
\hline & $\mathrm{kN}$ & & $\mathrm{kW}$ & & $\%$ & \multicolumn{2}{|r|}{$\mathrm{ml} / \mathrm{kW} \cdot \mathrm{h}$} & \\
\hline & \multicolumn{8}{|c|}{ Patinamento $10 \%$} \\
\hline A & 8,538 & 100 & 11,089 & 100 & 39,01 & 100 & 732,8 & 100 \\
\hline B & 7,671 & 89,8 & 10,408 & 93,9 & 35,54 & 91,1 & 772,4 & 105,4 \\
\hline $\mathrm{C}$ & 8,418 & 98,6 & 10,743 & 96,9 & 38,67 & 99,1 & 767,9 & 104,8 \\
\hline \multirow[t]{2}{*}{$\mathrm{D}$} & 6,440 & 75,4 & 8,715 & 78,6 & 30,12 & 77,2 & 827,7 & 113,0 \\
\hline & \multicolumn{8}{|c|}{ Patinamento $20 \%$} \\
\hline A & 12,084 & 99,6 & 13,931 & 100 & 53,68 & 99,6 & 646,5 & 100 \\
\hline B & 11,857 & 97,8 & 13,719 & 98,5 & 52,66 & 97,7 & 682,2 & 105,5 \\
\hline $\mathrm{C}$ & 12,128 & 100 & 13,648 & 98,0 & 53,89 & 100 & 695,9 & 107,6 \\
\hline \multirow[t]{2}{*}{$D$} & 10,133 & 83,6 & 11,852 & 85,1 & 45,71 & 84,8 & 715,4 & 110,7 \\
\hline & \multicolumn{8}{|c|}{ Patinamento $30 \%$} \\
\hline$A$ & 14,597 & 99,1 & 15,062 & 99,2 & 63,92 & 99,3 & 654,5 & 100 \\
\hline $\mathrm{B}$ & 14,697 & 99,8 & 15,186 & 100 & 64,21 & 99,8 & 682,9 & 104,3 \\
\hline $\mathrm{C}$ & 14,724 & 100 & 14,797 & 97,4 & 64,37 & 100 & 704,5 & 107,6 \\
\hline $\mathrm{D}$ & 13,010 & 88,4 & 13,492 & 88,8 & 57,63 & 89,5 & 693,4 & 105,9 \\
\hline
\end{tabular}


69.

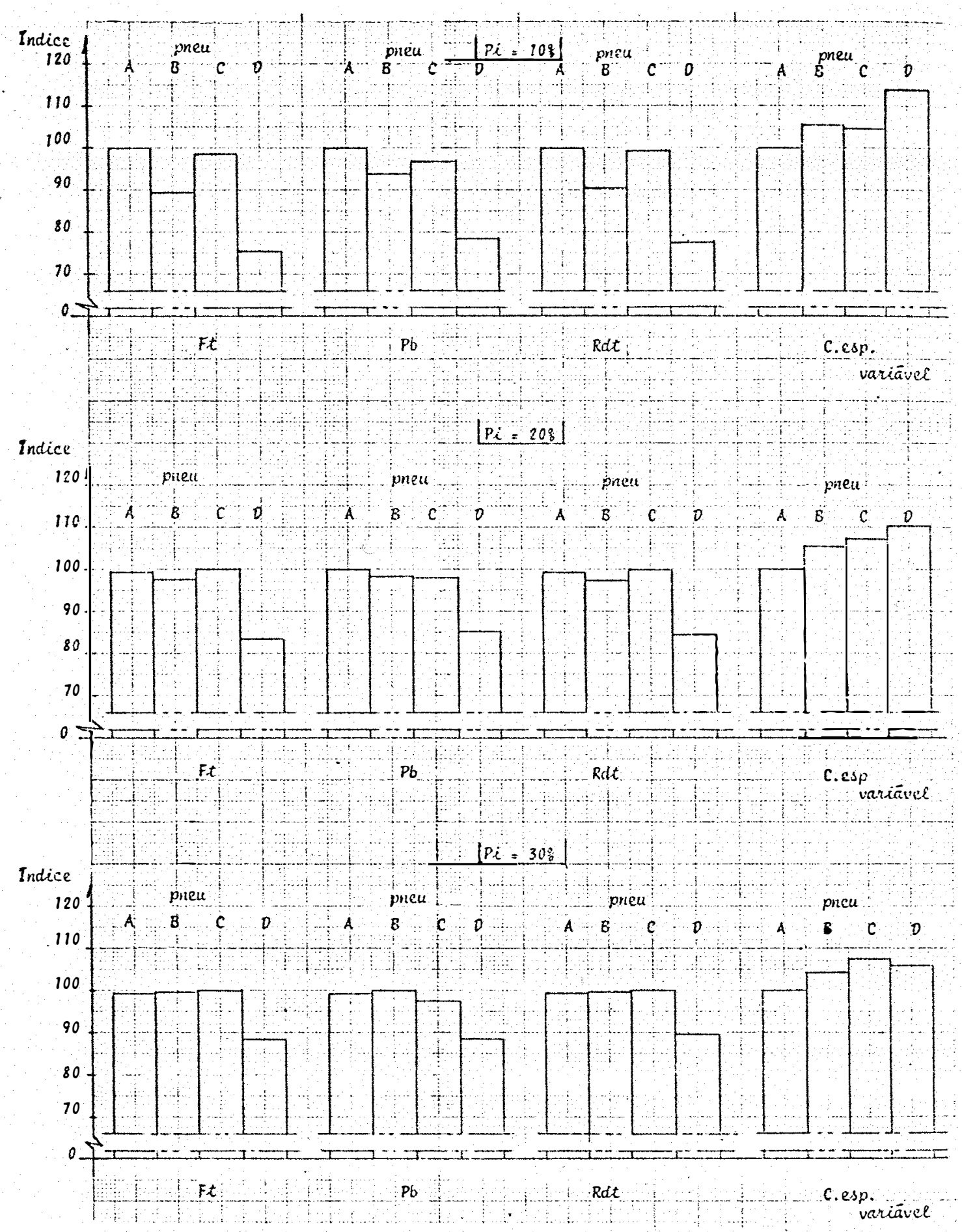

Figura 19 - Desempenho dos pneumáticos para as variáveis $\mathrm{Ft}, \mathrm{Pb}$, Rdt e C.esp a 10,20 e $30 \%$ de Pi. 
Para a condição de $10 \%$ de $\mathrm{Pi}$, os pneumáticos A e C apresentaram $O$ melhor desempenho para as variáveis $\mathrm{Ft}, \mathrm{Pb}$ e Rdt, o pneu B ocupou uma posição intermediária e o pneu D revelou um desempenho bem inferior aos demais. A $20 \%$ e $30 \%$ de $\mathrm{Pi}$ os pneus A, B e C foram equivalentes para as variáveis $\mathrm{Ft}$, $\mathrm{Pb}$ e Rdt, com $\circ$ pneu $\mathrm{D}$ revelando novamente um desempenho infe rior. Quanào à variável C.esp. o modelo A obteve o índice 100 para $10 \%$ e $20 \%$ de $\mathrm{Pi}$; para $30 \%$ de $\mathrm{Pi}$ seu desempenho foi equivalente ao modelo $B$.

Com estes resultados é lícito afirmar-se que para o intervalo de patinamento dentro da faixa normal de ope ração, não existem diferenças significativas de cesempenho dos modelos A, B e C, a não ser uma superioridade do pneu A em termos de C.esp.

\section{4. - COMPARAÇÃO DE DESEMPENHO ENTRE OS MODELOS OPERANDO NAS CONDIÇÕES CL E SL.}

Nas comparações entre pneumáticos operando nas condições SL e CL, adotou-se os mesmos critérios utilizados an teriormente, para a análise individual de cada condição.

\subsection{1. - Comparação entre niveis de patinamento que fornecem o máximo desempenho.}

Utilizando-se dos dados das Tabelas X e XII, elaborou-se a Tabela XXIVe a Figura 20. Na Tabela XXIV são apre sentados os desempenhos máximos dos pneumáticos para as condições CL e SL, os níveis de patinamento em que foram obtidos e dois indices comparativos. Para o cálculo do indice 1 atribuiu - se o indice 100 ao melhor desempenho observado, independentemente do modelo de pneu e da condição de lastragem. Para o cál culo do indice 2 atribuiu-se o valor 100 à condição de lastragem de melhor desempenho, para cada modelo de pneu. Assim, en- 
quanto o indice 1 reflete as diferenças globais entre os mode los e condição de lastragem, o indice 2 indica o efeito do lastro no comportamento de cada modelo de preu.

A Figura 20 apresenta a configuração gráfica do desempenho dos pneumáticos através do diagrama de barras. A Figura 20-a indica as diferenças de desempenho referentes ao indice 2 e a Figura $20-b$ as diferenças referentes ao indice 1. A Figura 20-c apresenta o nível de patinamento em que esses indices foram obtidos.

$$
\text { 4.4.1.1. - Comparação em relação ao indice } 1 .
$$

De acordo com o apresentado na Tabela XXIV e Fi gura 20-b, o desempenho global dos pneus pode ser caracteriza do da seguinte forma:

.) Para a variável Ft, o modelo D apresentou o melhor desempenho (índice 100) na condição CL mas com diferen ças não significativas em relação aos outros modelos na condi ção CL. O desempenho dos quatro pneus na condição SL foi bem inferior ao pneu D na condição CL (índice 100) com diferenças em relação a este de $18,1,14,1,26,2$ e 19,0 para os pneus A, $B, C$ e $D$ respectivamente.

Quanto ao nível de $\mathrm{Pi}$ não ocorreu tendência de uma condição apresentar niveis superiores em relação a outra, sendo que $O$ modelo $A$ e $B$ apresentaram niveis de $\mathrm{Pi}$ maiores na condição SL e os modelos C e D na condição CL.

.) Para a variável $\mathrm{Pb}$, o modelo $\mathrm{B}$ apresentou o melhor desempenho na condição CL (índice 100) com diferenças significativas em relação aos quatro modelos operando na condição SL e em relação ao pneu D na condição CL.

Quanto ao nivel de $\mathrm{Pi}$, não ocorreu tendência de uma condição apresentar niveis superiores em relação a outra; a variação do nivel de Pi entre os modelos e condições de las tragem foram inferiores"às observadas para a variável Ft. 

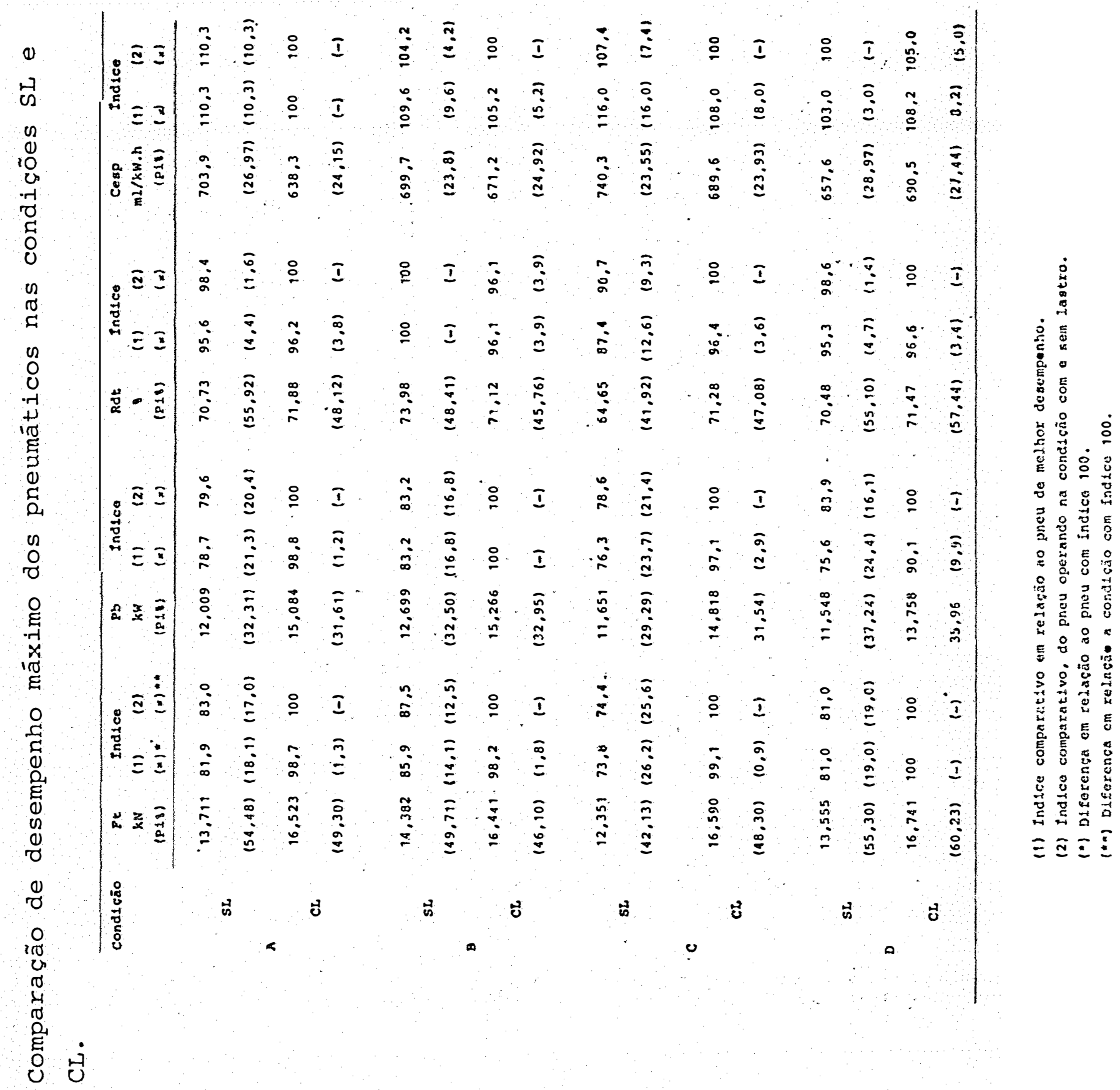
73.

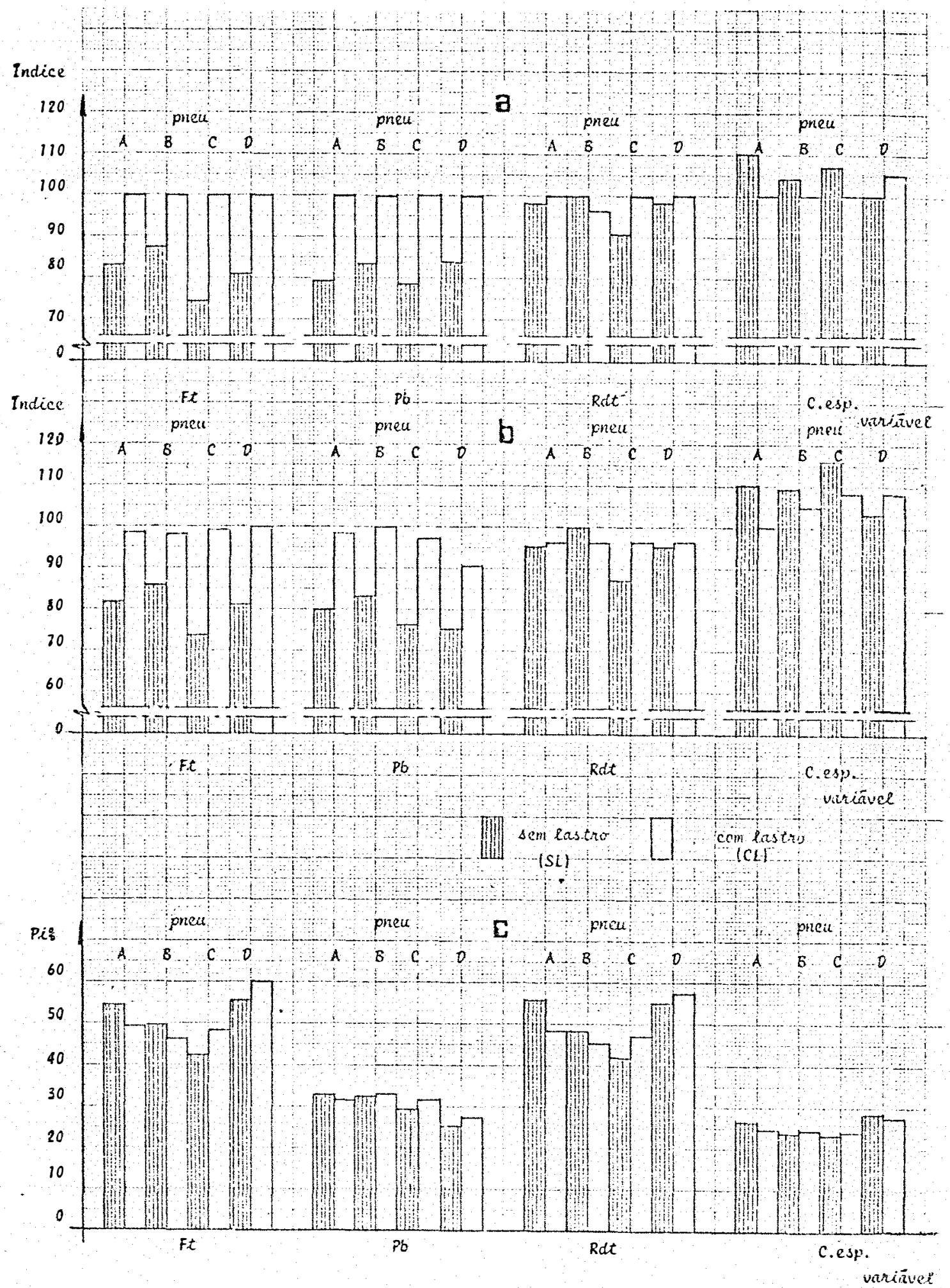

Figura 20 - Comparação de desempenho máximo entre os modelos operando nas condições SL e CL (20-a indice $2 ; 20-b$ indice $1 ; 20-c$ niveis de $\mathrm{Pi}$ ). 
-) Para a variável Rdt, o pneu B na condição SL apresentou o melhor desempenho (índice 100), não ocorrendo diferenças acentuadas em relação aos modelos e condições de lastragem, com exceção do pneu $C$ na condição SL, com um índice 87,4 .

Quanto ao nível de $\mathrm{Pi}$, ocorreram diferenças acentuadas em relação aos modelos, como por exemplo o modelo B e D, mas não houve uma tendência em relação à lastragem, com os modelos A e B obtendo niveis superiores de $\mathrm{Pi}$ na condição SL e os modelos C e D na condição CL.

-) Para a variável C.esp, o modelo A na condição CL, obteve o melhor desempenho (índice 100); o pneu D apresentou um desempenho superior na condição SL, em relação aos outros modelos excetuando-se, logicamente, o modelo A na condição CL.

Os níveis de Pi, entre os modelos e conaição de lastragem não apresentaram diferenças acentuadas situando-se todos na faixa normal de operação (0 a $30 \%$ de Pi).

\subsubsection{2. - Comparação em relação ao índice 2 .}

De acordo com o apresentado na Tabela. XXIV e Figura 20-a o desempento dos pneus em termos de índice da variável Ft, foi sempre superior para a condição lastrada. Na condição sem lastro, as diferenças em relação ao índice 100 foram de $17,0,12,5,25,6$ e 19,0 para os pneus A, B, C e D respectivamente.

Para a variável $\mathrm{Pb}$ o comportamento foi idêntico à variāvel Ft, com diferenças em relação ao índice 100 de $20,4,16,8,21,4$ e 16,1 para os pneus A, B, C e D respectiva mente.

No tocante à variável Rdt, apenas o modelo C $\underline{\mathrm{a}}$ presentou um desempenho que pode ser considerado superior na condição lastrada com diferença de 9,3 em relação a condição 
sem lastro.

Quanto a variável C.esp, os pneus A, B e C lastrados apresentaram 0 melhor desempenho com diferenças de $10,3,4,2$ e 7,4 respectivamente e para o modelo D, a condição SL foi superior com uma diferença de 5,9 .

Quanto aos níveis de $\mathrm{Pi}$, são válidas as mesmas considerações realizadas no item 4.4.1.1., ressaltando-se que a adição de lastros resultou em comportamento diferenciado em uma variável - aumento ou diminuição de Pi - para os modelos a valiados.

4.4.2. - Comparação de desempenho na faixa normal de operaUtilizando-se dos dados apresentados nas Tabelas XII e XXIII, elaborou-se as Tabelas XXV, XXVI e XXVII e as Figuras 21, 22 e 23. Nas Tabelas XXV a XXVII são apresentados os desempenhos dos pneumáticos para as condições CL e $\mathrm{SL}$ a niveis de $10 \%, 20 \%$ e $30 \%$ de $\mathrm{Pi}$ bem como os indices $11 \mathrm{e}$ 2) comparativos destes desempenhos. Nas Figuras 21 a 23 são a presentadas as performances dos modelos, através de diagramas de barras nos três niveis de $\mathrm{Pi}$ de acordo com o proposto no tem 4.4 .1 .

Conforme se observa, pela análise das Tabelas e Figuras, o desempenho dos pneus para as variáveis $\mathrm{Ft}$ e $\mathrm{Pb}$ alte ram-se de acordo com a lastragem (indice 2). Para a condição CL, estas variáveis foram sempre superiores à condição SL; para a variável Ft estas diferenças foram de um mínimo de 12,2 (pneu $\mathrm{D}$ a $10 \%$ de $\mathrm{Pi}$ ) a um máximo de 21,2 (pneu $\mathrm{C}$ a $30 \%$ de Pi). Para $\mathrm{Pb}$ estas diferenças foram de 9,0 (pneu $\mathrm{B}$ a $10 \%$ de $\mathrm{Pi}$ ) a 21,3 (pneu $\mathrm{C}$ a $30 \%$ de $\mathrm{Pi}$ ).

No tocante a variável Rdt, O pneu $A$ apresentou $O$ melhor desempenho na condição $C L$, O pneu $D$ na condição SL e os pneus $B$ e $C$ alternaram estas situações de acordo com $O$ nível de Pi. 


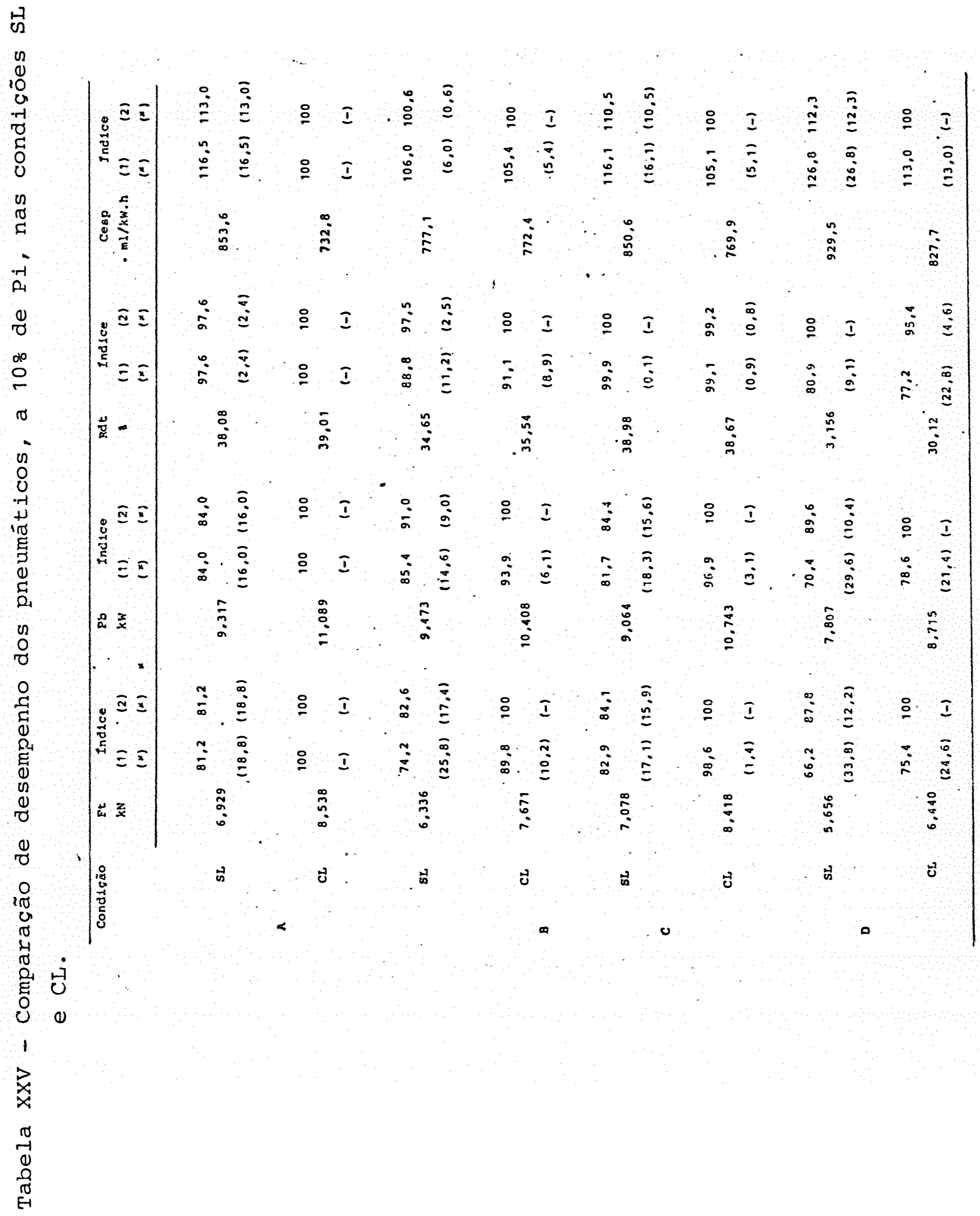




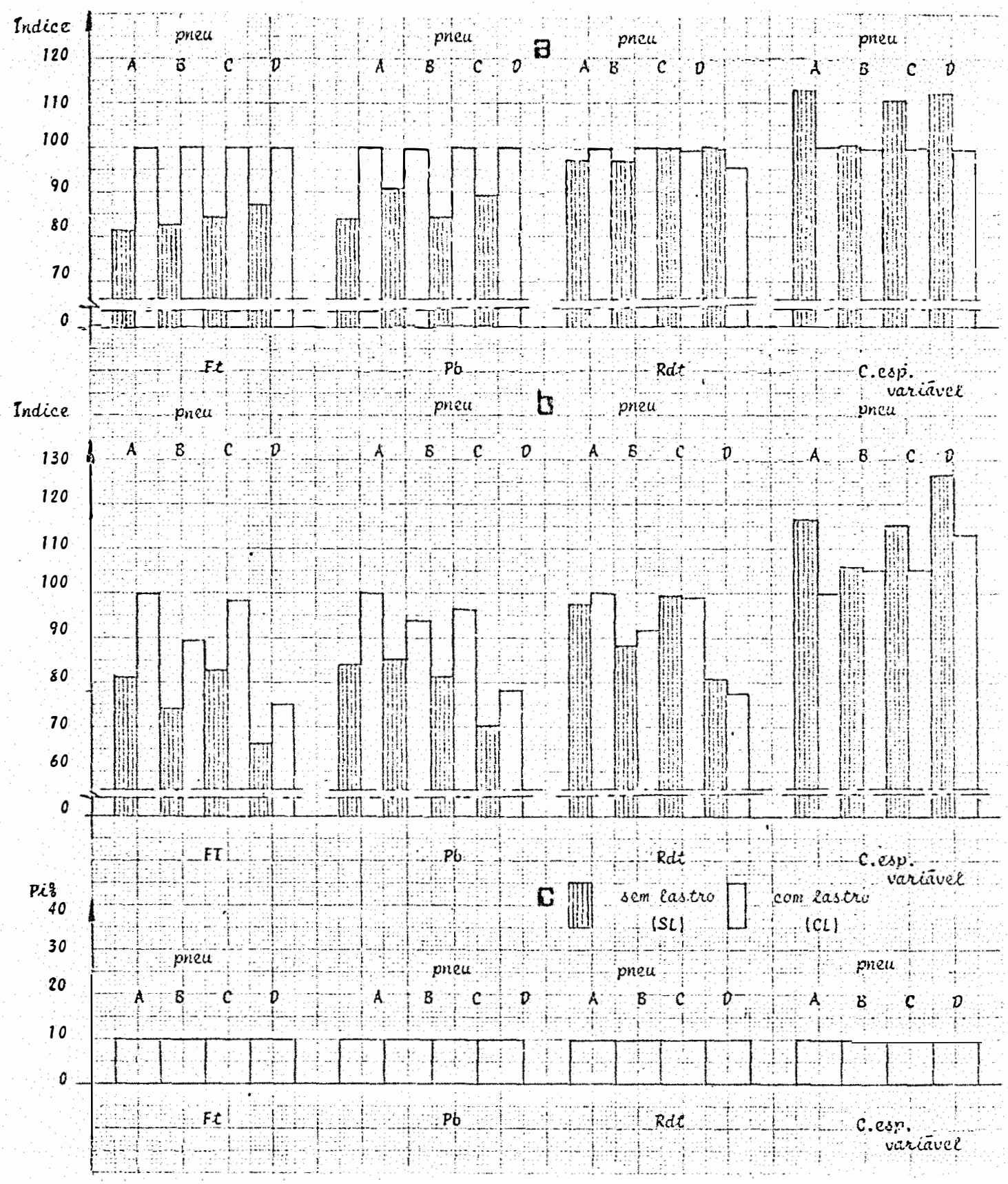

Figura 21 - Comparação de desempenho, a 10\% de Pi, para os modelos operando nas condições SL e C.L (21-a indice 2; 21-b indice 1). 


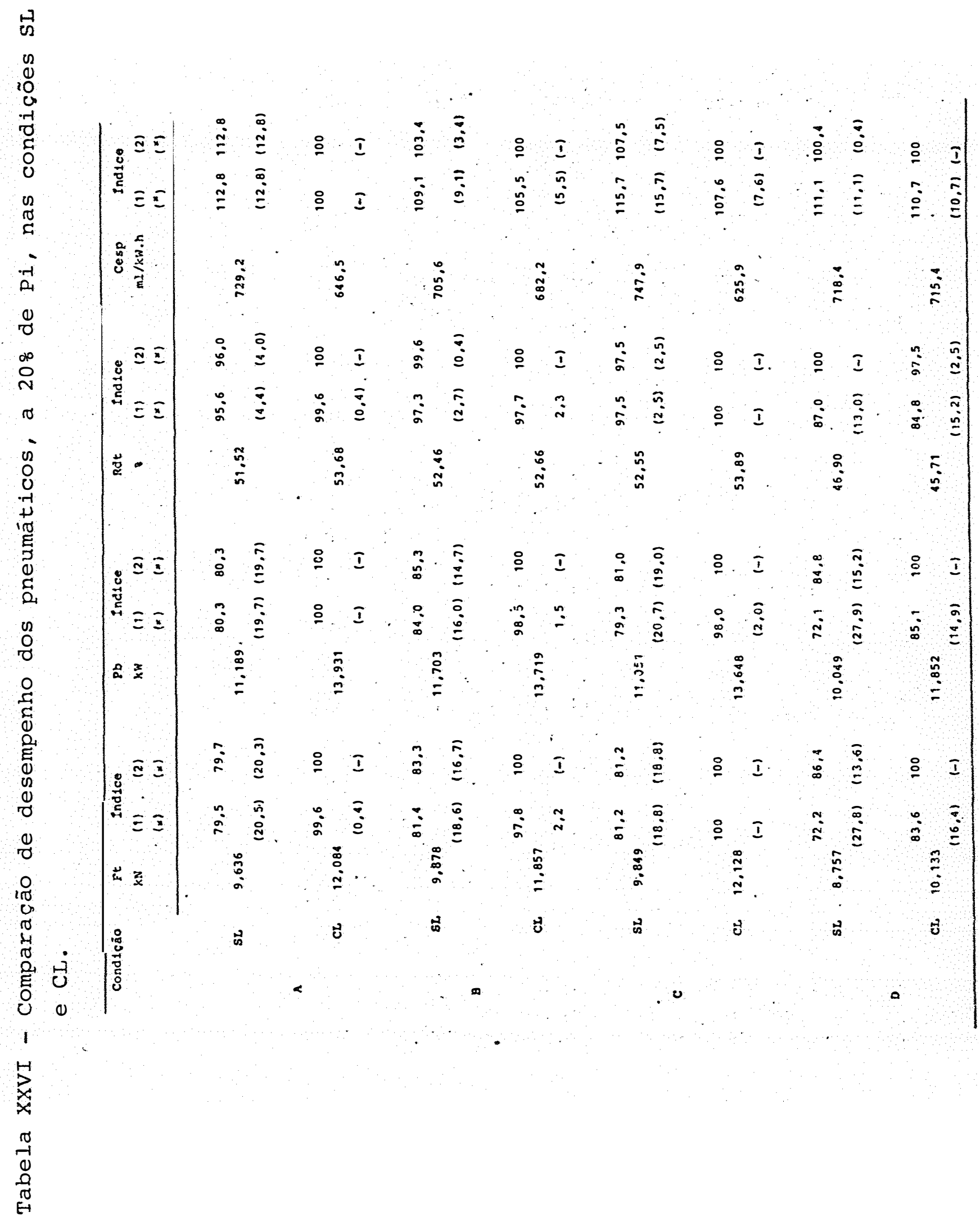




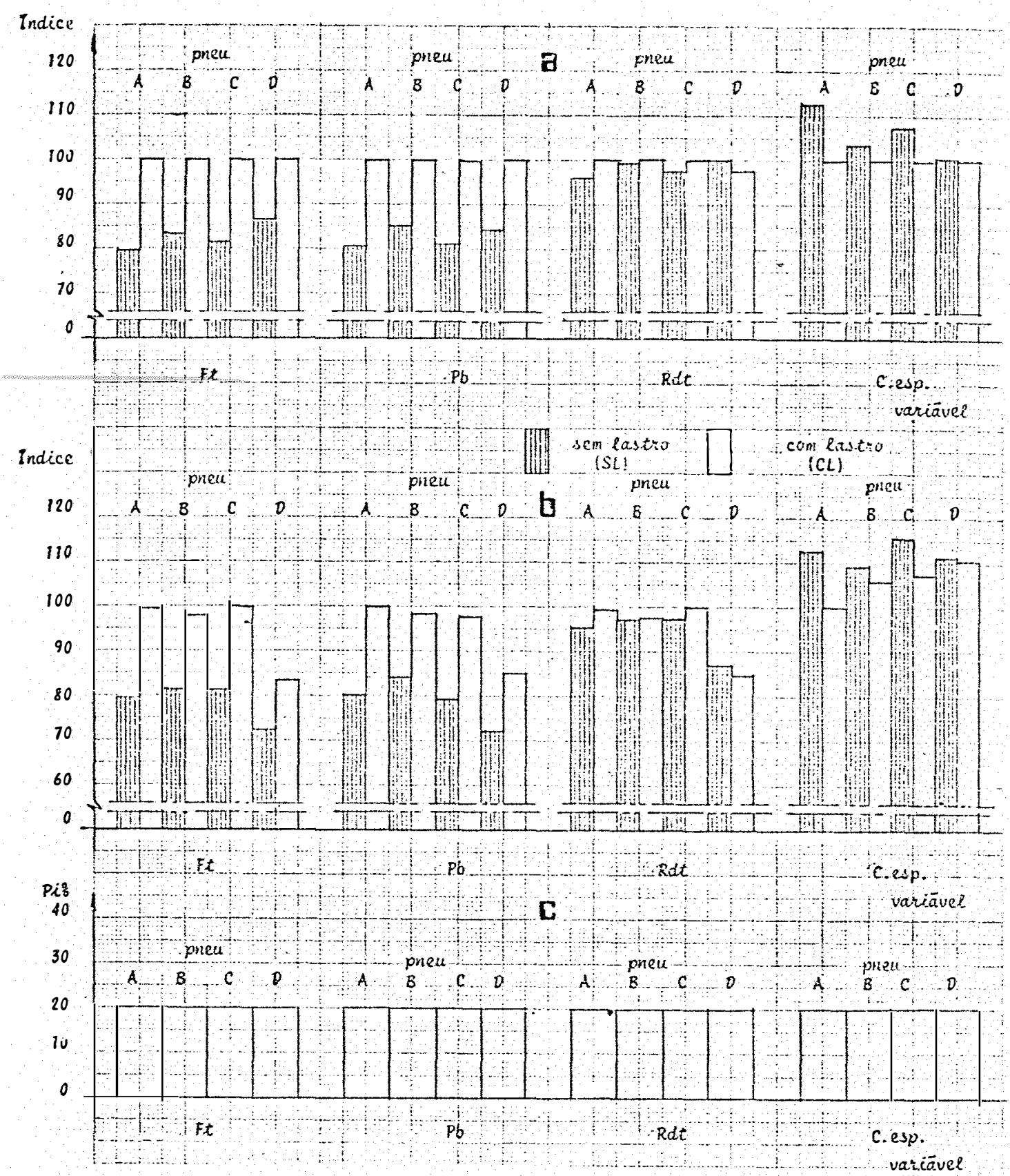

Figura 22 - Comparação de desempenho, a $20 \%$ de Pi, para os modelos operando nas condições SI e CL. $122-a$ indice $2 ; 22-b$ indice 1). 


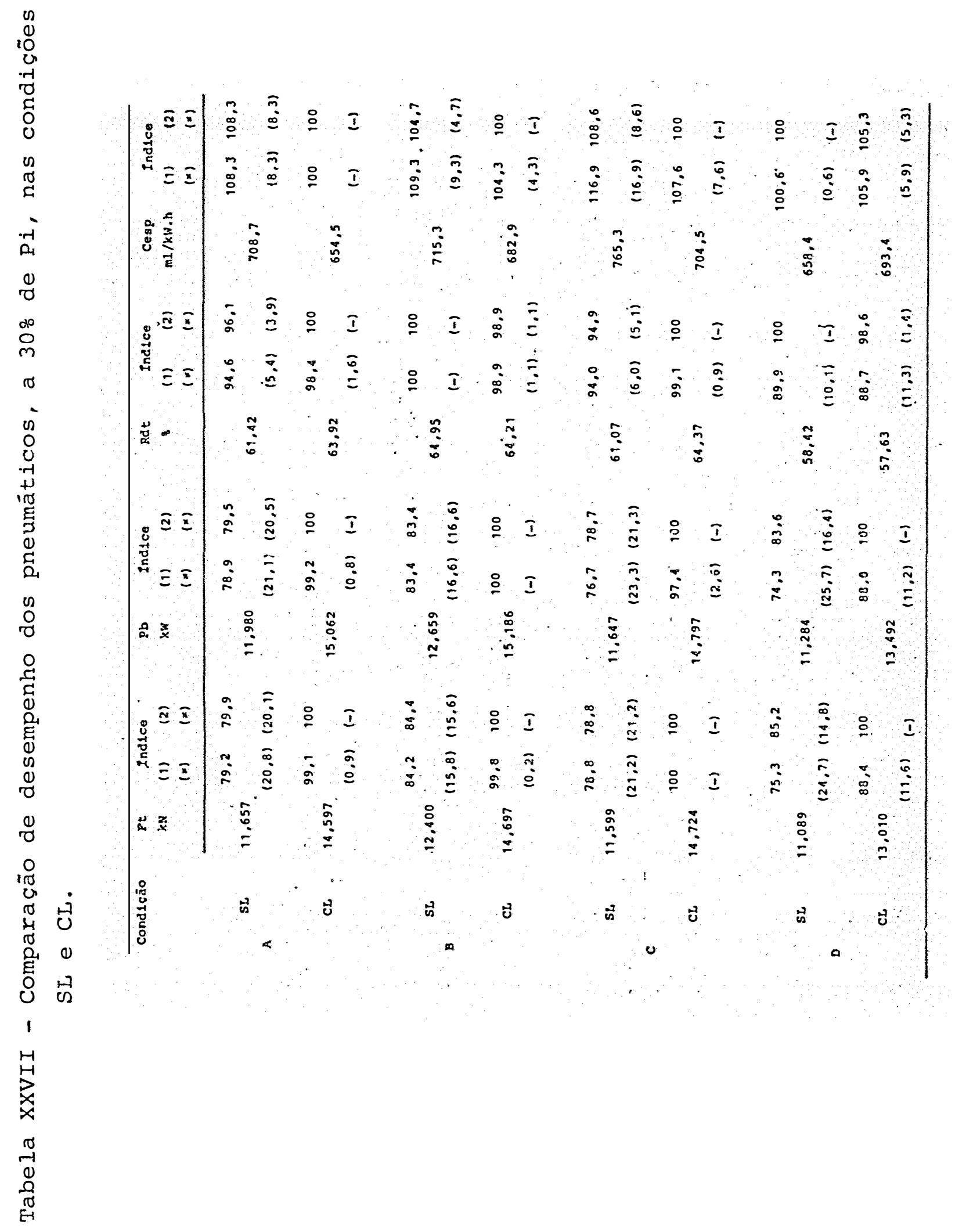




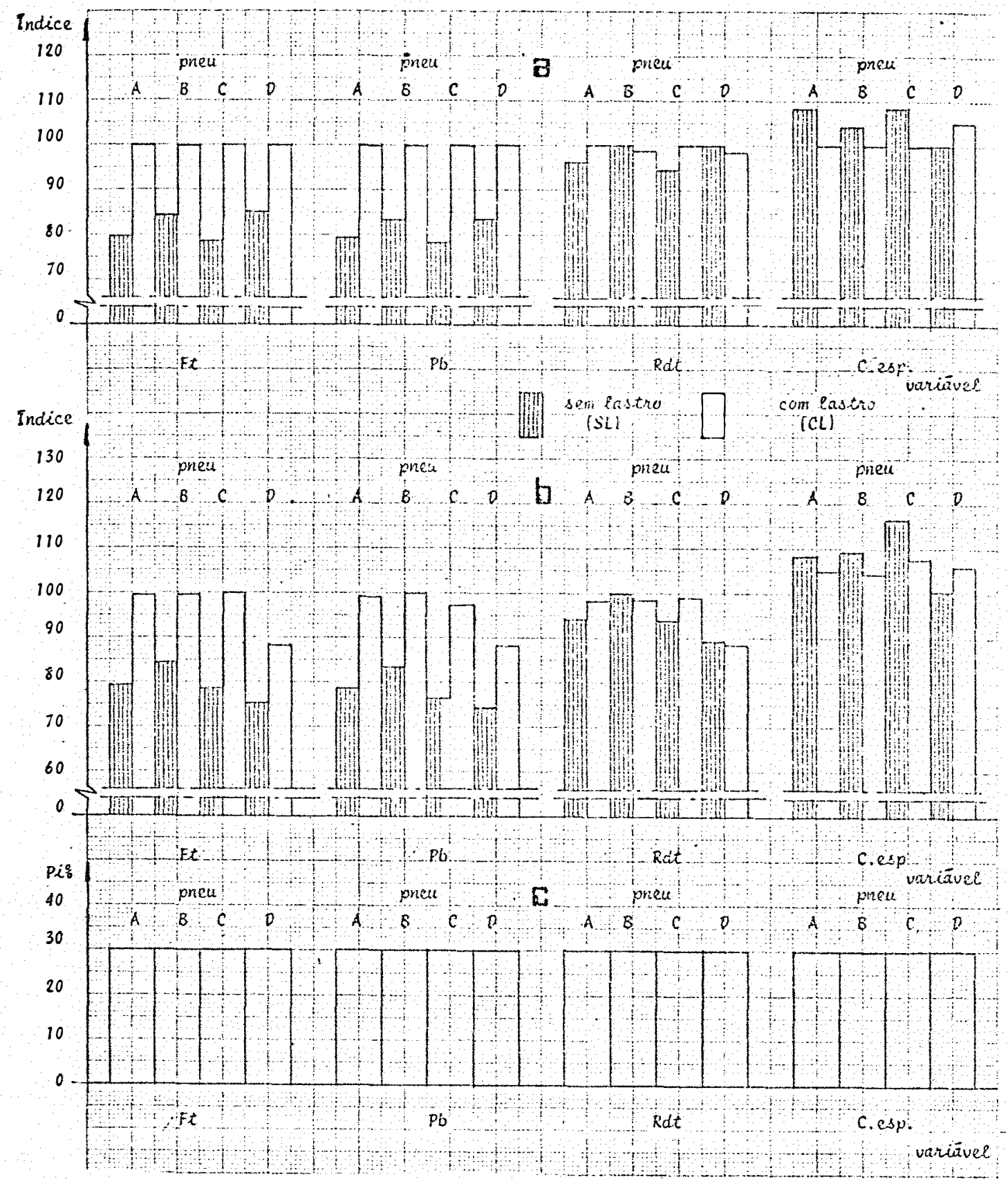

Figura 23 - Comparação de desempenho, a $30 \%$ de Pi, para os modelos operando nas condições SL e CL (23-a indice 2; 23-b indice 1) 
Em relação a variável C.esp, todos. os pneus apresentaram um melhor desempenho na condição CL, nos três niveis de Pi, exceção feita ao pneu $\mathrm{D}$ a $30 \%$ de $\mathrm{Pi}$ onde a melhor performance foi obtida na condição SL.

Quanto ao Indice 1 (Figuras 21-b, 22-b e 23-b)

de comparação entre os pneus sem levar em conta a lastragem ob serva-se a mesma tendência abordada no parágrafo anterior. Deve-se ressaltar que o pneu $D$ na condição CL para as variáveis Ft e $\mathrm{Pb}$ e níveis de $\mathrm{Pi}$ de $10 \%$ e $20 \%$ revelou desempenho inferior aos modelos A, B e C e na condição SL. Para a variável Rdt também ocorreu esta situação mas, nos três níveis de Pi $(10,20$ e $30 \%)$.

\subsection{DISCUSSÃO GERAL}

Embora os pneumáticos apresentem desenhos de banda de rodagem diferentes, principalmente o modelo D, não é possivel estabelecer qual o parâmetro do desenho que tem mais influência no desempenho. Para tanto, seria necessário orientar a pesquisa de acordo com aquelas realizadas por Reed e Shielcis (GIL e VANDEN BERG 1967), TAYLOR (1973 a) e TAYLOR. (1973 b) onde os modelos analisados diferem em apenas um parâmetro. No presente caso, embora se possa determinar as diferen ças de desempenho entre os modelos, não é possivel isolar as causas dessas diferenças em função do desenho da banda de roda gem.

O efeito da lastragem sobre o-desempenho dos pneumáticos foi significativo para as variáveis $\mathrm{Ft}$ e $\mathrm{Pb}$, o que vem de encontro às pesquisas realizadas por BURT e. BAILEY (1982) e BURT et alii (1983). Para a variável Pb, a não disponibilidade de equipamento, impediu o cálculo da eficiência tratória no presente trabalho.

Quanto a variável Rdt, não se observou uma ten- 
dência definida de influência da lastragem para os quatro modelos de pneus. O aumento na carga aplicada aos rodados de tração devido à lastragem, não foi acompanhado de um aumento substancial na Ft para determinados modelos e níveis de Pi. Este fato pode ser constatado para os pneus B e D que revelaram uma inversão de comportamento em relação a Rdt para as condições CL e SL conforme indicado nas Figuras 20-a e 22-a.

Para a variável C.esp, o aumento da potência na barra em função da adição de lastros, foi superior ao aumento de consumo de combustível correspondente. O pneu D constituiu - se exceção pois no intervalo aproximado de 20 a $40 \%$ de $\mathrm{Pi}$, re velou um menor consumo especifico na condição SL; este resultado está associado ao desempenho inferior em termos de $\mathrm{Pb}$, do modelo D, quando comparado aos outros três pneus na condição com lastro.

Um outro fator a ser observado é que, conforme a ABPA (1980), a cargà máxima que cada pneu pode suportar com a pressão de inflação de $110 \mathrm{kPa}(16 \mathrm{psi})$ è de $17,364 \mathrm{kN}$, totalizando $34,728 \mathrm{kN}$ para o eixo motriz (2 pneus). Como a máxí ma tração na barra obtida nos ensaios foi $16,741 \mathrm{kN}$, a máxima carga dinâmica aplicada sobre o eixo traseiro totaliza 23,314 $\mathrm{kN}$. Comparando-se estes valores observa-se que os pneus opera ram dentro dos limites de carga recomendados embora não se te nha explorado o limite máximo de lastragem tolerável. 
84.

5 - CONCLUSÕES

-) Para a condição SL, o modelo B obteve o melhor desempenho na situação limite de exigência (desempenho máximo). Para a faixa normal de operação (10 a $30 \%$ de $\mathrm{Pi})$, o desempenho dos modelos A, B e C foram equivalentes sendo que o pneu $D$ é o menos recomendado para operar nesta situação.

.) Para a condição CL, os modelos A, B e C são mais adequados do crue $0 .$. modelo $D$ nas condições de máximo desempenho. Para o intervalo de patinamento dentro da faixa normal de operação, não existem diferenças significativas de desempenho dos modelos A, B e C, a não ser uma superio ridade do pneu A em termos de C.esp.

.) O efeito da lastragem foi significativo para as variáveis $\mathrm{Ft}$ e $\mathrm{Pb}$.

.) Para a variável Rdt não se observa uma tendência definida da influência da lastragem para os quatro modelos de pneus.

.) Para a variável c.èsp, a adição de lastros aumentou a eficiência com relação ao aproveitamento do combus tivel.

.) Para a presente situação, o modelo polinomial de grau 2 é o que melhor explica o comportamento dos pneus. 
6. - LITERATURA CITADA

ABPA, 1980. Livro de normas técnicas. São Paulo, Associa ção Brasileira de Pneus e firos.

ASAE, 1978. S 296.2. Uniform terminology for traction of agricultural tractors, self-propelled implements, and other traction and transport devices. In: Agricultural Engineering Yeariook 1978-79. St. Joseph, Michigan, EE.UU., :255-257.

BURT, E.C. A A.C. BAILEY, 1982. Load and Inflation Pressure Effects on Tires. Transactions of the ASAE. St. Joseph, Michigan, EE.UU., 25(04):881-884.

; R.M. PATTERSON; J.H. TAYLOR, 1979. Combined Effects of Dynamic Load and Travel Reduction on Tire Performance. Transactions of the ASAE. St. Joseph, Michigan, EE.UU., 22(1):40-45.

; P.W.L. Lyne; P. MEIRING; J.F.KEEN, 1983. Ballast and Inflation Effects on Tire Efficiency. Transactions of the ASAE. St. Joseph, Michigan, EE.UU., 26 (05)1352-1354.

CAVALCHINI,A.G., 1978. Test of TM 300 PIRELLI radial tractor tires. Milan, Istituto di Ingegneria Agraria. 13 p. 
FRẼNÇA ,G.V., 1986. Comunicação pessoal, ESALQ/USP, Piracicaba, S.P.

GILL ,W.R. e G.E. VANDEN BERG, 1967. Soil dynamics

in tillage and traction. Agr. Handbook No. Agricultural Research Service, USDA, EE.UU. 511 p.

MEDINA, H.P. e A.C. MONIZ, Coord., 1975. Elementos de Pedologia. Rio de Janeiro, Livros Técnicos e Cientificos Editora S.A. 460 p.

MIALHE, L.G., 1980. Desempenho de tratores agrícolas com - um e dois eixos propulsores, em terrenos cultivados. Piracicaba, ESALQ/USP, 148 p. (Tese de Livre Docência).

PIMENTEL GOMES, F., 1963. Curso de Estatistica Exnerimental. 2 ed. Piracicaba, Gráfica Nobel Ltda. 334 p.

TAYLOR, J.H., 1973. Effect of lug spacing on tractive performance of pneumatic tractor tires. ASAE Technical Paper No. 73-136. American Society of Agricultural Engineering. St. Joseoh, Michigan. EE.UU., $8 \mathrm{p}$.

1973. Lug angle effect on traction performance of pneumatic tractor tire. Transaction of the ASAE. St. Joseph, Michigan, EE.UU., 16(1):16-18. 
TAYLOR, J.H., 1975. Comparative traction performance of $\mathrm{R}-1, \mathrm{R}-3$ and $\mathrm{R}-4$ tractor tires. ASAE Technical Paper No. 75-1011. American Society of Agricultural Engineering. St. Joseph, Michigan. EE.UU., 8 p. , E.C. BURT; A.C. BAILLEY, 1976. Radial Tire Performance in Firm and Soft Soils. Transactions of the ASAE. St. Joseph, Michigan, EE.UU., 19(6): 10621064 .

VASEY, G.H. e I.T. NAYLOR, 1958. Field Tests on 14-30 Tractor Tyres. Jour. Agr. Engin. Res. 3:1-8. 
Neste Apêndice são apresentadas as terminologias e as caracteristicas de construção dos pneumáticos avaliados.

Segundo a Associação de Pneus e Aros (ABPA-1980) a definição dos termos Banda de Rodageme. desenho da Banda de Rodagem é realizada da seguinte forma:

-) Banda de Rodagem - é a parte do pneu que entra em contacto com o' solo, constituída de elastômeros, produtos têxteis e outros materiais, com determinada forma e desenho, a fim de permitir a aderência ao solo e a resistência ao desgaste:

-) Desenho da Banda de Rodagem - è a disposição particular, forma e dimensões das cavidades e saliências da banda de rodagem.

A classificação dos pneus para tratores agrícolas - rodas de tração - quanto ao desenho da banda de rodagem, de acordo com a ABPA (1980), é apresentada como se segue:

\begin{tabular}{ll}
\hline Tipo & \multicolumn{1}{c}{ Desenho de banda de rodagem } \\
\hline R-1 & Tração regular \\
R-2 & Tração extra - Arrozeiro (raia profunda) \\
R-3 & Raia superficial (pouco profunda) \\
R-4 & Industrial
\end{tabular}

Fonte: Normas Técnicas - ABPA/1980.

A terminologia empregada para o desenho de banda 
de rodagem de pneus agrícolas, com base na padronização

ASAE S 296.2(1983) é realizada como se segue:

-) Angulo da garra - ângulo formado entre a linha de centro da face da garra e a linha de centro do pneu.

-) Passo da garra - espaço de centro a centro en tre as garras de um lado, tomada na linha de centro do pneu. E medida na face da garra.

-) Comprimento da garra - distância medida do início ao fim da garra, tomada ao longo da linha de centro da face da garra.

-) Espaçamento da garra (perpendicular) - distân cia medida perpendicularmente do lado anterior ao lado posterior da garra a sua frente.

-) Espaçamento da garra (circunferencial) - dis tância do lado anterior da garra ao lado posterior da garra aä jacente medida paralelamente à linha de centro do pneu.

- Altura da garra - distāncia da base da banda de rodagem a face da garra.

-) Largura da garra - dimensão da face da garra, medida perpendicularmente a linha de centro da mesma.

os termos apresentados, podem ser visualizados na Figura I.1.
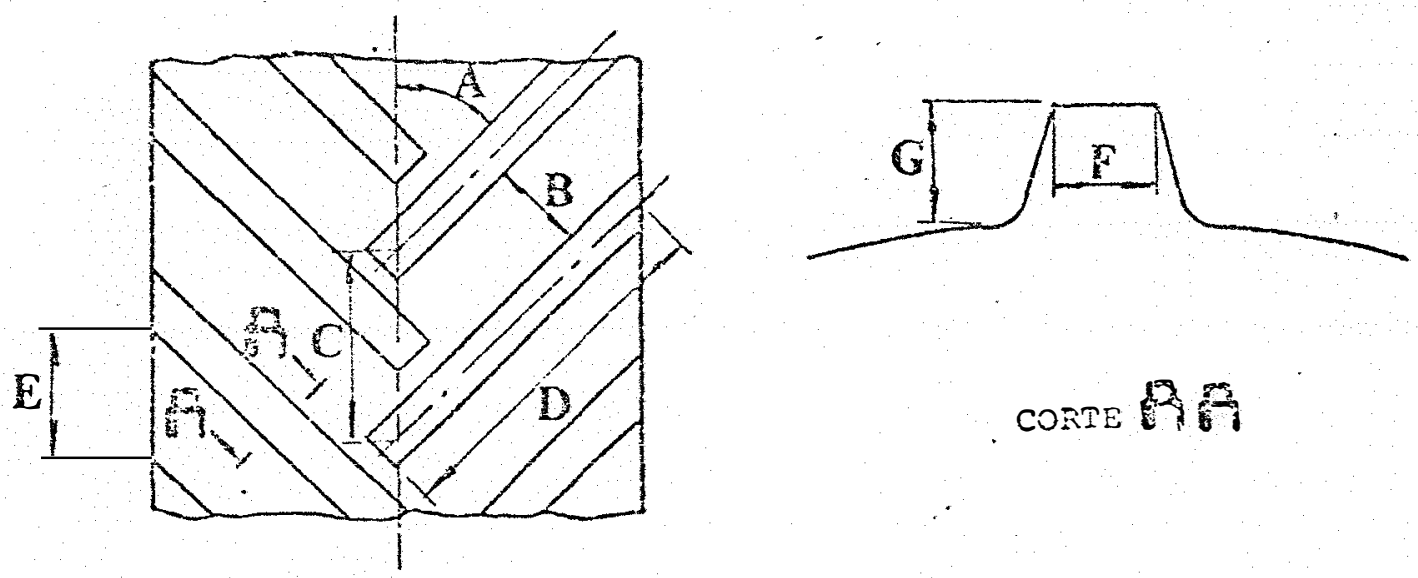

CORTE

Figura I.1. - Terminologia para banda de rodagem. A-ângulo da garra; B- espaçamento da garra (perpendicular); C-passo da garra; D-comprimento da garra; E-espaçamento da garra lcircunferenciall ; F-largura da garra; G-altura da garra. Fonte: Padronização ASAE S 296.2 (1983). 
As dimensões da banda de rodagem dos pneumáticos avaliados, com base na terminologia oroposta, são apresen tadas na Tabela I.I.

Tabela I.I - Dimensões da banda de rodagem dos pneus avaliados.

\begin{tabular}{|c|c|c|c|c|}
\hline \multirow[t]{2}{*}{ Discriminação } & \multicolumn{4}{|c|}{ Pneu } \\
\hline & A & $B$ & I & $c$ \\
\hline Ângulo da garra (graus) & 45 & 45 & 60 & 45 \\
\hline Passo da garra (mm) & 224 & 225 & 234 & 230 \\
\hline Comp: da garra (mm) & 264 & 271 & 244 & 261 \\
\hline Espaçam. da garra per & & & & \\
\hline pendicular (mm) & 123 & 123 & 145 & 135 \\
\hline Espaçam. da garra cir & & & & \\
\hline cunferencial (mm) & 169 & 163 & 182 & 167 \\
\hline Altura da garra (mm) & 77 & 72 & 106 & 89 \\
\hline Largura da garra (mm) & 47 & 49 & 39 & 46 \\
\hline
\end{tabular}


Neste Apêndice são apresentadas as principais especificações técnicas dos tratores utilizados nos ensaios.

II 1 - Especificações técnicas do trator de tração (Tt).

a) Marca - Ford; Modelo - 5600

b) Motor - Tipo - Ford Diesel; Modelo OHV 4256; Potência - $75 \mathrm{cv}(55,2 \mathrm{kw})$ a $2100 \mathrm{rpm}$; Torque máximo - $26,5 \mathrm{mkgf}(264 \mathrm{Nm}) \quad$ a $1400 \mathrm{rpm}$;

Rotação máxima - 2375 rpm; Cilindrada - $4195 \mathrm{~cm}^{3}$; No de cilindros - 04; Diāmetro dos cilindros - 111,2 mm; curso do êmbolo $107 \mathrm{~mm}$; Razão de compressão - 16,3:1; Sistema de alimentação - por injeção direta, aciọnada mecanicamente; sistema de purificação de ar - em banho de óleo, com pré purificador centrifugo: Sistema de refrigeração - a ãgua, pres surizado.

c) Transmissão: Embreagem - monodisco a seco, 330 mm de diâmetro; Caixa de câmbio engrenamento permanente com 8 velocidades a frente e duas a ré. 
d) Eixo traseiro: Redução final - aupla redução feita através do conjunto diferencial, coroa e pinhão e também com um conjunto de pla netárias, montada nos semi-e xos, completando a tração final; bloqueio do diferencial - aciorado por pedal, destrava automática.

e) Velocidades de deslocamento com motor a 2100 rpm (medidas aproximadas dependendo do tamanho dos pneus).

$\begin{array}{crcr}\text { Marcha } & \mathrm{km} / \mathrm{h} & \text { Marcha } & \mathrm{km} / \mathrm{h} \\ 1 \mathrm{a} & 2,5 & 6 a ̣ & 11,3 \\ 2 a & 3,2 & 7 a ̣ & 19,9 \\ 3 a & 5,6 & 8 a ̣ & 27,0 \\ 4 a & 7,6 & 1 a \text { Ré } & 3,7 \\ 5 a+ & 9,1 & 2 a \text { Ré } & 13,0\end{array}$

f) Barra de tração: Oscilante, com suporte ajus tável para engate duplo.

g) Pneus disponiveis:

$$
\begin{array}{r}
\text { Dianteiros }-7,50-166 \text { lonas } F 2 \\
\text { Traseiros }-13,6 / 12-386 \text { lonas R1 } \\
18,4 / 15-306 \text { lonas R2 } \\
18.4 / 15-306 \text { lonas R1 } \\
16.9 / 14-306 \text { lonas R1 }
\end{array}
$$


h) Características dimensionais e ponderáis (principais)

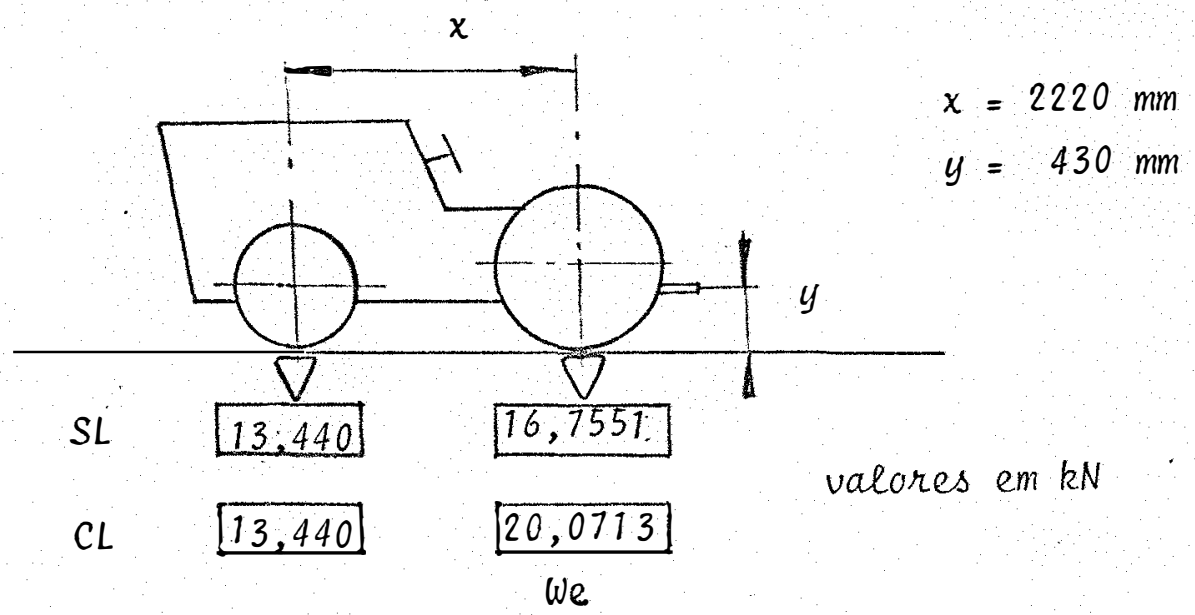

Figura II.1 - Caracteristicas dimensionais e ponderais do Tt.

As especificações técnicas constantes nos itens a a $g$, foram obtidas diretamente do catálogo fornecido pelo fa bricante; para o item $h$, as dimensões foram obtidas com o auxí Iio de uma trena. As características ponderais constituem média de 3 determinações, realizadas em balança de plataforma do Departamento de Zootecnia da ESALQ/USP com capacidade para 30 $\mathrm{kN}$.

\section{II - 2 Trator de Frenagem (TF)}

Como carga de formação utilizou-se de um trator marca valmet modelo 118,4 com lastro metálico nos aros e na dianteira. As marchas, relações de transmissão e a velocidade teórica de deslocamento são apresentadas a seguir: 


\begin{tabular}{|c|c|c|c|c|c|}
\hline \multirow[t]{3}{*}{ Marcha } & \multirow{3}{*}{$\begin{array}{l}\text { Relação de } \\
\text { transmissão } \\
\text { (motor-roda) }\end{array}$} & \multicolumn{4}{|c|}{ Pneu $18.4 / 15-34$} \\
\hline & & \multicolumn{4}{|c|}{ Velocidade teórica em km/h } \\
\hline & & 800 & $\mathrm{rpm}$ & $1747 \mathrm{rpm}$ & $2300 \mathrm{rpm}$ \\
\hline 1 a (L1) & $219,55: 1$ & & 1,0 & 2,4 & 3,1 \\
\hline $2 a(I 2)$ & $163,29: 1$ & & 1,5 & 3,2 & 4,1 \\
\hline $3 a \quad(\mathrm{~L} 3)$ & $136,86: 1$ & & 1,8 & 3,8 & 5,0 \\
\hline $4 a$ (M1) & $112,30: 1$ & & 2,1 & 4,6 & 6,1 \\
\hline $5 a(\mathrm{~L} 4)$ & $102,94: 1$ & & 2,3 & 5,1 & 6,7 \\
\hline $6 a(M 2)$ & $83,52: 1$ & & 2,9 & 6,2 & 8,2 \\
\hline $7 a \quad$ (M3) & $70,00: 1$ & & 3,4 & 7,4 & 9,8 \\
\hline $8 \mathrm{a}$ (H1) & $55,60: 1$ & & 4,3 & 9,4 & 12,3 \\
\hline $9 a \quad$ (M4) & $52,65: 1$ & & 4,5 & 10,0 & 13,0 \\
\hline $10 a(\mathrm{H} 2)$ & $41,35: 1$ & & 5,8 & 12,6 & 16,0 \\
\hline $11 \mathrm{a}(\mathrm{H} 3)$ & $34,66: 1$ & & 6,9 & 15,0 & 19,8 \\
\hline $12 \mathrm{a}$ ( $\mathrm{H} 4)$ & $26,07: 1$ & & 9,1 & 20,0 & 26,3 \\
\hline 1 ạ $R \bar{e}$ (R1) & $129,15: 1$ & & 1,8 & 4,0 & 5,3 \\
\hline $2 a R^{2} \quad(R 2)$ & $96,05: 1$ & & 2,5 & 5,4 & 7,1 \\
\hline 3ạ Ré (R3) & $80,50: 1$ & & 3,0 & 6,5 & 8,5 \\
\hline 4 ạ Ré (R4) & $60,55: 1$ & & 3,9 & 8,6 & 11,3 \\
\hline
\end{tabular}

As especificações técnicas do Tf foram obtidas diretamente do catálogo fornecido pelo fabricante. 
Apêndice III

Neste Apêndice, são apresentadas as princịnais características, detalhes de instalação e calibrações efetuadas dos equipamentos utilizados.

III. 1 Conjunto odométrico

o conjunto odométrico é constituído de uma roda odométrica e dois conjuntos compostos de sensores magnéticos e engrenagens (100 dentes); um conjunto - sensor, engrenagem - é instalado no eixo de tração do Tt e outro instalado na roda odométrica. A Figura III.1 apresenta a roda odométrica acoplada ao Tf.

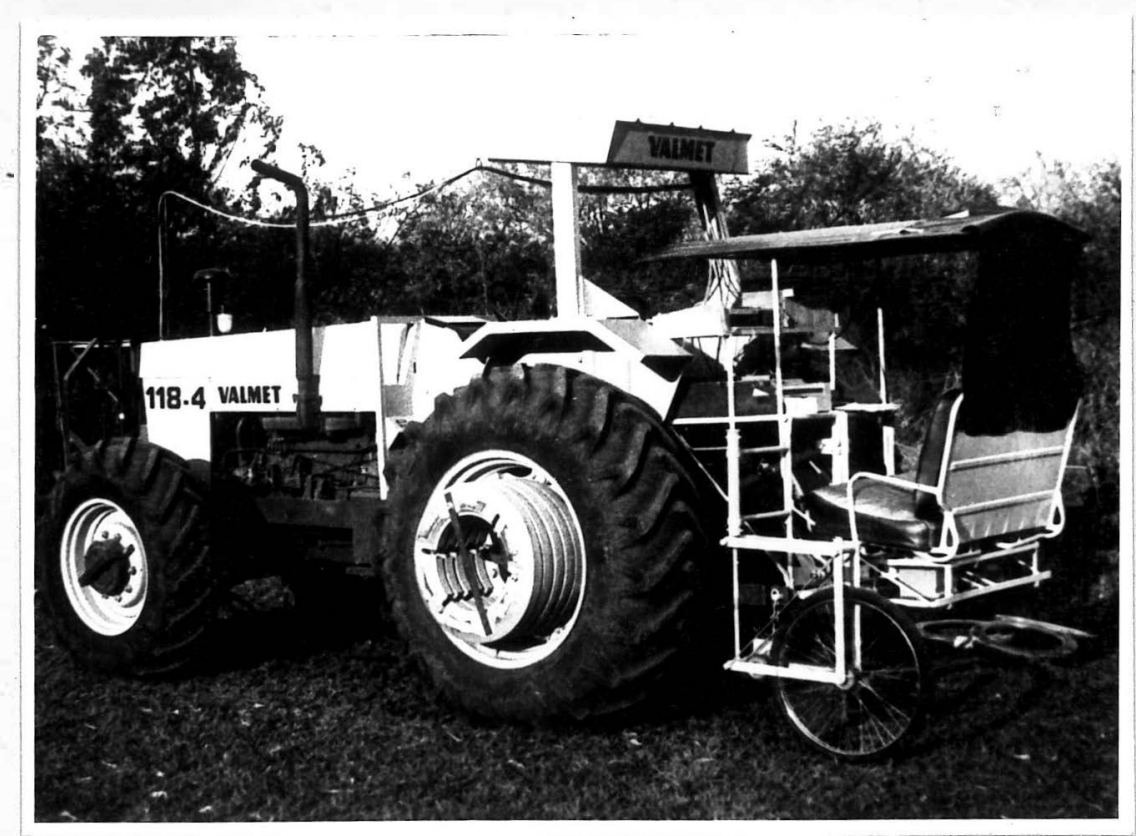

Figura III.1 - Roda odométrica acoplada ao Tf. 
A calibração da roda odométrica, foi realizada no campo de ensaio, antes do início das avaliações. Para tanto, percorria-se com o conjunto if e odométrica uma determina da distância medida com trena anotando-se o número de impulsos emitidos pelo sensor. A relação número de impulsos pela distância percorrida é dada por:

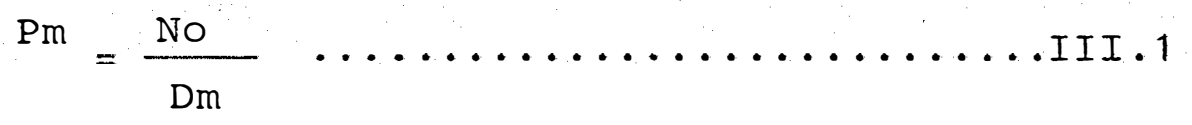

onde:

$\mathrm{Pm}=$ número de impulsos por metro linear percorrido pela odométrica.

No $=$ número de impulsos emitidos pelo sensor ao longo da distância Dm.

$\mathrm{Dm}=$.distância percorrida em metros.

Foram feitas 3 determinações sobre a área de ensaio, sendo utilizado o valor médio de pm para os cálculos.

Cabe ressaltar que a cada volta da odométrica e do pneu instalado no Tt, são emitidos 100 impulsos pelo sen sor.

\section{2 Cronodômetro}

o equipamento é constituído cie um circuito èle trônico de forma a registrar, em dois displays, os pulsos emi tidos pelos sensores instalados na roda odométrica, e no eixo traseiro do Tt, e um display para registro do tempo com preci são de décimos de segundos.

O equipamento permite o acionamento simultâneo, da contagem dos pulsos emitidos pelos sensores, do cronô metro e do medidor do consumo de combustivel. o esquema do painel frontal, com as indicações dos comandos, pode ser visualizado na Figura III.2. 


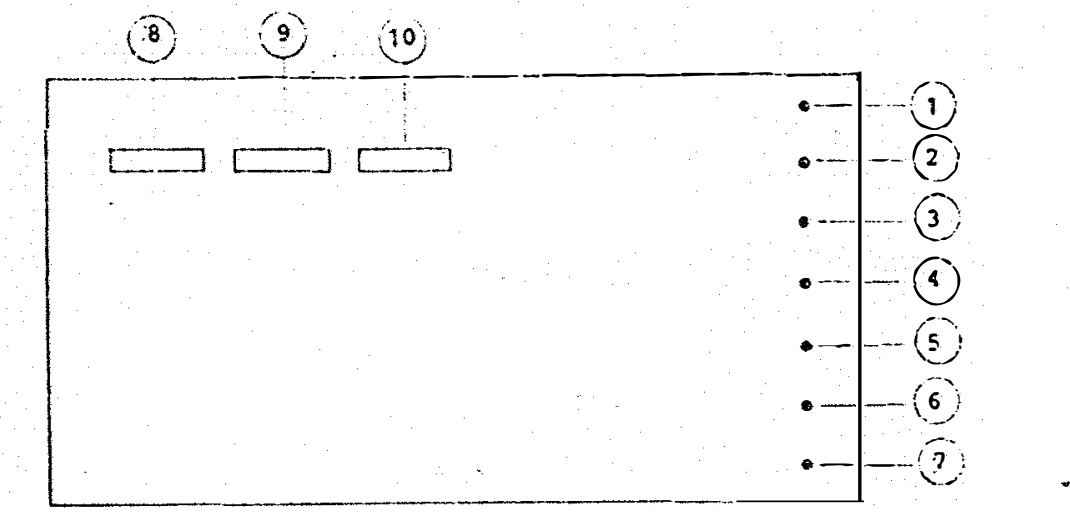

1. Start - inficio do ensaio acionando mealdor de combustivel

2. Stcp - flm do ensaio clesligando medidor de combustivel, senso res da odométrica do $T t, e$, cronōnetro

3. Reset - zera os "display"

4. Start manual - aciona os sensores da olométrica, do it e o cronömetro

5. Seleção de start - operação cio equipamento de modo automático ou manual

5. Memória - fixa os valores dos "display", mas a contagem continua en lapso.

7. 1.1ga-desliga - l1ga e desliga o cronotôrietro.

8. Display da odonētrica.

9. Display do $T \hat{\text {. }}$

10.D1splay do cronômetro.

Figura III.2 - Painel frontal do cronodômetro (esquema)

\section{III.3 Medidor de consumo}

III.3.1. Constituição e funcionamento

o equipamento de mensuração de consumo de combustível, constituído basicamente por cinco buretas, cinco eletroválvulas e um fotosensor, é instalado no sistema de alimentação do Tt entre o tanque de combustivel e a bomba injeto ra. O seu esquema básico pode ser visualizado na Figura III.3 
RETORNO DE COMBUS-

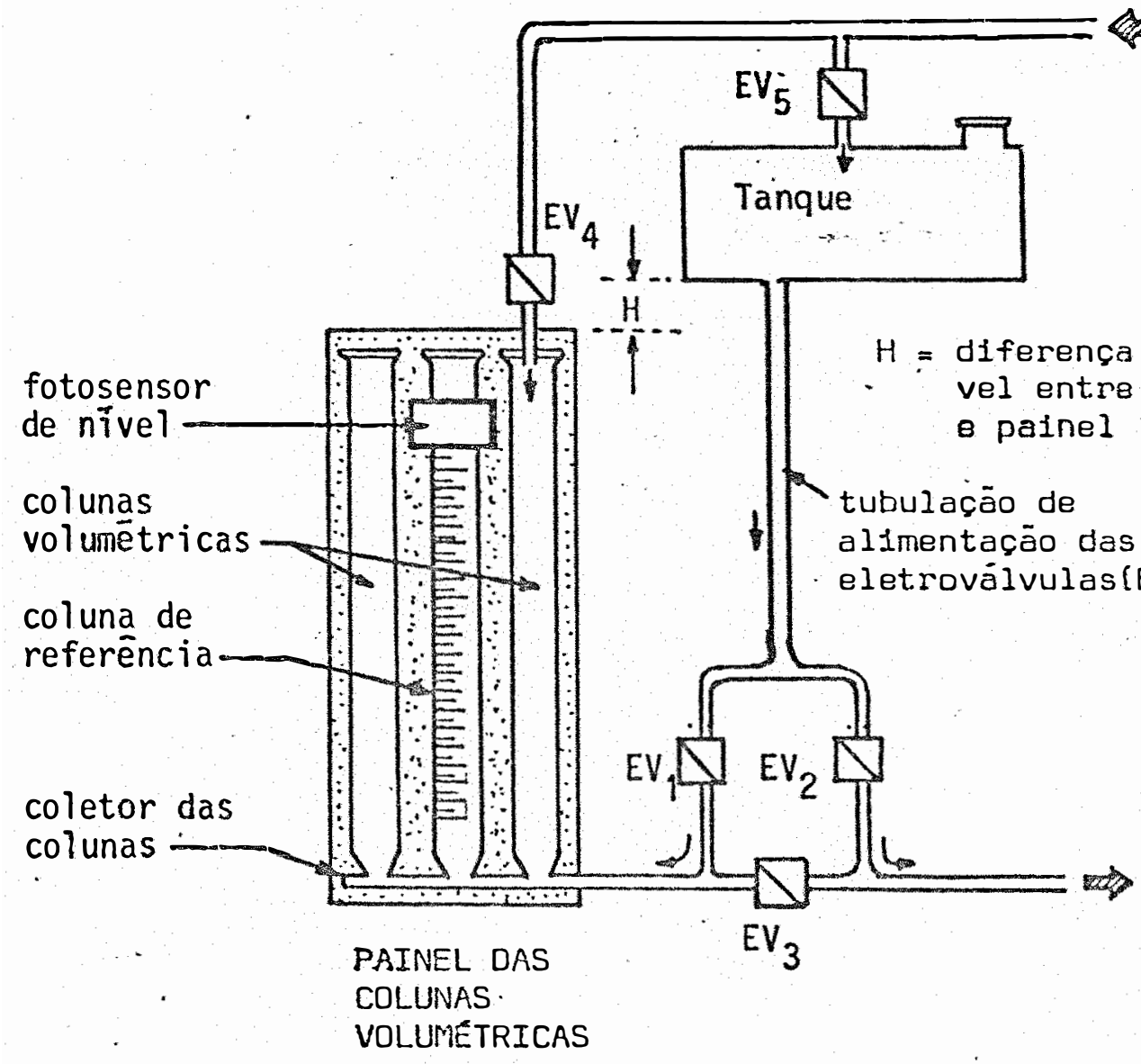

TIVEL DO MOTOR

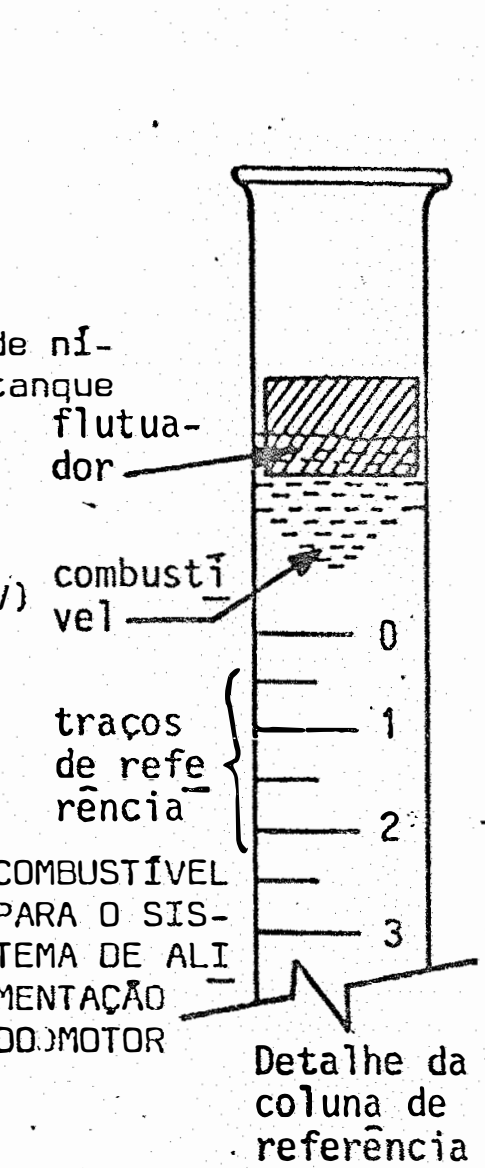

Figura III.3 - Esquema do medidor de consumo Fonte: MIALHE, L.G. Ensaios de Tratores Agricolas em Solos Cultivados. (Seminário, GFE/DER/ESALQ-USP, 1983).

As eletrováluulas permitem, alternativamente, - enchimento das buretas com o combustivel contido no tanque, o consumo pelo motor do combustivel contido nas buretas, consumo pelo motor diretamente do tanque e o retorno do combustível não consumido pelo motor ao tanque ou às buretas.

o fotosensor de nível está instalado na bureta central e quando da passagem do flutuador pelo traço de referência correspondente ao nível zero, emite um sinal elétrico. Este sinal permite o acionamento simultâneo dos sensores, ins 
talados na roda odométrica e no eixo do $\mathrm{Tt}$, e do cronômetro; a interrupção deste sistema, (final de ensaio), é realizada a partir do comando instalado no painel do cronodômetro, desligando simultanemente os sensores, cronômetro e o consumo do combustivel pelas buretas.

\section{III.3.2. Calibração}

O sistema de medição foi calibrado antes do iní cio dos ensaios, utilizando-se para tanto de um recipiente graduado em $\mathrm{ml}$.

Foram efetuadas 10 determinações e a equação ob tida é apresentada como se segue:

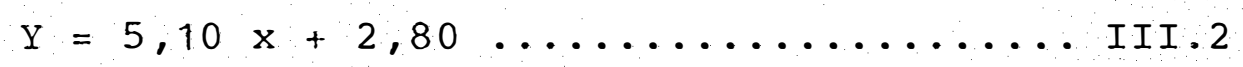

onde

$\mathrm{x}=$ valor lido, em $\mathrm{ml}$, na bureta central, na fa ce inferior do flutuador.

$Y=$ volume em $\mathrm{ml}$, referente ao valor lido na bu reta central, e corresponde à notação CC do item 3.2.2.6.

O coeficiente de determinação $\left(r^{2}\right)$ obtido para a equação foi 0,99977 . 
Apêndice IV

Neste Apêndice, são apresentadas a's terminologias sobre tração para rodados empregados nesta pesquisa, ten do como base a padronização ASAE S 296.2; apresenta-se também a metodologia para cálculo dạs variáveis utilizadas.

\section{IV - 1 Terminologia}

.) Lastro - qualquer peso que pode ser acoplado ou removido de um trator ou veículo similar, com o propósito de alterar seu peso total ou a distribuição de peso.

-) Eficiência tratória - razão entre a potência útil e a potência motora.

-) Potência na barra de tração - produto da velocidade do trator pela tração na barra, na direção de deslocamento.

.) Potência motora - produto do torque nas semi -árvores motoras do rodado por sua velocidade angular.

.) Potência útil - produto de tração líquida pe la velocidade avanço do rodado.

.) Tração na barra - força desenvolvida, na direção do deslocamento, na barra de tração do trator.

-) Patinamento - movimento relativo na direção do deslocamento, na superfície mútua de contato do rodado de tração e a superfície de patinamento. Patinamento e redução de deslocamento são usados como sinônimos e frequen- 
temente expressos em percentagem (\%).

-) Tração líquida - força na direção do deslocamento, desenvolvida pelo rodado de tração e transferido ao chassi do trator ou veícu10 .

-) Razão dinâmica de tração - razão entre a tração na barra de um veículo e a carga dinâmica aplicada sobre o rodado de tração deste veículo.

IV - 2 Metodologia de cálculo

.) Tração na barra - Ft (kN)

A tração na barra é fornecida pela média dos valoŕes obtidos em cada ensaio. O equipamento (célula de carga) imprime os valores em kgf (ver item 3.2.2.3), sendo a conversão realizada através das relações:

$$
\begin{aligned}
& 1 \mathrm{kgf}=9.81 \mathrm{~N} \\
& 1 \mathrm{kN}=1000 \mathrm{~N}
\end{aligned}
$$

-) Potência na barra - Pb (kT)

A potência na barra ( $\mathrm{Pb}$ ) para cada ensaio é ob tida pela equação:

$\mathrm{Pb}(\mathrm{kW})=\mathrm{Ft}(\mathrm{kN}) \cdot \mathrm{Vt}(\mathrm{m} / \mathrm{s})$ IV 1

onde:

Vt é a velocidade média de deslocamento do Tt durante o ensaio é (ver item 3.2.2.4).

-) Razão dinâmica de tração - Rdt(\%)

A razão dinâmica de tração (Rdt) para cada ensaio é obtida pela equação:

$$
\text { Rdt }=\frac{\text { Ft }(\mathrm{kN})}{\text { Wd }(\mathrm{kN})} \cdot 100 .
$$

onde

Wd é a carga dinâmica aplicada sobre o rodado traseiro do Tt dada por: 


$$
\begin{aligned}
& \text { Wd }=\text { We }+F t \frac{\mathrm{y}}{\mathrm{x}} \\
& \mathrm{y}=\text { altura da barra de tração do } \mathrm{Tt} \mathrm{em} \mathrm{mm.} \\
& \mathrm{x}=\text { distância entre eixos do } \mathrm{Tt} \mathrm{em} \mathrm{mm} . \\
& \text { We }=\text { carga estática sobre o rodado traseiro. } \\
& \text { Os valores de We, y e } \mathrm{x} \text { são apresentados no A- }
\end{aligned}
$$
pêndice II.

-) Consumo especifico de combustivel - C. esp (ml/kW.h)

o consumo especifico de combustivel (C. esp)

(ml/kW.h) para cada ensaio é obtido pela equação:

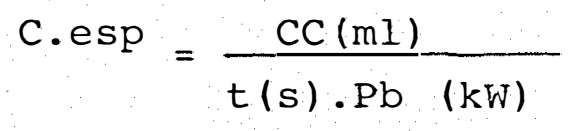

onde

$$
\begin{aligned}
C C= & \text { consumo de combustível - ver Apêndice } \\
& \text { III, equação III. } 2 . \\
t= & \text { tempo de duração do ensaio. }
\end{aligned}
$$


103.

Apêndice V

Neste Apêndice, são apresentados os quadros da análise de variāncia, as equações polinomiais até grau 4, bem como o coeficiente de determinação obtidos para os quatro pneus e condição de lastragem (SL e CL) .

* analise da VARIAVEl fT RN - arQUivo: A/SL * *

**********************************************************

QUADRO DA ANALISE DE VARIANCIA

\begin{tabular}{lrlrrr}
\hline CAUSAS DA UARIACAO & G.L. & S.0. & Q.K. & UALOR F & PROB.IF \\
\hline REGRESSAO LINEAR & 1 & 80.2340007 & 80.2340007 & 250.81820 & 0.00001 \\
REGRESSAD QULDR. & 1 & 12.0653449 & 12.0653449 & 37.71728 & 0.00025 \\
REGRESSAO CUBICA & 1 & 2.7649788 & 2.7649788 & 8.64356 & 0.01431 \\
REGRESSAO GRAU 4 & 1 & 0.7465832 & 0.7465832 & 2.33388 & 0.15512 \\
DESUIOS DE REGR. & 10 & 3.1988907 & 0.3198891 & & \\
\hline
\end{tabular}

EQUACOES POLINOHIAIS

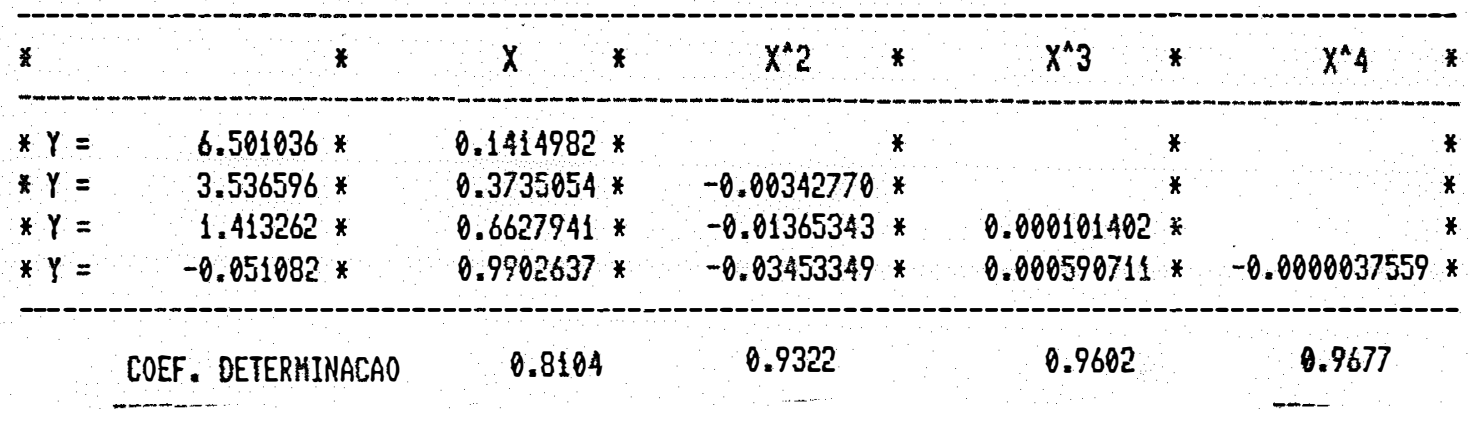


* ANALISE DA VARIAUEL POT KH - ARQUIVO A/SL * *

****************************************************************

QUADRO DA ANALISE DE VARIANCIA

\begin{tabular}{|c|c|c|c|c|c|}
\hline CAUSAS DA VARIACAO & G.L. & S.A. & Q.H. & VALOR $F$ & PROB.IF \\
\hline REGRESSAO LINEAR & 1 & 1.0943920 & 1.8943920 & 5.86800 & 0.03441 \\
\hline REGRESSAO QUADR. & 1 & 29.9992963 & 29.9992963 & 160.853265 & 0.00001 \\
\hline REGRESSAO CUBICA & 1 & 9.0628109 & 9.0628109 & 48.59371 & 0.00013 \\
\hline REGRESSAO GRAU 4 & 1 & 2.1722767 & 2.1722767 & 11.64749 & 0.00668 \\
\hline DESUIOS DE REGR. & 10 & 1.8650173 & 0.1865017 & & \\
\hline
\end{tabular}

EQUACOES POLINOHIAIS

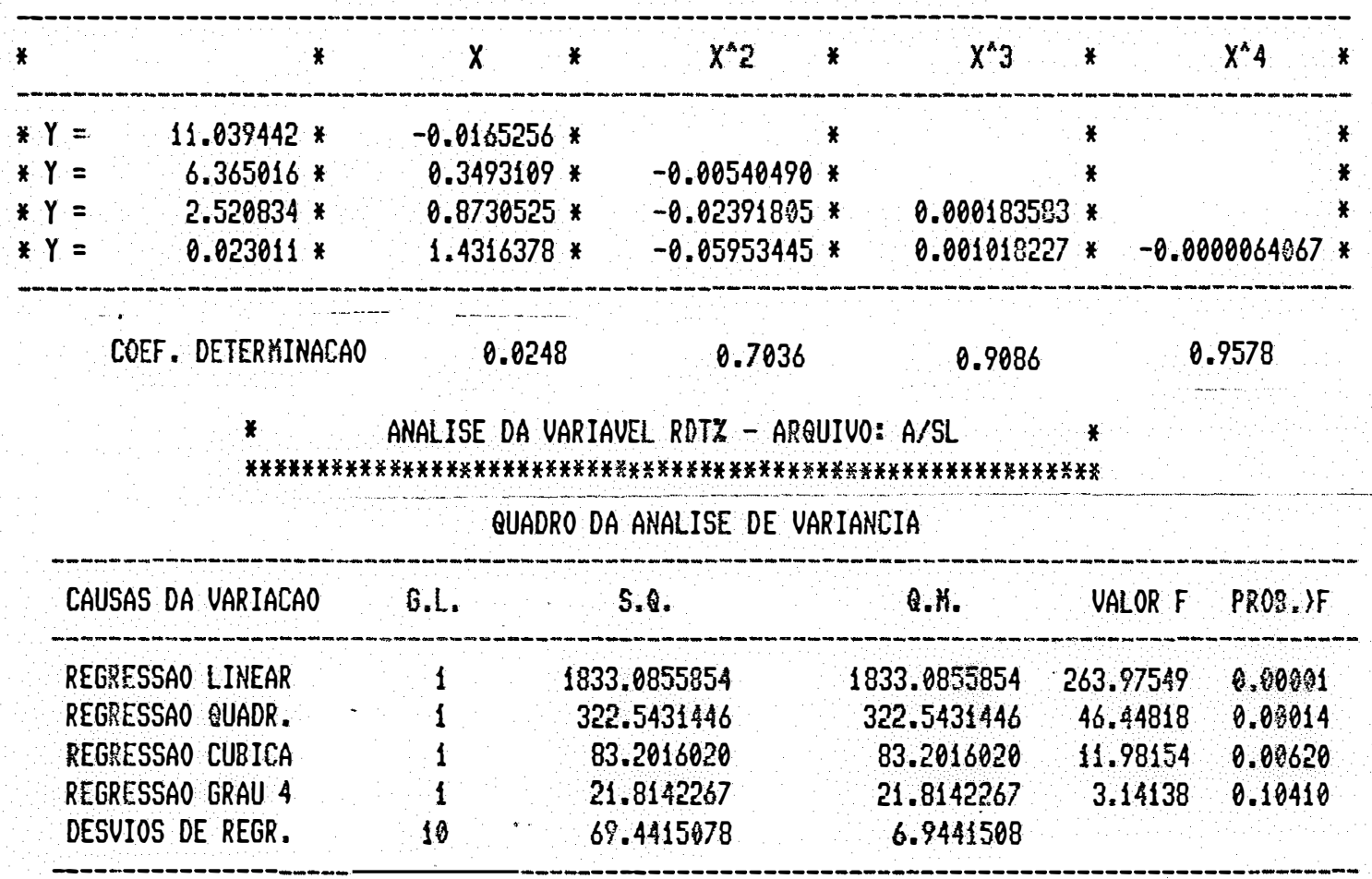

EQUACOES POLINOHIAIS

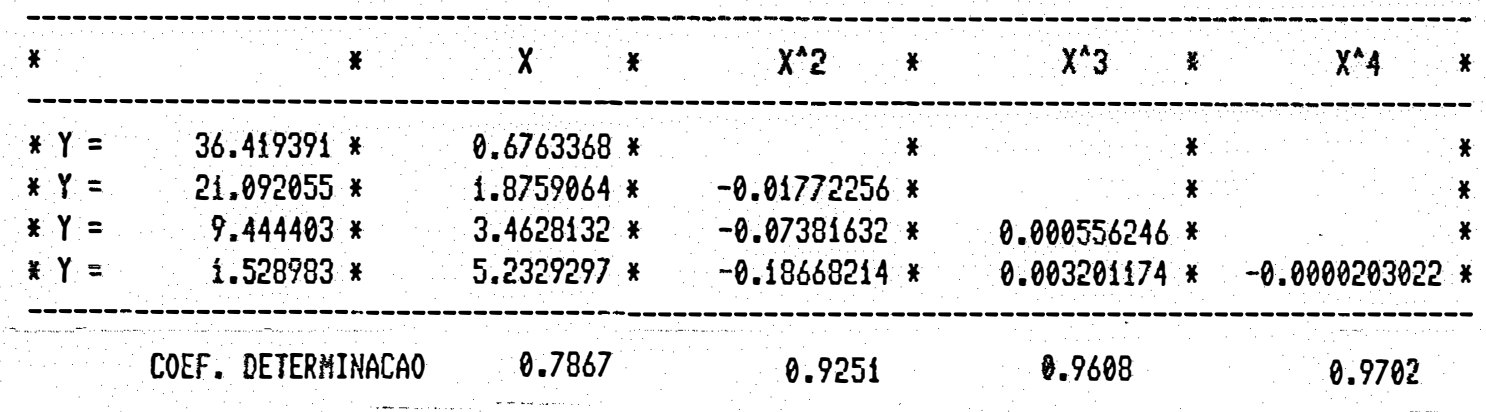


* ANALISE dA VARIAVEL CONS.ESP - ARQUIVO: A/SL *

******************************************************

QUADRO DA ANALISE DE VARIANCIA

\begin{tabular}{|c|c|c|c|c|c|}
\hline CAUSAS DA UARIACAO & G.L. & S.Q. & Q.H. & VALOR $F$ & PROB. IF \\
\hline REGRESSAO LINEAR & 1 & 204483.8652101 & 204483.8652101 & 196.56796 & 0.00001 \\
\hline REGRESSAO QUADR. & 1 & 277296.4219151 & 277296.4219151 & 266.56182 & 0.00001 \\
\hline REGRESSAO CUBICA & 1 & 43246.0563888 & 43246.0563888 & 41.57193 & 0.00019 \\
\hline REGRESSAO GRAU 4 & 1 & 29007.9177904 & 29007.9177904 & 27.88497 & 0.00058 \\
\hline DESVIOS DE REGR. & 10 & 10402.7059269 & 1040.2705927 & & \\
\hline
\end{tabular}

EQUACOES POLINOHIAIS

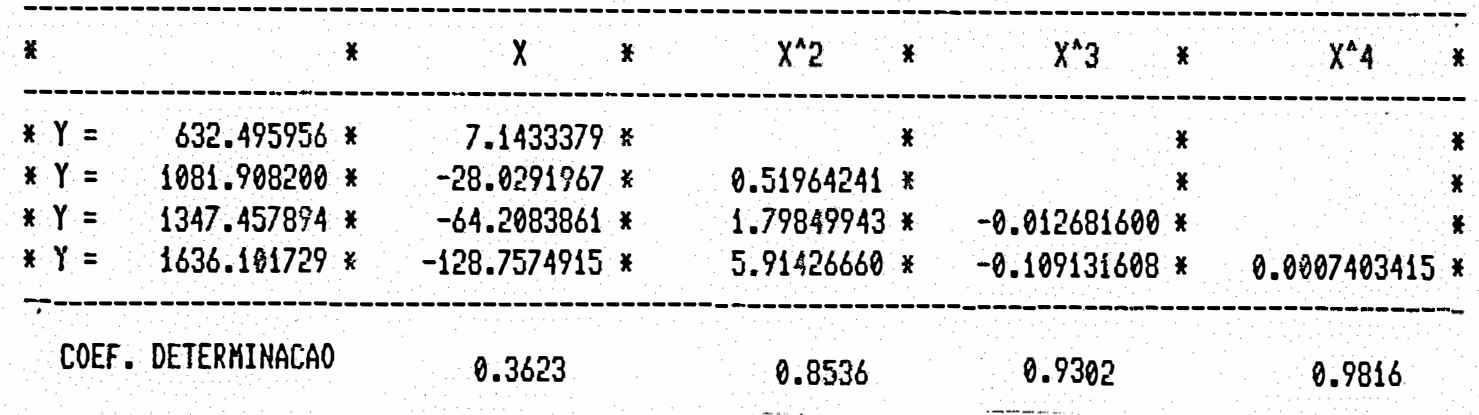

* aNALISE Da VARIAUEL fT KN - ARQUivo: B/SL * *

**************************************************************

QUADRO DA ANALISE DE VARIANCIA

\begin{tabular}{|c|c|c|c|c|c|}
\hline CAUSAS DA VARIACAO & G.L. & S.Q. & Q.M. & VALOR $F$ & PROB. IF \\
\hline REGRESSAO LINEAR. & 1 & 170.5521798 & 170.5521798 & 609.44942 & 0.00001 \\
\hline REGRESSAO QUADRR. & 1 & 32.9099321 & 32.9099323 & 117.60002 & 0.00091 \\
\hline REGRESSAO CUEICA & 1 & 8.3003292 & 8.3003292 & 29.56031 & 0.00030 \\
\hline REGRESSAO GRAU A & 1. & 0.9349828 & 0.9349828 & 3.34106 & 0.08972 \\
\hline DESUIOS DE REGR. & 12 & 3.3581559 & 0.2798463 & & \\
\hline
\end{tabular}

EOUACOES POLINOMIAIS

\begin{tabular}{|c|c|c|c|c|c|c|c|}
\hline * & * & $x$ & * & $x^{\wedge} 2$ & * & $x^{\wedge} 3$ & $x^{\wedge} 4$ \\
\hline$* Y=$ & $5.360702 *$ & 0.1848839 & * & & $*$ & * & * \\
\hline$* Y=$ & $1.773279 *$ & 0.5072959 & $*$ & -0.00510238 & * & * & * \\
\hline$* Y=$ & $-0.830900 *$ & 0.9330514 & $*$ & -0.02126758 & $*$ & $0.000168132 *$ & * \\
\hline$* Y=$ & $-2.217857 *$ & 1.2671568 & $*$ & -0.04280758 & $*$ & $0.000673992 *$ & $-0.0000039021 *$ \\
\hline \multicolumn{2}{|c|}{ COEF. DETERMINACAO } & \multicolumn{2}{|l|}{0.7894} & 0.9417 & & 0.9801 & 0.9845 \\
\hline
\end{tabular}


* aNALISE DA VARIAVEL POT KW - ARQUIVO: $B / S L$ *

********************************************************

QUADRO DA ANALISE DE VARIANCIA

\begin{tabular}{|c|c|c|c|c|c|}
\hline CAUSAS DA UARIACAO & G.L. & S. 0. & Q.H. & VALOR F & PROB.JF \\
\hline REGRESSAO LINEAR & 1 & 0.6661562 & 0.6661562 & 2.35423 & 0.14816 \\
\hline REGRESSAO QUAAR. & 1 & 51.3239549 & 51.3239549 & 181.38114 & 0.00001 \\
\hline REGRESSAO CUBICA & 1 & 6.0592064 & 6.0592064 & 21.41351 & 0.00083 \\
\hline REGRESSAO GRAU 4 & 1 & 0.0158100 & 0.0158100 & 0.05587 & 0.81152 \\
\hline DESUIOS DE REGR. & 12 & 3.3955429 & 0.2829619 & & \\
\hline
\end{tabular}

EOUAOES POLINOHIAIS

\begin{tabular}{|c|c|c|c|c|c|c|c|c|}
\hline * & * & $x$ & * & $x^{\wedge} 2$ & * & $x^{\wedge} 3$ & * & $x^{\wedge} 4$ \\
\hline$* Y=$ & $10.448476 *$ & $0.0115547 *$ & * & & $*$ & & $*$ & 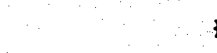 \\
\hline$* Y=$ & $5.968465 *$ & $0.4141862 *$ & $*$ & -0.00637191 & * & & * & \\
\hline$* Y=$ & 3.743459 * & $0.7779508 *$ & * & -0.02018342 & $*$ & 0.000143651 & $*$ & \\
\hline$* Y=$ & 3.923813 * & $0.7345050 *$ & * & -0.01738244 & * & 0.000077871 & $*$ & 0.0000005074 \\
\hline
\end{tabular}

* aNalise da VaRIAVEL RDTY - ARQUiVO: B/SL

************************************************************

QUADRO DA ANALISE DE VARIANCIA

\begin{tabular}{lrrrrr}
\hline CAUSAS DA VARIACAO & G.L. & S.Q. & Q.H. & UALOR F & PROB. IF \\
\hline REGRESSAO LINEAR & 1 & 4011.4986156 & 4011.4986156 & 498.71579 & 0.00001 \\
REGRESSAO QUADR. & 1 & 898.3187424 & 898.3197424 & 111.685339 & 0.00001 \\
REGRESSAO CUBICA & 1 & 244.9474680 & 244.9474680 & 30.45225 & 0.00028 \\
REGRESSAO GRAU 4 & 1 & 36.0889422 & 36.0889422 & 4.48663 & 0.05345 \\
DESUIOS DE REGR. & 12 & 96.5238812 & 8.0436568 & & \\
\hline
\end{tabular}

EQUACOES POLINOHIAIS

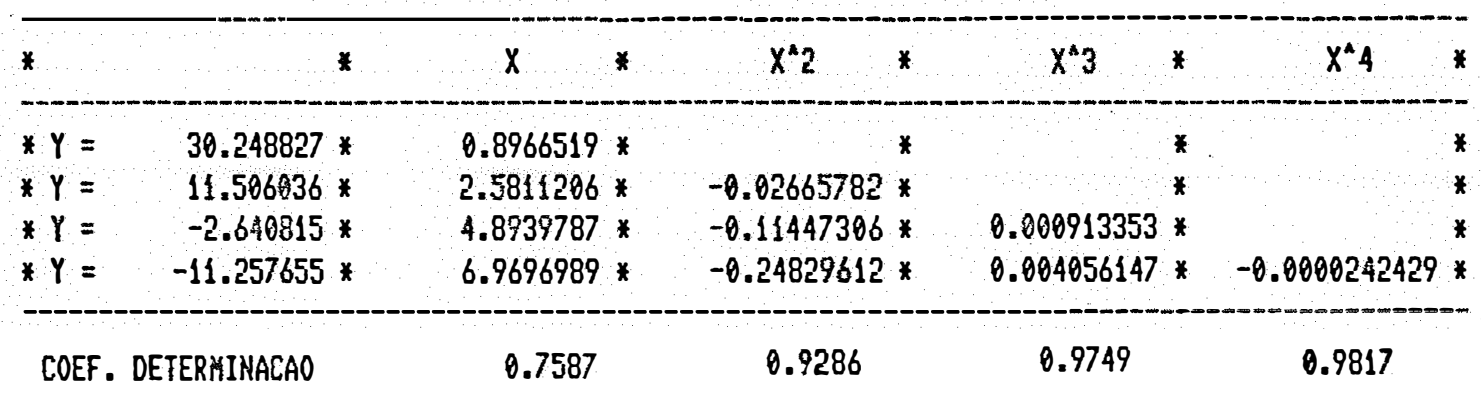


- ANALISE DA UARIAUEL CONS.ESP - ARQUIUO B/SL *

**********************************************************)

QUAORO DA ANALISE DE VARIANCIA

\begin{tabular}{|c|c|c|c|c|c|}
\hline CAUSAS DA UARIACAO & G.L. & S.8. & Q.H. & VALOR F & PROB.IF \\
\hline REGRESSAO LINEAR & 1 & 199996.2381813 & 199996.2381813 & 88.48376 & 0.00001 \\
\hline REGRESSAO QUADR. & 1 & 208495.0612751 & 208495.0612751 & 92.24387 & 0.00001 \\
\hline REGRESSAO CUBICA & 1 & 1159.8759194 & 1159.8759194 & 0.51316 & 0.50652 \\
\hline REGRESSAO GRAU 4 & 1 & 760.4637752 & 760.4637752 & 0.33645 & 0.57831 \\
\hline DESUIOS DE REGR. & 12 & 27123.1117483 & 2260.2593124 & & 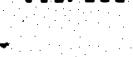 \\
\hline
\end{tabular}

EQUACOES POLINOHIAIS

\begin{tabular}{|c|c|c|c|c|c|c|c|c|}
\hline * & * & $x$ & $*$ & $x^{\wedge} 2$ & * & $x^{\wedge} 3$ & * & $x^{\wedge} 4$ \\
\hline$* y=$ & $644.232195 *$ & 6.3311337 & * & & $*$ & & $*$ & \\
\hline$* Y=$ & $929.772167 *$ & -19.3311667 & $*$ & 0.40612267 & * & & $*$ & \\
\hline$* y=$ & $960.556451 *$ & -24.3640665 & $*$ & 0.59721320 & * & -0.001987503 & $*$ & \\
\hline$* \gamma=$ & $1000.111346 *$ & -33.8924890 & * & 1.21151693 & $*$ & -0.016414239 & $x$ & 0.0001112829 \\
\hline
\end{tabular}

* analise da variavel fT KN - arguivo: C/SL *

*********************************************************

QUADRO DA ANALISE DE VARIANCIA

\begin{tabular}{|c|c|c|c|c|c|}
\hline CAUSAS DA VARIACAO & G.L. & S.Q. & Q.H. & VALOR F & PROB. $/ F$ \\
\hline REGRESSAO LINEAR & 1 & 41.0564540 & 41.0564540 & 156.51552 & 0.00092 \\
\hline REGRESSAO QUADR. & 1 & 16.4416289 & 16.4416289 & 62.67882 & 0.00010 \\
\hline REGRESSAO CUBICA & 1 & 0.0230934 & 0.0230934 & 0.08804 & 0.76955 \\
\hline REGRESSAO GRAU 4 & 1 & 0.5386752 & 0.5386752 & 2.05354 & 0.18364 \\
\hline DESUIOS DE REGR. & 9 & 2.3608399 & 0.2623155 & & \\
\hline
\end{tabular}

EOUACOES POLINOHIAIS

\begin{tabular}{|c|c|c|c|c|c|c|c|c|}
\hline$*$ & * & $x$ & * & $x^{\wedge} 2$ & * & $x^{a} 3$ & * & $x^{4}$ \\
\hline$* Y=$ & $7.053596 *$ & 0.1118306 & * & & $*$ & & $x$ & n \\
\hline$* y=$ & $3.286037 *$ & 0.4302799 & * & -0.00510614 & * & & $\star$ & * \\
\hline$* Y=$ & $3.491595 *$ & 0.3998323 & * & -0.00395361 & $*$ & -0.0000012391 & $*$ & . \\
\hline$* Y=$ & 1.666917 * & 0.8073061 & $*$ & -0.03001429 & $*$ & 0.000609326 & * & $-0.0000049383 *$ \\
\hline COEF & ERHINACAO & 0.6795 & & 0.9516 & & 0.9520 & & 0.9609 \\
\hline
\end{tabular}


* analise da variavel pot KW - arQUivo: C/SL *

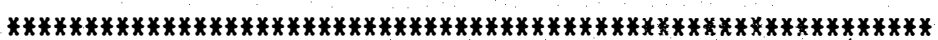

QUADRO DA ANALISE DE VARIANCIA

\begin{tabular}{llrrrr}
\hline CAUSAS DA UARIACAO & G.L. & S.Q. & 0.1. & UALOR F & PROB. IF \\
\hline REGRESSAO LINEAR & 1 & 2.2848412 & 2.2848412 & 12.53148 & 0.00642 \\
REGRESSAO QUADR. & 1 & 30.5012036 & 30.5012036 & 167.28742 & 0.00001 \\
REGRESSAO CUBICA & 1 & 0.6529277 & 0.6529277 & 3.58106 & 0.08858 \\
REGRESSAO GRAU 4 & 1 & 0.0810096 & 0.0810096 & 0.44431 & 0.52729 \\
DESVIOS DE REGR. & 9 & 1.6409533 & 0.1823281 & & \\
\hline
\end{tabular}

EOUACOES POLINOHIAIS

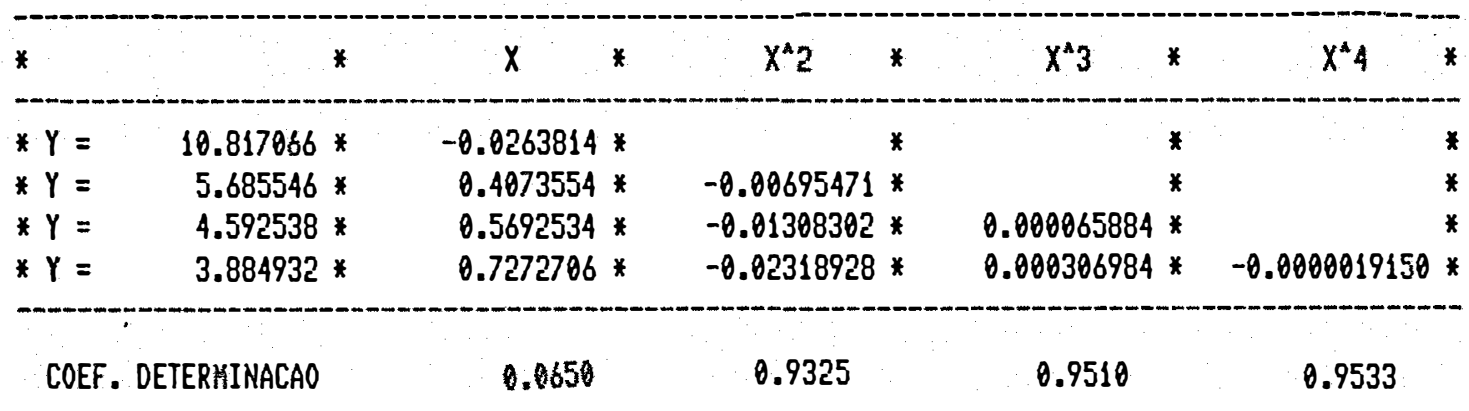

* aNAlise da VARIAVEl RDTZ - ARQUIVO: C/SL *

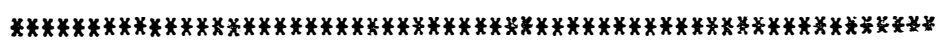
QUADRO DA ANALISE DE VARIANCIA

\begin{tabular}{lrrrrr}
\hline CAUSAS DA VARIACAO & G.L. & S.Q. & Q.K. & UALOR F & PROB. IF \\
\hline REGRESSAO LINEAR & 1 & 960.6946174 & 960.6946174 & 171.38038 & 0.00001 \\
REGRESSAO QUADR. & 1 & 400.3679256 & 400.3679256 & 71.42250 & 0.00008 \\
REGRESSAO CUBICA & 1 & 0.0002018 & 0.0002018 & 0.00004 & 0.99112 \\
REGRESSAO GRAU 4 & 1 & 13.4113096 & 13.4113096 & 2.39247 & 0.15400 \\
DESUIOS OE REGR. & 9 & 50.4506497 & 5.6056277 & & \\
\hline
\end{tabular}

EQUACOES

POLINOHIAIS

\begin{tabular}{l}
$*$ * \\
\hline$*$
\end{tabular}


* ANALISE DA VARIAUEL CONS.ESP - ARQUIUO C/SL *

***************************************************************

QUADRO DA ANALISE DE UARIANCIA

\begin{tabular}{lrrrrrr}
\hline CAUSAS OA UARIACAO & G.L. & S.0. & & Q.H. & UALOR F & PROB. IF \\
\hline REGRESSAO LINEAR & 1 & 275493.1389309 & 275493.1389309 & 204.81245 & 0.00001 \\
REGRESSAO QUADR. & 1 & 227228.7060020 & 227228.7060020 & 168.93077 & 0.00001 \\
REGRESSAO CUBICA & 1 & 2538.6253607 & 2538.6253507 & 1.88731 & 0.20097 \\
REGRESSAO GRAU 4 & 1 & 16100.6068304 & 16100.5068304 & 11.96983 & 0.00722 \\
DESVIOS DE REGR. & 9 & 12105.8960631 & 1345.0995626 & & \\
\hline
\end{tabular}

EOUACOES POLINONIAIS

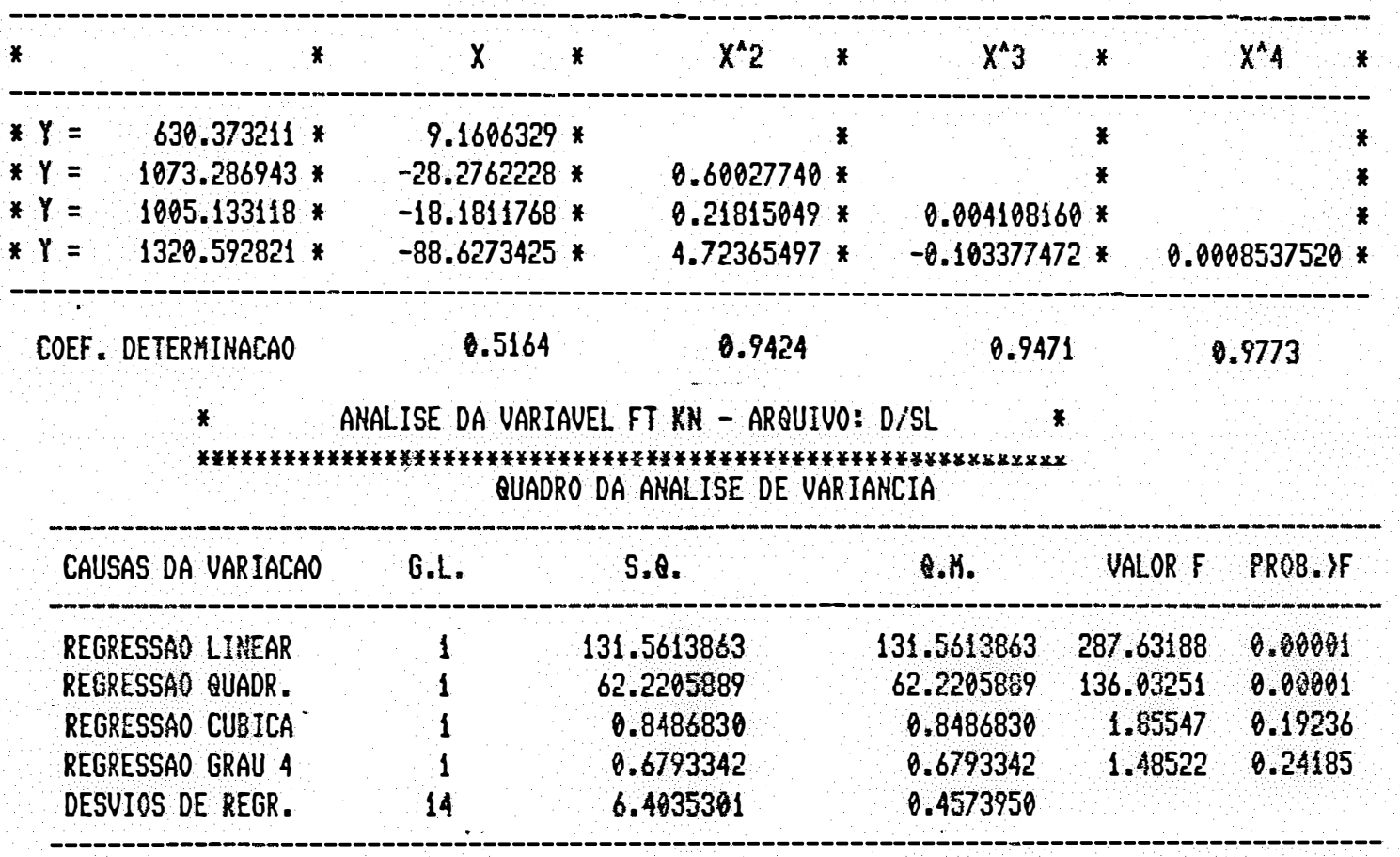

EOUACOES POLINOHIAIS

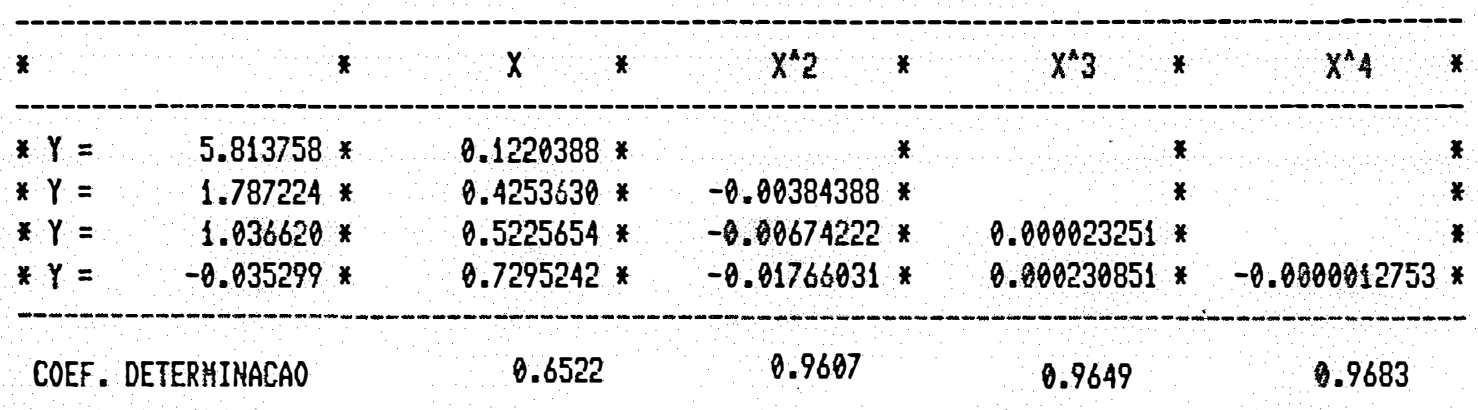


* ANALISE DA VARIAUEL POT KH - ARQUIVO: D/SL * *

*******************************************************

QUADRO DA ANALISE DE VARIANCIA

\begin{tabular}{|c|c|c|c|c|c|}
\hline CAUSAS DA VARIACAO & G.L. & S. & Q.H. & UALOR F & PROB. IF \\
\hline REGRESSAO LINEAR & 1 & 4.4177040 & 4.4177040 & 8.32043 & 0.01162 \\
\hline REGRESSAO QUADR. & 1 & 107.0574931 & 107.0574031 & 201.63508 & 0.00001 \\
\hline REGRESSAO CUBICA & 1 & 11.0907933 & 11.0907933 & 20.88873 & 0.00066 \\
\hline REGRESSAO GRAU 4 & 1 & 1.5684730 & 1.5684730 & 2.95411 & 0.10465 \\
\hline DESUIOS DE REGR. & 14 & 7.4332485 & 0.5309463 & & \\
\hline
\end{tabular}

EOUACOES POLINOHIAIS

\begin{tabular}{|c|c|c|c|c|c|c|c|c|c|}
\hline * & * & $x$ & * & $x^{\wedge} 2$ & * & $x^{\wedge} 3$ & * & $x^{\wedge} 4$ & $*$ \\
\hline$* Y=$ & 9.837668 * & -0.0223631 & * & & * & & * & & $*$ \\
\hline$* Y=$ & 4.555981 * & 0.3755134 & * & -0.00504209 & * & & * & & * \\
\hline$* Y=$ & 1.842545 * & 0.7269004 & * & -0.01551960 & * & 0.000084051 & * & & $*$ \\
\hline$x Y=$ & 0.213778 * & 1.0413715 & * & -0.03210949 & * & 0.000399497 & * & -0.0000019377 & $7 *$ \\
\hline COEF & RMINACAO & 0.0336 & & 9.8473 & & 0.9316 & & 0.9435 & \\
\hline
\end{tabular}

* ANALISE DA VARIAVEL RDT\% - ARQUIVO: D/SL * *

***********************************************************

QUADRO DA ANALISE DE VARIANCIA

\begin{tabular}{lrrrrr}
\hline CAUSAS DA UARIACAO & G.L. & S.Q & O.A. & VALOR F & PROB. $F$ \\
\hline REGRESSAO LINEAR & 1 & 3166.2680417 & 3166.2690417 & 275.99570 & 0.00001 \\
REGRESSAO QUADR. & 1 & 1541.9891206 & 1541.9891206 & 134.41135 & 0.02001 \\
REGRESSAO CUBICA & 1 & 42.9956120 & 42.9956120 & 3.74782 & 0.07958 \\
REGRESSAO GRAU 4 & 1 & 22.6684832 & 22.6684832 & 1.97596 & 0.17911 \\
DESUIOS DE REGR. & 14 & 160.6103010 & 11.4721644 & & \\
\hline
\end{tabular}

EOUACOES POLINOMIAIS

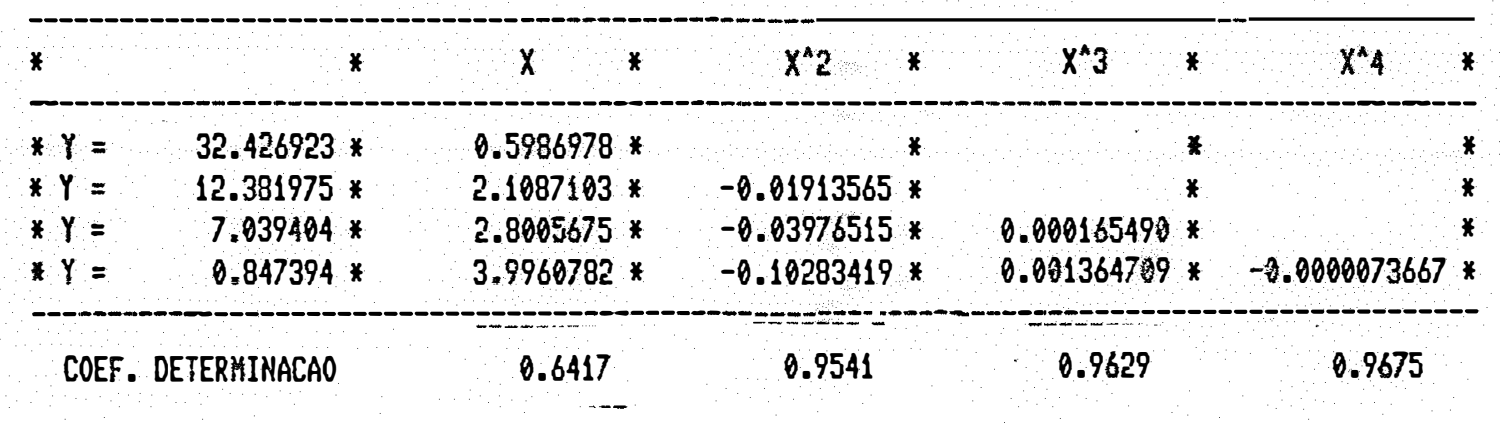


* aNalise da variavel CONS.ESP - arQUIVO: D/SL *

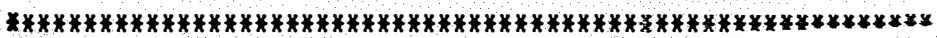
QUADRO DA ANALISE DE UARIANCIA

\begin{tabular}{|c|c|c|c|c|c|}
\hline CAUSAS OA UARIACAO & G.L. & S.Q. & Q.H. & VALOR F & PROB.IF \\
\hline REGRESSAO LINEAR & 1 & 2225701.9985441 & 2221701.9985441 & 187.44790 & 0.00001 \\
\hline REGRESSAO QUADR. & 1 & 2406305.8893488 & 2406385.8893488 & 203.02318 & 0.00001 \\
\hline REGRESSAO CUBICA & 1 & 13390.6808375 & 13390.6808375 & 1.12979 & 0.30648 \\
\hline REGRESSAO GRAU 4 & 1 & 66407.4931861 & 66407.4931861 & 5.60289 & 0.03127 \\
\hline DESUIOS DE REGR. & 14 & 165933.1859716 & 11852.3704265 & 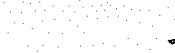 & \\
\hline
\end{tabular}

EOUACOS POLINOHIAIS

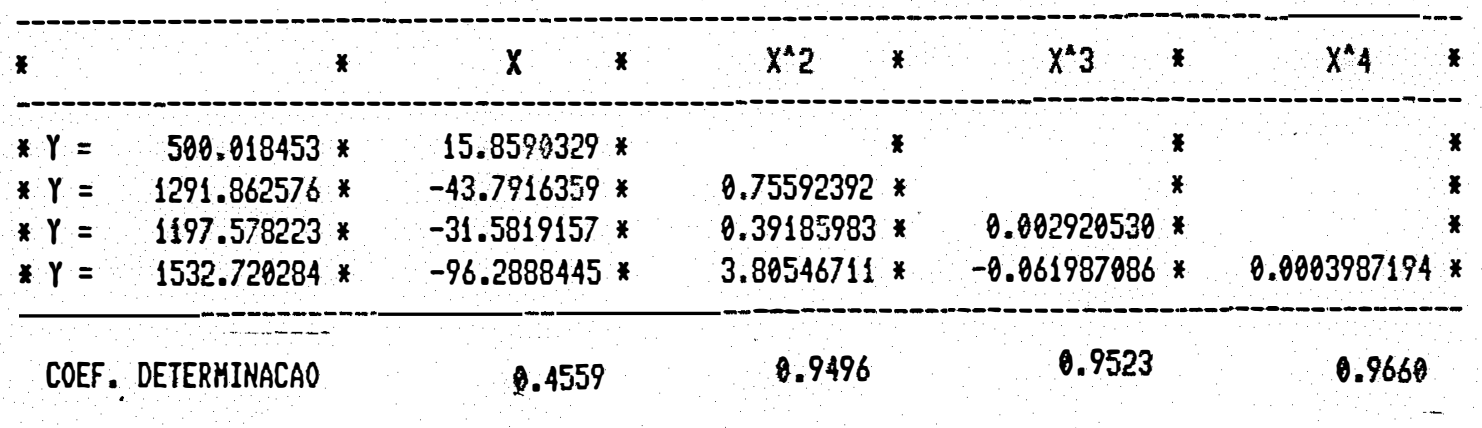

* analise da variavel fT KN - arQUiVO: A/Cl *

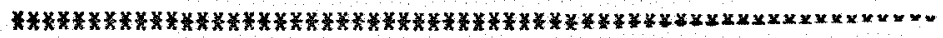

QUADRO DA ANALISE DE VARIANCIA

\begin{tabular}{|c|c|c|c|c|c|}
\hline CAUSAS DA VARIACAO & G.L. & S.8. & Q.H. & VALOR F & PROB. IF \\
\hline REGRESSAO LINEAR & 1 & 190.1428495 & 190.1428495 & 694.12025 & 0.00001 \\
\hline REGRESSAO QUADR. & 1 & 27.6502426 & 27.6502426 & 100.93776 & 0.00001 \\
\hline REGRESSAO CUBICA & 1 & 0.4700718 & 0.4700718 & 1.71601 & 0.2152 \\
\hline REGRESSAO GRAU 4 & 1 & 0.2338984 & 0.2338984 & 0.85385 & 0.62169 \\
\hline DESUIOS OE REGR. & 11 & 3.0132695 & 0.2739336 & & \\
\hline
\end{tabular}

EOUACOES POLIHOHIAIS

\begin{tabular}{|c|c|c|c|c|c|c|c|c|}
\hline * & * & $x$ & * & $x^{\wedge} 2$ & $*$ & $x^{\wedge} 3$ & $*$ & $x^{*} 4$ \\
\hline$* Y=$ & 7.092168 * & 0.1973653 & * & & $*$ & & $x$ & \\
\hline$* Y=$ & 3.956922 * & 0.5097705 & * & -0.00517016 & * & & $\star$ & \\
\hline$* Y=$ & $3.463921 *$ & 0.6028984 & * & -0.00906311 & $*$ & 0.000043635 & * & \\
\hline$* Y=$ & $3.060058 *$ & 0.7298698 & $*$ & -0.01861116 & * & 0.000292904 & * & -0.0000020928 \\
\hline COEF. & MINACAO & 0.8584 & & 0.9832 & & 0.9853 & & 0.9864 \\
\hline
\end{tabular}


* analise da Variauel pot KH - arquivo: a/Cl *

*****************************************************************

QUADRO DA ANALISE DE UARIANCIA

\begin{tabular}{|c|c|c|c|c|c|}
\hline CAUSAS DA YARIACAO & G.L. & S.8. & Q.K. & VALOR $F$ & PROB.JF \\
\hline REGRESSAO LINEAR & 1 & 2.8031548 & 2.8031548 & 8.16922 & 0.01500 \\
\hline REGRESSAO QUADR. & 1 & 75.6509493 & 75.6509493 & 220.46916 & 0.00001 \\
\hline REGRESSAO CUBICA & 1 & 3.1723631 & 3.1723631 & 9.24520 & 0.01095 \\
\hline REGRESSAO GRAU 4 & 1 & 0.1909071 & 0.1989071 & 0.55636 & 0.52285 \\
\hline DESUIOS DE REGR. & 11 & 3.7744982 & 0.3431362 & 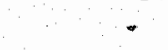 & \\
\hline
\end{tabular}

EOUACOES POLINOMIAIS

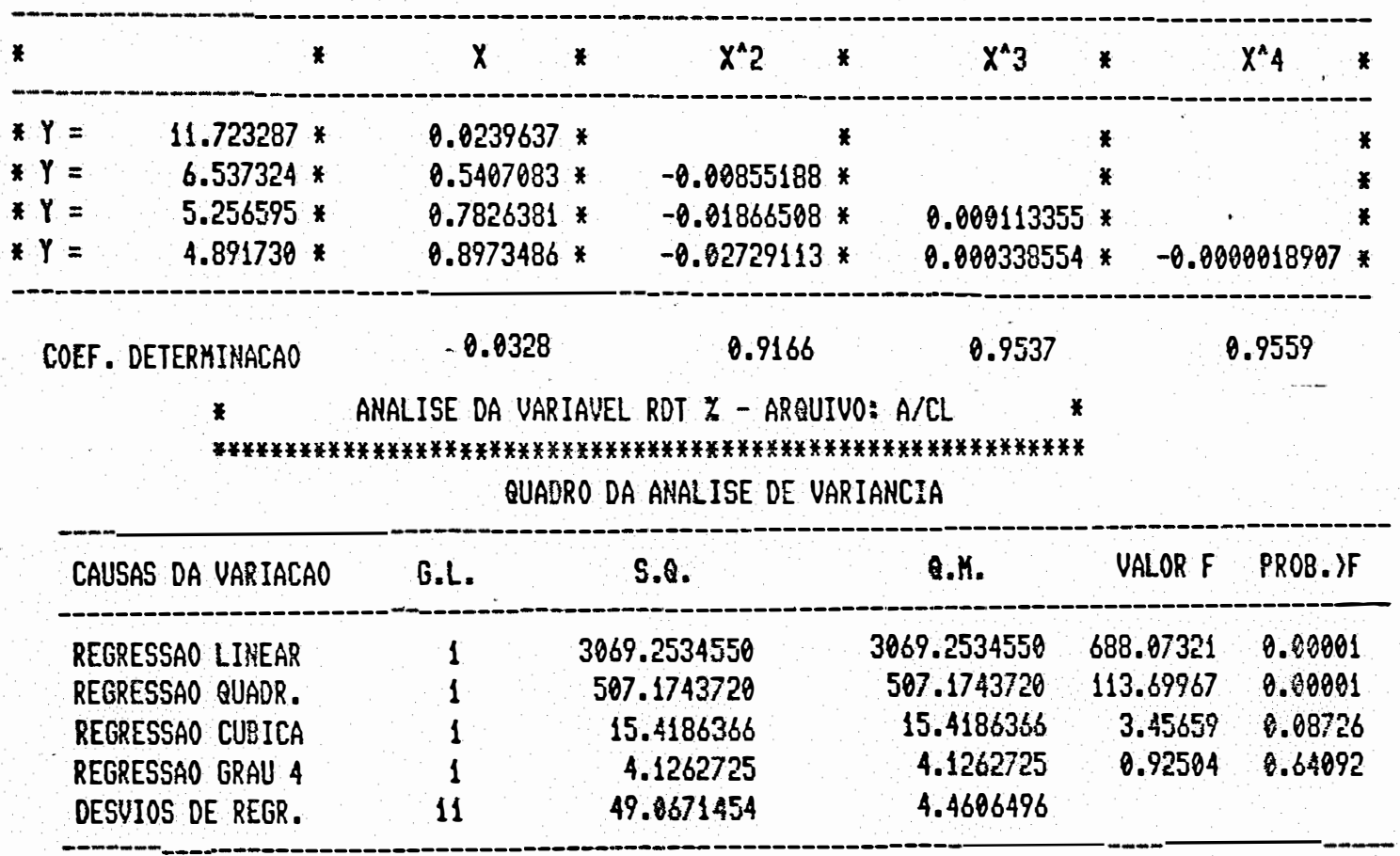

EQUACOES POLINOMIAIS

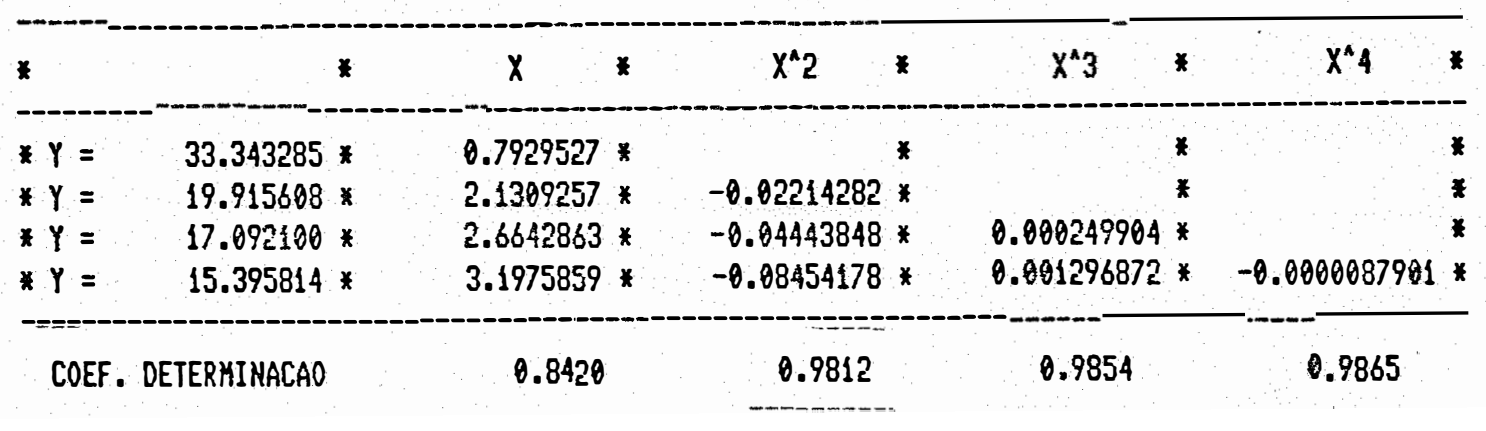


* analise da variavel cons.esp - arQUivo: a/CL

*******************************************************

QUADRO DA ANALISE DE VARIANCIA

\begin{tabular}{lrrrrrr}
\hline CAUSAS DA VARIACAO & G.L. & S.0. & & Q.H. & VALOR F & PROB. IF \\
\hline REGRESSAO LINEAR & 1 & 159914.0061474 & 159914.0061474 & 313.27386 & 0.00001 \\
REGRESSAO GUADR. & 1 & 230347.9029880 & 230347.9029880 & 451.25489 & 0.00001 \\
REGRESSAO CUBICA & 1 & 5946.3168148 & 5946.3168148 & 11.64892 & 0.00588 \\
REGRESSAO GRAU 4 & 1 & 10673.5951069 & 10673.5951009 & 20.90973 & 0.00107 \\
DESUIOS DE REGR. & 11 & 5615.0680982 & 510.4607362 & & \\
\hline
\end{tabular}

EOUACOES POLINONIAIS

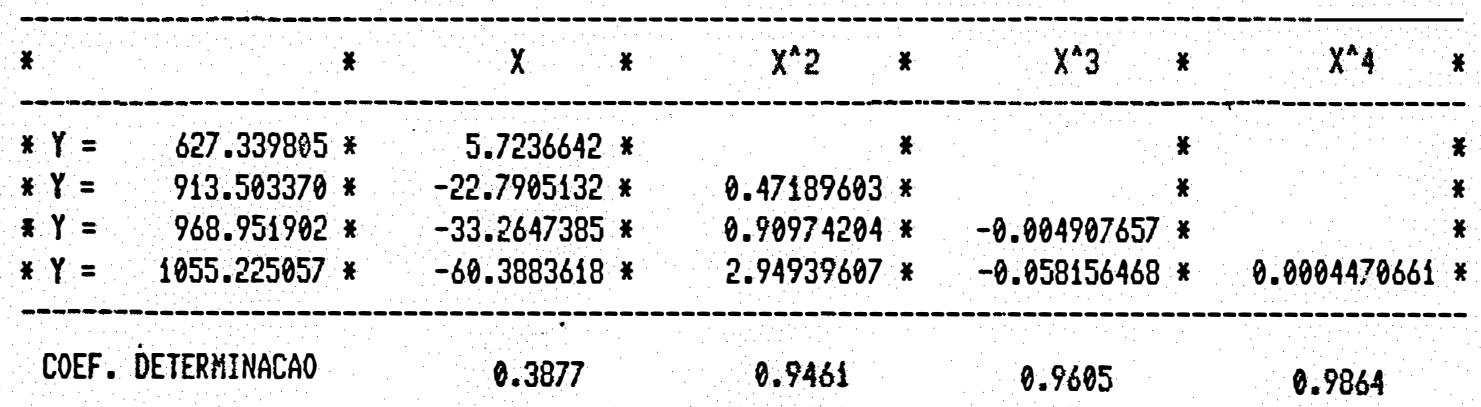

* ANALISE DA VARIAUEL fT KN - ARQUIVO: 8/CL

**********************************************************

- QUADRO DA ANALISE OE VARIANCIA

\begin{tabular}{llllll}
\hline CAUSAS DA VARIACAO & G.L. & S.0. & Q.M. & UALOR F & PROB. IF \\
\hline REGRESSAO LINEAR & 1 & 110.9521113 & 110.9521113 & 176.87802 & 0.00002 \\
REGRESSAO QUADR. & 1 & 32.9555225 & 32.95555225 & 52.53715 & 0.60024 \\
REGRESSAO CUBICA & 1 & 8.9626711 & 8.9626711 & 14.28814 & 0.00560 \\
REGRESSAO GRAU 4 & 1 & 0.8310049 & 0.8310049 & 1.32477 & 0.28297 \\
DESUIOS DE REGR. & 8 & 5.0182430 & 0.6272804 & & \\
\hline
\end{tabular}

EQUACOES POLINOHIAIS

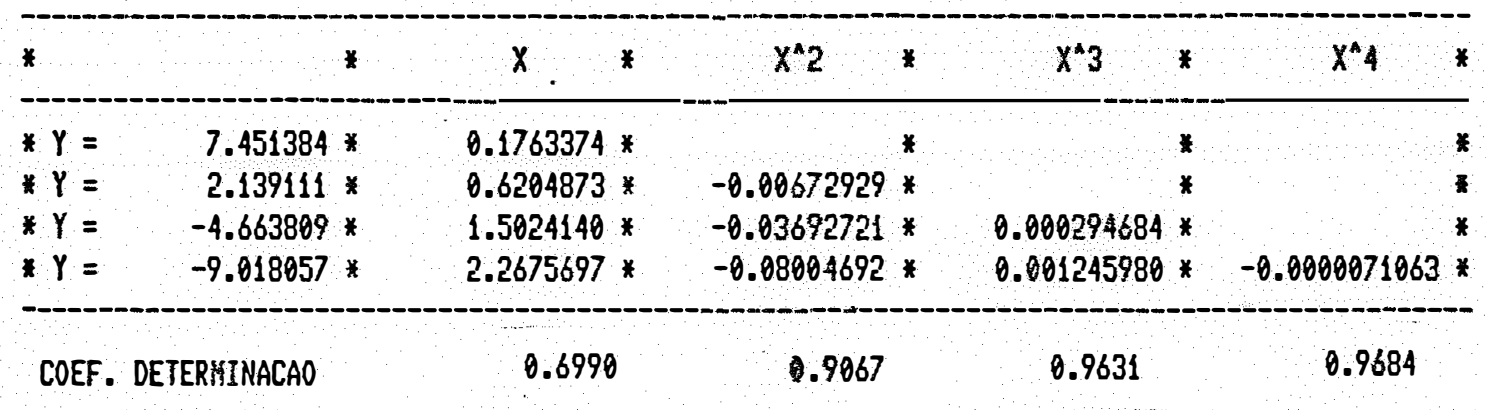


* ANALISE DA VARIAUEL POT KH - ARQUIVO: B/CL *

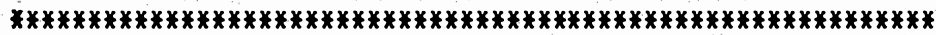

QUADRO DA ANALISE DE VARIANCIA

\begin{tabular}{|c|c|c|c|c|c|}
\hline CAUSAS DA UARIACAO & G.L. & S.Q. & Q.H. & YALOR F & PROB.IF \\
\hline REGRESSAO LINEAR & 1 & 0.0034863 & 0.0034863 & 0.00451 & 0.94666 \\
\hline REGRESSAO QUADR. & 1 & 61.9433323 & 61.9433323 & 80.18528 & 0.90010 \\
\hline REGRESSAO CUBICA & 1 & 13.3341191 & 13.3341191 & 17.26094 & 0.00351 \\
\hline REGRESSAO GRAU 4 & 1 & 1.1188331 & 1.1188331 & 1.44832 & 0.26269 \\
\hline DESUIOS DE REGR. & 8 & 6.1800205 & 0.7725026 & & \\
\hline
\end{tabular}

EOUACOES POLINOHIAIS

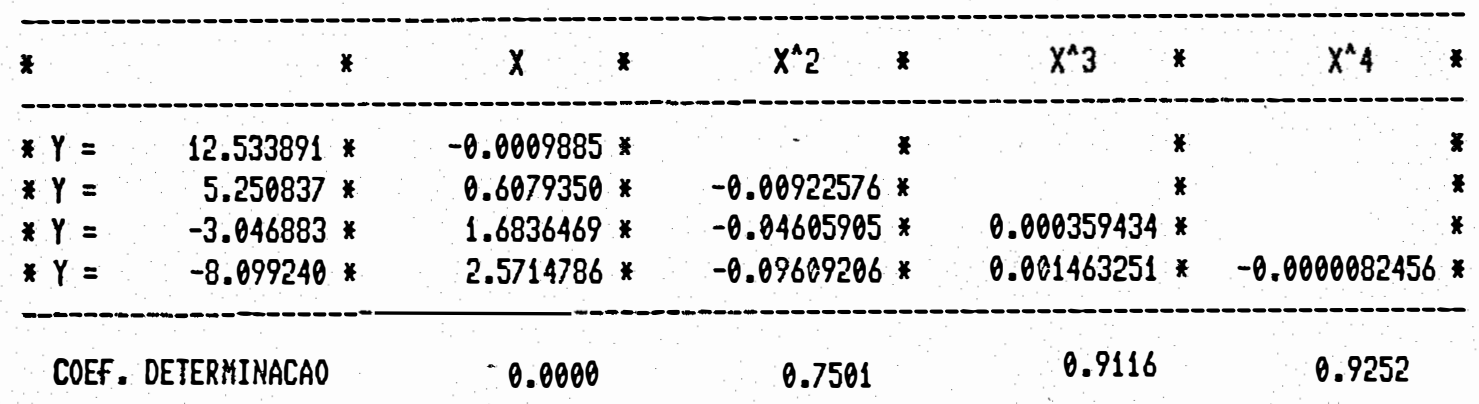

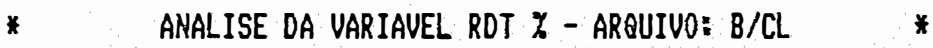

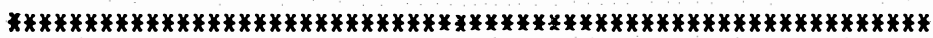

QUADRO DA ANALISE DE VARIANCIA

\begin{tabular}{lllllll}
\hline CAUSAS DA VARIACAO & G.L. & S.Q. & Q.K. & UALOR F & PROB.JF \\
\hline REGRESSAO LINEAR & 1 & 1797.8498838 & 1797.8498838 & 168.24018 & 0.00003 \\
REGRESSAO QUADR. & 1 & 563.3297937 & 563.3297937 & 52.71558 & 0.00023 \\
REGRESSAO CUBICA & 1 & 163.2886292 & 163.2886292 & 15.28031 & 0.00475 \\
REGRESSAO GRAU 4 & 1 & 17.5367646 & 17.5367846 & 1.64106 & 0.23497 \\
DESUIOS DE REGR. & 8 & 85.4896799 & 10.6862100 & & \\
\hline
\end{tabular}

EOUACOES POLINOHIAS

\begin{tabular}{|c|c|c|c|c|c|c|c|c|c|}
\hline * & $*$ & $x$ & $*$ & $x^{\wedge} 2$ & * & $x^{\wedge} 3$ & * & $x^{\wedge} 4$ & \\
\hline$* y=$ & $34.828357 *$ & 0.7098283 & * & & * & & * & & \\
\hline$* Y=$ & $12.865056 *$ & 2.5461418 & * & -0.02782186 & * & & * & & $*$ \\
\hline$* y=$ & $-16.172134 *$ & 6.3105071 & * & -0.15671695 & $*$ & 0.001257811 & $*$ & & $x$ \\
\hline$* Y=$ & $-36.174719 *$ & 9.8254859 & $*$ & -0.35480063 & * & 0.095627887 & $*$ & -0.0000326449 & * \\
\hline COEF & rens & 0.6842 & & 8.8986 & & 0.9608 & & 0.9675 & \\
\hline
\end{tabular}


* aNALISE DA VARIAVEL CONS. ESP - ARQUIVO: B/CL * *

***********************************************************

QUADRO DA ANALISE DE VARIANCIA

\begin{tabular}{|c|c|c|c|c|c|}
\hline CAUSAS DA VARIACAO & G.L. & 5.2 & e.h. & VALOR F & PROB. IF \\
\hline REGRESSAO LINEAR & 1 & 192465.2206096 & 192465.2206096 & 72.49016 & 0.00012 \\
\hline REGRESSAO QUADR. & 1 & 150335.1036517 & 150335.1036517 & 56.62226 & 0.06020 \\
\hline REGRESSAO CUBICA & 1 & 21347.0753367 & 21347.0753367 & 8.04017 & 0.02125 \\
\hline REGRESSAO GRAU 4 & 1 & 3496.7459751 & 3496.7459751 & 1.31702 & 0.28431 \\
\hline DESUIOS DE REGR. & 8 & 21240.4243072 & 2655.0530384 & & \\
\hline
\end{tabular}

EOUACOES POLINOHIAIS

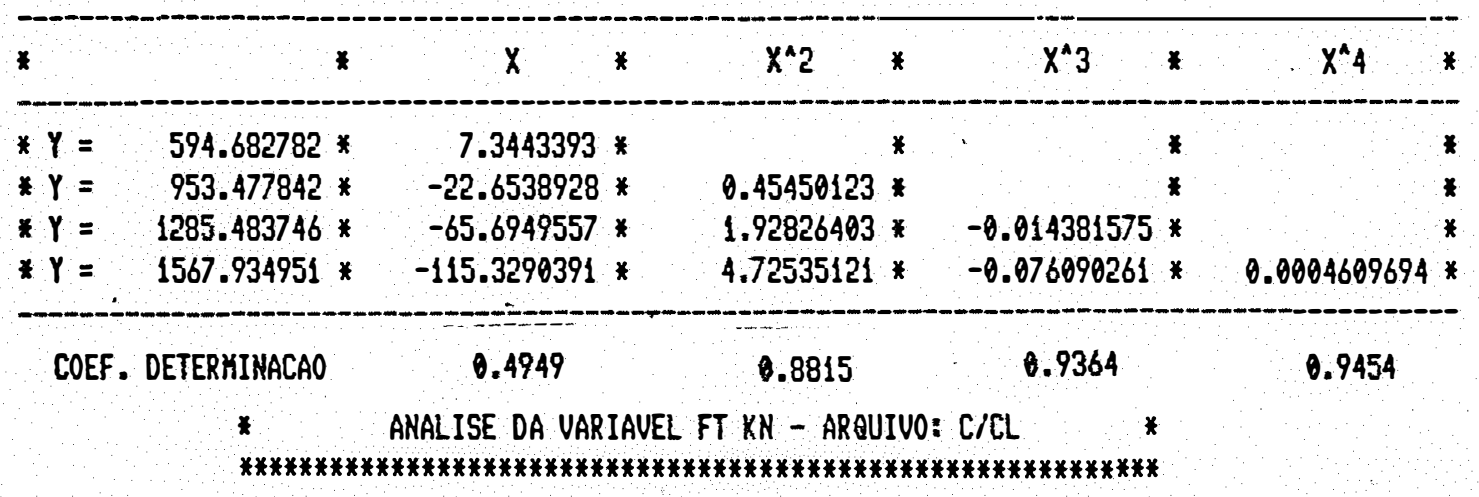

QUADRO DA ANALISE DE VARIANCIA

\begin{tabular}{|c|c|c|c|c|c|}
\hline CAUSAS DA VARIACAO & G.L. & S.e. & Q.H. & VALOR $F$ & PROB. IF \\
\hline REGRESSAO LINEAR & 1 & 102.7701971 & 102.7701971 & 2600.83175 & 0.00001 \\
\hline REGRESSAO QUADR. & 1 & 13.4703290 & 13.4703290 & 340.89707 & 0.00001 \\
\hline REGRESSAO CUBICA & 1 & 0.8691723 & 0.8691723 & 21.99637 & 0.00191 \\
\hline REGRESSAO GRAU 4 & 1 & 0.0030716 & 0.0030716 & 0.07773 & 0.78273 \\
\hline DESUIOS DE REGR. & 8 & 0.3161149 & 0.0395144 & & \\
\hline
\end{tabular}

EOUACES POLINOHIAIS

\begin{tabular}{|c|c|c|c|c|c|c|c|c|c|}
\hline$\star$ & $*$ & $x$ & $*$ & $x^{\star} 2$ & $*$ & $x^{\wedge} 3$ & * & $x^{4} 4$ & $*$ \\
\hline$* Y=$ & $7.720516 *$ & 0.1947108 & $*$ & & * & & $*$ & & * \\
\hline * $Y=$ & $3.594827 *$ & 0.5380623 & $*$ & -0.00556953 & * & & 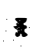 & & z \\
\hline$* Y=$ & $1.997323 *$ & 0.7815102 & * & -0.01526828 & * & 0.000110084 & $*$ & & $\star$ \\
\hline$* Y=$ & $2.168960 *$ & 0.7420894 & * & $-\hat{0} .01261592$ & $*$ & 0.000042521 & $*$ & 0.0000005774 & $*$ \\
\hline COEF & RMINACAO & 0.8752 & & 0.9899 & & 0.9973 & & 0.9973 & \\
\hline
\end{tabular}


* ANALISE DA VARIAUEL POT KW - ARQUIUO: $C / C L$ *

******************************************************

QUADRO DA ANALISE DE VARIANCIA

\begin{tabular}{|c|c|c|c|c|c|}
\hline CAUSAS DA UARIACAO & G.L. & s.e. & Q.H. & VALOR F & PROB.JF \\
\hline REGRESSAO LINEAR & 1 & 0.4311705 & 0.4311705 & 9.67485 & 0.01411 \\
\hline REGRESSAO QUADR. & 1 & 33.4788297 & 33.4788297 & 751.21739 & 0.00001 \\
\hline REGRESSAO CUBICA & 1 & 2.2210773 & 2.2210773 & 49.83782 & 0.00027 \\
\hline REGRESSAO GRAU 4 & 1 & 0.0777087 & 0.0777087 & 1.74367 & 0.22187 \\
\hline DESUIOS DE REGR. & 8 & 0.3565288 & 0.0445661 & & \\
\hline
\end{tabular}

EOUACOES POLINOHIAIS

\begin{tabular}{|c|c|c|c|c|c|c|c|c|c|}
\hline$*$ & $x$ & $x$ & $*$ & $x^{A} 2$ & * & $x^{\wedge} 3$ & * & $x^{\wedge} 4$ & 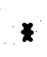 \\
\hline$Y=$ & $12.586342 *$ & 0.0126119 & $*$ & & * & & * & & ¿ \\
\hline$* Y=$ & $6.082163 *$ & 0.5539082 & * & -0.00878041 & * & & * & & * \\
\hline$* Y=$ & $3.528457 *$ & 0.9430742 & * & -0.02428444 & * & 0.000175975 & * & & * \\
\hline$* Y=$ & $2.665147 *$ & 1.1413553 & $*$ & -0.03762545 & * & 0.000515805 & * & -0.0000029040 & * $*$ \\
\hline COEF & EERMINACAO & 0.0118 & & 0.9274 & & 0.9881 & & 0.9902 & \\
\hline
\end{tabular}

* analise da variavel rot * - arevivo: C/CL

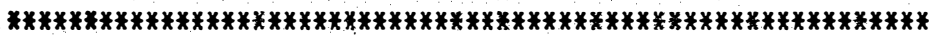

QUADRO DA ANALISE DE VARIANCIA

\begin{tabular}{|c|c|c|c|c|c|}
\hline CAUSAS DA VARIACAO & G.L. & S.Q. & Q.H. & VALOR $F$ & PROB.JF \\
\hline REGRESSAO LINEAR & 1 & 1612.8266728 & 1612.8266728 & 2706.49111 & 0.0001 \\
\hline REGRESSAO QUADR. & 1 & 244.5417113 & 244.5417113 & 410.36446 & 0.00001 \\
\hline REGRESSAO CUBICA & 1 & 19.3782053 & 19.3782053 & 32.51965 & 0.00072 \\
\hline REGRESSAO GRAU 4 & 1 & 0.0063937 & 0.0063937 & 0.01073 & 0.91670 \\
\hline DESUIOS DE REGR. & 8 & 4.7672846 & 0.5959106 & & \\
\hline
\end{tabular}

EOUACOES POLINOHIAIS

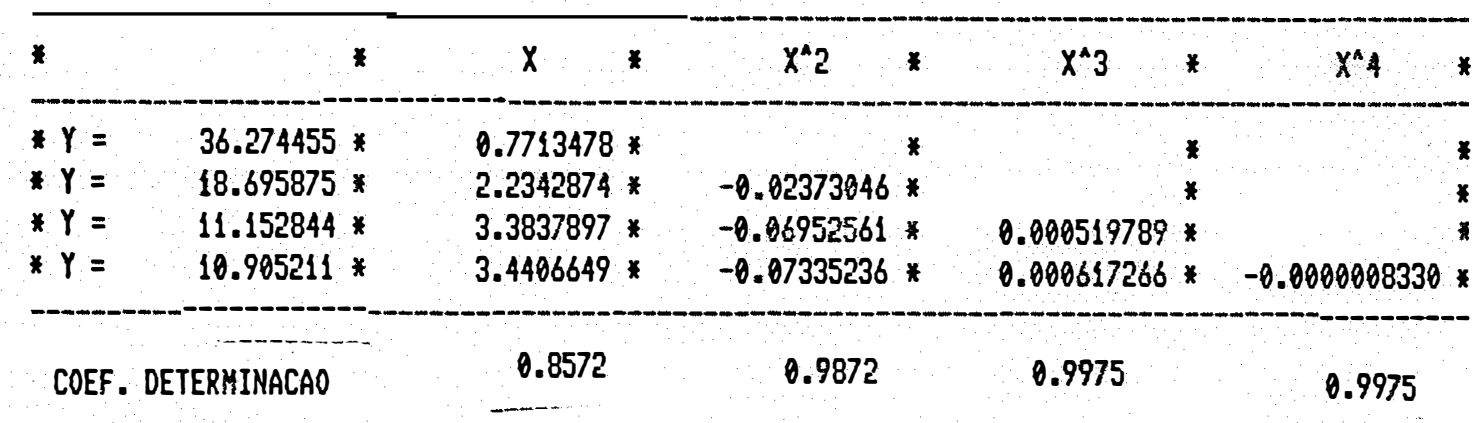


* ANALISE DA UARIAUEL CONS.ESP - ARQUIVO C C/CL *

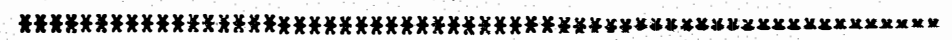

QUADRO DA ANALISE DE VARIANCIA

\begin{tabular}{|c|c|c|c|c|c|}
\hline CAUSAS DA VARIACAO & G.L. & 5.0 & Q.H. & VALOR F & PROB.SF \\
\hline REGRESSAO LINEAR & 1 & 83549.8043703 & 83549.8043703 & 234.32217 & 0.00002 \\
\hline REGRESSAO QUADR. & 1 & 70489.3312548 & 70489.3312548 & 197.69302 & 0.00002 \\
\hline REGRESSAO CUBICA & 1 & 1553.7779820 & 1553.7779820 & 4.35770 & 0.06826 \\
\hline REGRESSAO GRAU 4 & 1 & 1249.1444220 & 1249.1444220 & 3.59333 & 0.09588 \\
\hline DESUIOS OE REGR. & 8 & 2852.4763430 & 356.5595429 & & \\
\hline
\end{tabular}

d

EOUACES POLINOHIAIS

\begin{tabular}{|c|c|c|c|c|c|c|c|c|c|}
\hline * & * & $x$ & $*$ & $x^{\wedge} 2$ & * & $x^{\wedge} 3$ & * & $x^{a} 4$ & * \\
\hline$* Y=$ & $621.997195 *$ & 5.5517398 & $x$ & & * & & * & & $*$ \\
\hline$* Y=$ & $920.445436 *$ & -19.2859741 & * & 0.40289458 & $*$ & & * & & * \\
\hline$* Y=$ & $987.988940 *$ & -29.5791064 & * & 0.81296378 & $*$ & -0.004654408 & * & & * \\
\hline$* Y=$ & $1097.444514 *$ & -54.7183727 & $x$ & 2.50441788 & $*$ & -0.047740118 & * & 0.0003681914 & $*$ \\
\hline Col & ETERHINACAO & 0.5232 & & 0.9646 & & 0.9743 & & 0.9821 & \\
\hline
\end{tabular}

* ANALISE DA VARIAUEL FT KN - ARQUITUO: D/CL * *

**********************************************************

QUADRO DA ANALISE DE VARIANCIA

\begin{tabular}{llllll}
\hline CAUSAS DA UARIACAO & G.L. & S.0. & & & \\
\hline REGRESSAO LINEAR & 1 & 249.2269839 & 249.2269839 & 1330.79539 & 0.00601 \\
REGRESSAO QUADR. & 1 & 16.8423116 & 16.8423116 & 89.93276 & 0.00092 \\
REGRESSAO CUBICA & 1 & 1.6292496 & 1.6292496 & 8.69969 & 0.01281 \\
REGRESSAO GRAU 4 & 1 & 0.1518644 & 0.1548644 & 0.81091 & 0.60938 \\
DESUIOS DE REGR. & 11 & 2.060438 & 0.1872767 & & \\
\hline
\end{tabular}

EOUAOES POLINOHIAIS

\begin{tabular}{|c|c|c|c|c|c|c|c|}
\hline 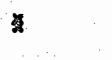 & * & $x$ & $x^{\wedge} 2$ & * & $x^{A} 3$ & $*$ & $x^{4} 4$ \\
\hline$* Y=$ & $4.892372 *$ & $0.2302825 *$ & & $*$ & & $*$ & \\
\hline$* Y=$ & $1.930399 *$ & $0.4917728 *$ & -0.00408226 & * & & * & \\
\hline$* Y=$ & $0.297765 *$ & $0.7318377 x$ & -0.01285704 & * & 0.000089632 & $*$ & \\
\hline$* Y=$ & $1.197745 *$ & $0.5392596 *$ & -0.00068314 & $*$ & -0.000198079 & * & 0.0000022504 \\
\hline
\end{tabular}


118

* aNALISE dA VARIAVEL POT $* H$ - ARQUIVO: D/CL * * ******************************************************** QUADRO DA ANALISE DE VARIANCIA

\begin{tabular}{lcccccc}
\hline CAUSAS DA VARIACAO & G.L. & S.Q. & 0.4. & VALOR F & PROB.JF \\
\hline REGRESSAO LINEAR & 1 & 16.2873806 & 16.2873806 & 59.67755 & 0.00005 \\
REGRESSAO QUADR. & 1 & 56.5837538 & 56.5837538 & 207.32491 & 0.00001 \\
REGRESSAO CUBICA & 1 & 3.7474380 & 3.7474380 & 13.73075 & 0.00370 \\
REGRESSAO GRAU 4 & 1 & 0.0281108 & 0.0281108 & 0.10300 & 0.75175 \\
DESUIOS DE REGR. & 11 & 3.0021539 & 0.2729231 & & \\
\hline
\end{tabular}

EOUACOES POLINOHIAIS

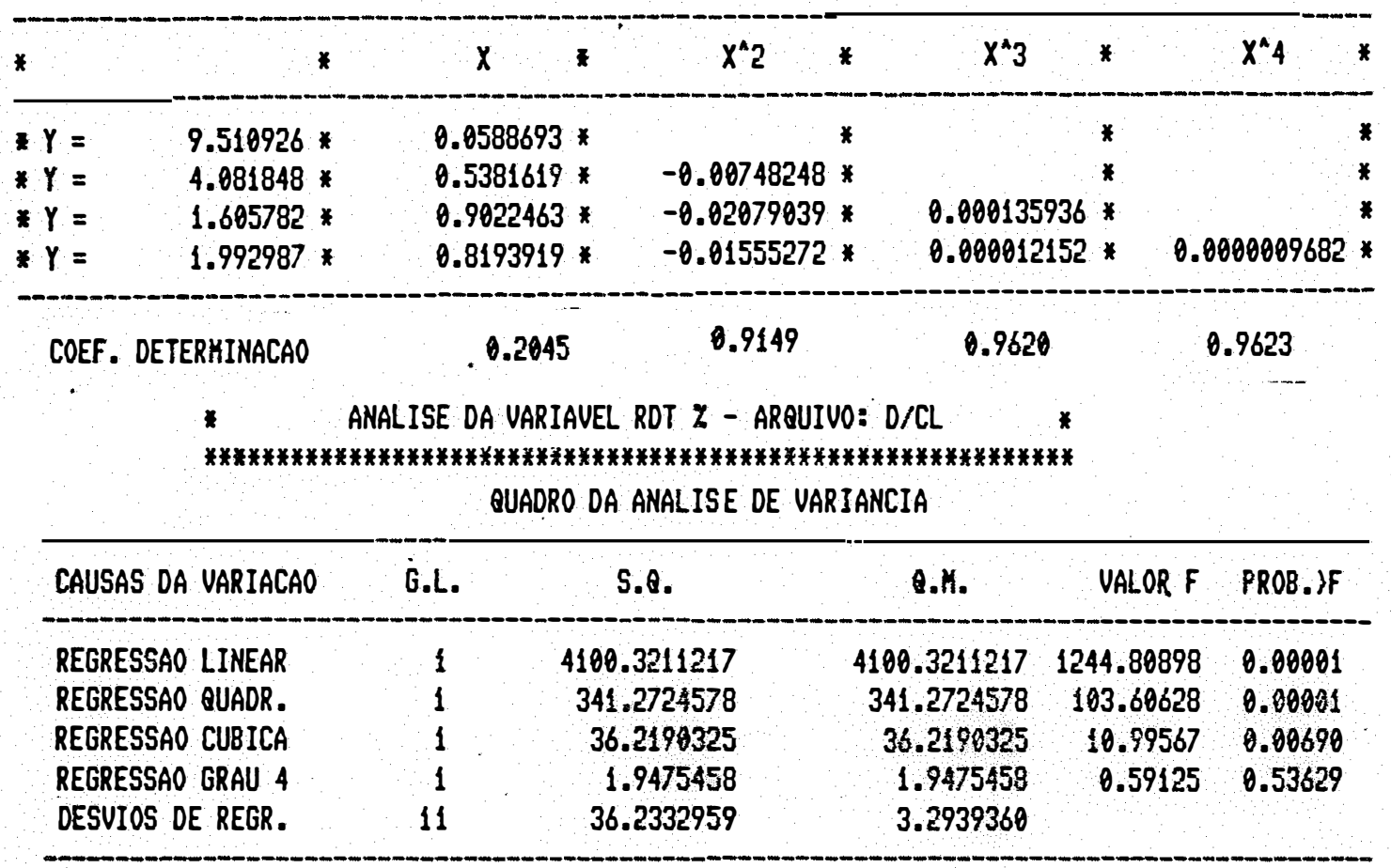

EOUACOES POLINOHIAIS

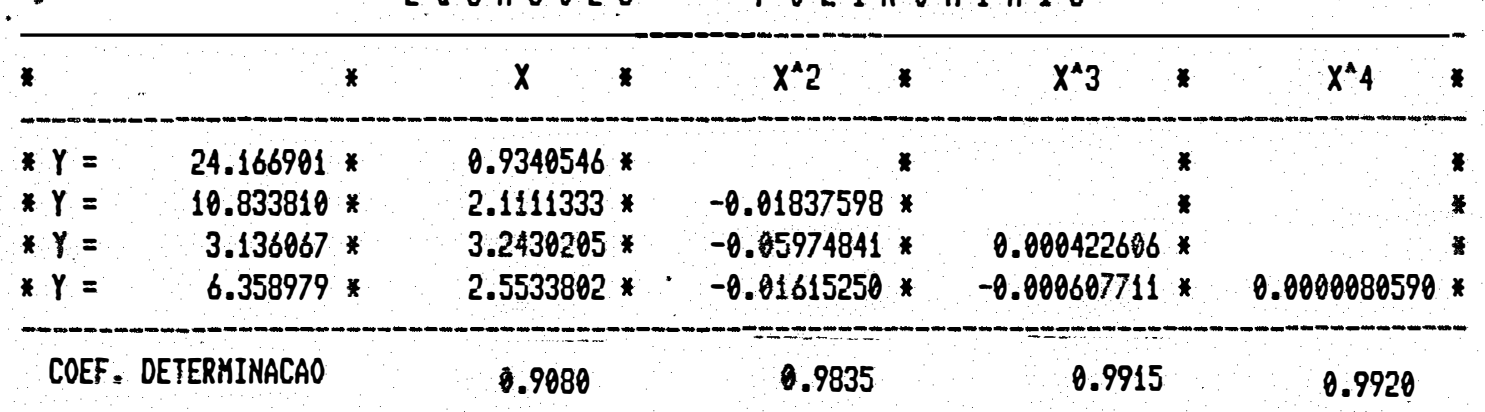


* aNALISE da variavel CONS.ESP - arQuivo: D/CL *

************************************************************

QUADRO DA ANALISE DE VARIANCIA

\begin{tabular}{|c|c|c|c|c|c|}
\hline CAUSAS DA VARIACAO & G.L. & S.Q. & Q.H. & UALOR $F$ & PROB. IF \\
\hline REGRESSAO LINEAR & 1 & 80704.0752815 & 80704.0752815 & 58.15225 & 0.00006 \\
\hline REGRESSAO QUADR. & 1 & 265803.4927518 & 205803.4927518 & 148.29408 & 0.00001 \\
\hline REGRESSAO CUBICA & 1 & 26092.7773074 & 26092.77739074 & 18.80145 & 0.00147 \\
\hline REGRESSAO GRAU 4 & 1 & 7103.1393126 & 7103.1393126 & 5.11825 & 0.04301 \\
\hline DESUIOS DE REGR. & 11 & 15265.8721350 & 1387.8065577 & & \\
\hline
\end{tabular}

EOUACOES POLINOHIAIS

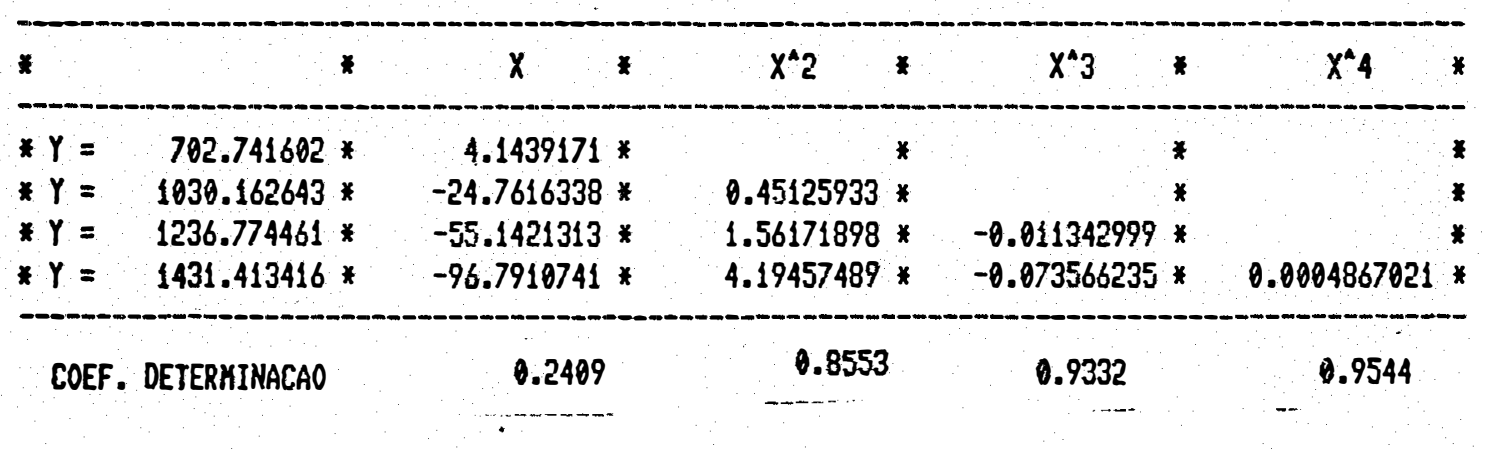

